\title{
Catecholamines, angiotensin II and the neointima
}

Citation for published version (APA):

Bruijns, R. (2000). Catecholamines, angiotensin II and the neointima: a search for the cause of the relative insensitivity of the neointima for a1-adrenoceptor blockade. [Doctoral Thesis, Maastricht University]. Universiteit Maastricht. https://doi.org/10.26481/dis.20000420rb

Document status and date:

Published: 01/01/2000

DOI:

10.26481/dis.20000420rb

Document Version:

Publisher's PDF, also known as Version of record

\section{Please check the document version of this publication:}

- A submitted manuscript is the version of the article upon submission and before peer-review. There can be important differences between the submitted version and the official published version of record.

People interested in the research are advised to contact the author for the final version of the publication, or visit the DOI to the publisher's website.

- The final author version and the galley proof are versions of the publication after peer review.

- The final published version features the final layout of the paper including the volume, issue and page numbers.

Link to publication

\footnotetext{
General rights rights.

- You may freely distribute the URL identifying the publication in the public portal. please follow below link for the End User Agreement:

www.umlib.nl/taverne-license

Take down policy

If you believe that this document breaches copyright please contact us at:

repository@maastrichtuniversity.nl

providing details and we will investigate your claim.
}

Copyright and moral rights for the publications made accessible in the public portal are retained by the authors and/or other copyright owners and it is a condition of accessing publications that users recognise and abide by the legal requirements associated with these

- Users may download and print one copy of any publication from the public portal for the purpose of private study or research.

- You may not further distribute the material or use it for any profit-making activity or commercial gain

If the publication is distributed under the terms of Article $25 \mathrm{fa}$ of the Dutch Copyright Act, indicated by the "Taverne" license above, 


\section{CATECHOLAMINES, ANGIOTENSIN II AND THE NEOINTIMA}

A search for the cause of the relative insensitivity

of the neointima for $\alpha_{1}$-adrenoceptor blockade 
Basisvormgeving: Richard HJ Bruijns, Maastricht Omslag: Poême de la Vigne, 1877-1878, Golden Gate Park, San Francisco, California Druk en afwerking: Datawyse bv, Maastricht

Lettertype: SwitzerlandLight

(c) RHJ Bruijns, Maastricht 2000

Niets uit deze uitgave mag worden verveelvoudigd en/of openbaar gemaakt door middel van druk, fotokopie, microfilm of op welke andere wijze dan ook zonder voorafgaande schriftelijke toestemming van de auteur.

No part of this book may be reproduced in any form, by print, photoprint, microfilm or any other means without written permission from the author. 


\section{CATECHOLAMINES, ANGIOTENSIN II AND THE NEOINTIMA}

A search for the cause of the relative insensitivity of the neointima for $\alpha_{1}$-adrenoceptor blockade

\section{Proefschrift}

Ter verkrijging van de graad van doctor aan de Universiteit Maastricht,

op gezag van de Rector Magnificus, Prof.dr. A.C. Nieuwenhuijzen Kruseman volgens het besluit van het College van Decanen,

in het openbaar te verdedigen op

donderdag 20 april 2000 om 16.00 uur

door

Richard Bruijns

geboren te Nijmegen in 1969 
Promotor:

Prof.dr. M.J.A.P. Daemen

Beoordelingscommissie:

Prof.dr. C.A. Bruggeman (voorzitter)

Prof.dr. H. Bult (Universiteit Antwerpen, België)

Prof.dr. J.M.A. van Engelshoven

Prof.dr. P.J.E.H.M. Kitslaar

Prof.dr. K.M.L. Leunissen

Financial support by the Netherlands Heart Foundation for the publication of this thesis is gratefully acknowledged

For financial support for the publication of this thesis, I also thank:

- Dr. Saal van Zwanenbergstichting 
Het nieuwe ontstaat nooit eenvoudigweg door interpolatie van het oude... -Michel Houellebecq- 

Table of Contents

Chapter 1 General Introduction 9

1.1 Introduction $\quad 10$

1.2 Vascular Layers $\quad 10$

1.3 Vascular Remodeling $\quad 12$

1.4 Renin Angiotensin System 13

1.5 The Sympathetic Nervous System and the 17 Vascular Response to Injury

$1.6 \alpha_{1}$-Adrenergic Receptors 18

1.7 The Sympathetic Nervous System of Response to Angll 23

$\begin{array}{ll}1.8 \text { Hypothesis } & 23\end{array}$

1.9 This Thesis 23

Chapter 2 Distribution of the mRNAs of the $\alpha_{1}$-Adrenoceptor Subtypes in 25 the Rat Carotid Artery After Balloon Catheter Induced Injury

Chapter 3 Detection of Norepinephrine Transporter mRNA in the Balloon Injured Rat Carotid Artery After Stimulation With Angl|

Chapter 4 Effects of Chemical Sympathectomy on Angiotensin II-Induced Neointimal Growth in the Balloon Injured Rat Carotid Artery

Chapter 5 Angiotensin II Modifies the Contribution of Adrenal Medulla Derived Catecholamines to the Regulation of Neointimal Growth After Balloon Injury of the Rat Carotid Artery

Chapter 6 Anastomotic Innervation in Peripheral Bypasses and Graft Arteriovenous Fistulas in Humans

Chapter 7 General Discussion $\quad 73$

$\begin{array}{ll}7.1 \text { Introduction } & 74\end{array}$

$\begin{array}{ll}7.2 \text { The Media } & 74\end{array}$

$\begin{array}{ll}7.3 \text { The Neointima } & 75\end{array}$

$\begin{array}{ll}7.4 \text { Presence of } \alpha_{1} \text {-Adrenoceptors } & 77\end{array}$

7.5 Proposed Mechanisms of Angll-Induced Increase in SMC $\quad 77$ Growth of the Rat Carotid Artery

7.6 Neointimal Innervation in Humans $\quad 77$

7.7 Cross-talk Between Receptors $\quad 78$

$\begin{array}{ll}7.8 \text { Limitations of the Study } & 79\end{array}$

7.9 Future Outlook 80

$\begin{array}{ll}\text { Reference List } & 81\end{array}$

Samenvatting $\quad 95$

$\begin{array}{ll}\text { Curriculum Vitae } & 97\end{array}$

List of Publications $\quad 99$

Dankwoord 101 


$\begin{array}{ll}\text { ACE } & \text { angiotensin I converting enzyme } \\ \text { Angl } & \text { angiotensin I } \\ \text { Angll } & \text { angiotensin II } \\ \text { AT, receptor } & \text { angiotensin type 1 receptor } \\ \text { AT }_{2} \text { receptor } & \text { angiotensin type } 2 \text { receptor } \\ \text { AV } & \text { arteriovenous } \\ \text { BrdU } & \text { 5-bromo-2'-deoxyuridine } \\ \text { CEC } & \text { chloroethylclonidine } \\ \text { COMT } & \text { catechol-O-methyl transferase } \\ \text { CSA } & \text { cross-sectional area } \\ \text { DAG } & \text { diacylglycerol } \\ \text { FGF } & \text { fibroblast growth factor } \\ \text { G protein } & \text { guanine nucleotide-binding regulatory protein } \\ \text { IP } & \text { inositol 1,4,5-triphosphate } \\ \text { ISH } & \text { in situ hybridization } \\ \text { LA } & \text { lumen area } \\ \text { LF } & \text { labeling fraction } \\ \text { MAO } & \text { monoamine oxidase } \\ \text { MAPK } & \text { mitogen-activated protein kinase } \\ \text { NET } & \text { norepinephrine transporter } \\ \text { NF } & \text { neurofilament } \\ \text { NO } & \text { nitric oxide } \\ \text { NPY } & \text { neuropeptide tyrosine } \\ \text { O.D. } & \text { optical density } \\ \text { PDGF } & \text { platelet derived growth factor } \\ \text { PGP-9.5 } & \text { protein gene product-9.5 } \\ \text { PiP } & \text { phosphatidylinositol 4,5-biphosphate } \\ \text { PKC } & \text { protein kinase C } \\ \text { PLA } & \text { phospholipase A } \\ \text { PLC } & \text { phospholipase C } \\ \text { PLD } & \text { phospholipase D } \\ \text { PTCA } & \text { percutaneous transluminal coronary angioplasty } \\ \text { PTFE } & \text { polytetrafluoroethylene } \\ \text { RAS } & \text { renin angiotensin system } \\ \text { RT-PCR } & \text { reverse transcription-polymerase chain reaction } \\ \text { SMC } & \text { smooth muscle cell } \\ \text { SNS } & \text { sympathetic nervous system } \\ \text { TGF- } \beta_{1} & \text { transtorming growth factor- } \beta_{1} \\ \text { TH } & \text { tyrosine hydroxylase } \\ & \end{array}$




\section{CHAPTER 1}

General Introduction 


\subsection{Introduction}

Percutaneous transluminal coronary angioplasty (PTCA) has become a successful and widely used treatment for patients with coronary artery disease since its first clinical application by Andreas Grüntzig in 1977.(Grüntzig et al., 1977) Despite the increase in procedure and case complexity, primary success rates have improved. However, late restenosis, which constitutes the most important problem after successful angioplasty, continues to occur in $30-40 \%$ of patients within 3-6 months. Restenosis after PTCA involves a fibroproliferative response to the vascular injury in the setting of mural thrombosis with platelet activation, thrombin generation, and the release of mitogens. (Ip et al., 1991)

The balloon injury model in the rat carotid artery has often been used as a model to study the fibroproliferative response after injury and has been critical in elucidating the key regulators of the response. The present study focuses on two of these regulators, angiotensin II (Angll) and the sympathetic nervous system (SNS).

\subsection{Vascular Layers}

The connective tissue sheath around the vascular lumen consists of three layers. The innermost layer, called 'tunica intima' is defined as the combination of endothelium and connective tissue on the luminal side of the internal elastic lamina. The tunica intima of the aorta and other large arteries contains a matrix of collagen, proteoglycans, and small amounts of elastin. The major cell type in the tunica intima is the intimal smooth muscle cell (SMC). Other cells that occasionally reside include lymphocytes, macrophages and other inflammatory cells derived from the blood. The tunica intima is particularly important in atherosclerosis and restenosis after angioplasty, since lipid and SMC accumulation primarily affect this layer of the vessel wall.(Schwartz et al., 1986) Proceeding outward, the vessel wall displays layers of SMCs collectively called the 'tunica media'. Breakdown of the media, particularly its elastic layers, leads to formation of aneurysms.(Schwartz et al., 1986) The outermost layer of the vessel wall is the 'tunica adventitia'. This layer is a collagen-rich connective tissue sheath, containing numerous fibroblasts, small vessels which give rise to the vasa vasorum, and nerves. The 'vasa vasorum' located in the connective tissue sheath surrounding large vessels develop small branches and penetrate into the tunica media from the exterior of the vessel wall, the adventitia, into the media.(Wolinsky and Glagov, 1967)

\subsection{Repsonse to Injury}

Formation of an intima may occur by proliferation of cells already trapped in the intima during formation of the internal elastic lamina, migration of cells from the media with their subsequent proliferation or by proliferation of entrapped cells derived from the blood stream. The vessel wall responds to angioplasty by forming a new layer in the intima called the 'neointima'.

Neointimal formation after injury is studied in vessels like the rat carotid artery that normally have little or no intima. The injury to a rat carotid artery by a balloon catheter completely removes the endothelium and injures the underlying media, causing death of $\sim 30 \%$ of SMCs.(Clowes et al., 1983a) Shortly after injury, a monolayer of platelets adhere to the denuded surface and thrombin is activated.(Ross, 1986) Subsequent cellular events can be divided into three partially overlapping 'waves': (1) medial smooth muscle proliferation; (2) migration of medial SMCs to the intima; and (3) proliferation of intimal SMCs. Medial DNA synthesis takes place approximately 30 hours after injury and is largely complete within 48 hours. As many as $40 \%$ of SMCs remaining after balloon injury enter the cell cycle and synchronously progress into $S$ phase within 33 hours of wounding.(Majesky et al., 1987) DNA synthesis is followed by cell division and SMC 
numbers lost by balloon injury induced apoptosis begin to be restored in the damaged media within 48 hours of injury. (Perlman et al., 1997)

\subsubsection{Mediators in the Response to Injury}

A great number of polypeptide growth factors have been demonstrated to be induced after balloon injury (table 1.1). Possible mitogenic signals include: (1) platelet adherence and release of peptide growth factors (e.g. platelet derived growth factor (PDGF), transforming growth factor (TGF)- $\beta 1$ ) into the damaged vessel wall(Ross et al., 1986) (2) activation of preformed, inactive or sequestered growth factors present in the artery wall prior to the injury event, by SMC death and release of intracellular mitogens,(Gajdusek and Carbon, 1989) or by proteases of for instance the coagulation cascade,(Gajdusek et al, 1986; Carlos and Harlan, 1990) (3) formation of Angll(Gibbons et al., 1992) and (4) release from local growth inhibition due to loss of endothelium(Castellot et al., 1982) or to inactivation of SMC growth inhibitors present in the arterial media.(Clowes and Clowes, 1985; Fritze et al., 1985)

In the carotid balloon injury model the 'first wave' of medial DNA synthesis is the result of the release of endogenous fibroblast growth factor (FGF) from traumatized SMCs.(Lindner and Reidy, 1991) Angll is also an endogenous SMC mitogen since antagonists of the angiotensin type 1 receptor $\left(A T_{1}\right)$ block the first wave(Prescott et al., 1991) and infused Angll is mitogenic for the intact medial SMCs.(Daemen et al., 1991) The process of SMC migration appears to be separable from SMC proliferation per se, since cells that have not undergone DNA replication are found among those that have migrated into the intima.(Clowes and Schwartz, 1985) Of particular interest to the acquisition of a motile phenotype(Gabbiani et al., 1982; Kocher et al., 1991) may be the decrease in expression of smooth muscle $\alpha$-actin,(Gabbiani et al., 1984) loss of intermediate filament protein desmin,(Gabbiani et al., 1982; Kocher et al., 1991) changes in the splicing pattern of vinculin,(Glukhova et al., 1988) a protein involved in cell-cell and cell-substrate adhesion, and changes in the splicing pattern of fibronectin, an adhesive cell matrix protein.(Glukhova et al., 1989)

Table 1.1 Mediators of Neointimal Formation(Schwartz et al., 1995)

\begin{tabular}{|c|c|c|c|c|}
\hline & \multirow[b]{2}{*}{ Mediators } & \multicolumn{2}{|c|}{ Inhibition } & \multirow{2}{*}{$\frac{\text { Stimulation }}{\text { Agonist }}$} \\
\hline & & Antibody & Antagonist & \\
\hline \multirow[t]{4}{*}{ 1st wave; medial SMC replication } & FGF & + & NA & + \\
\hline & PDGF & \pm & NA & - \\
\hline & TGF- $\beta$ & NA & ND & \pm \\
\hline & Angll & ND & + & $N D^{*}$ \\
\hline \multirow[t]{3}{*}{ 2nd wave: SMC migration } & PDGF & + & NA & + \\
\hline & Angll & ND & + & ND \\
\hline & FGF & + & NA & + \\
\hline \multirow[t]{4}{*}{ 3rd wave; intimal SMC replication } & FGF & . & NA & \pm \\
\hline & PDGF & - & NA & - \\
\hline & TGF- $\beta$ & NA & ND & $+\S$ \\
\hline & Angli & ND & - & $+\S$ \\
\hline
\end{tabular}

+ Indicates supporting evidence; - evidence against hypothesis; \pm weak response; NA not available; ND not determined. * Angll does stimulate medial smooth muscle. $\S$ Restimulation experiments.

A number of molecules in the platelets, including PDGF, are chemotactic for SMCs.(Grotendorst et al., 1981) Tissue-type plasminogen activator and urokinase also 
increase SMC migration.(Jackson et al., 1993; Kenagy et al., 1996) Once formed, the neointima continues to grow by cell replication. A relatively high percentage of intimal SMC nuclei continue to replicate for weeks, particularly at the luminal surface.(Schwartz et al., 1975) When animals were infused chronically with Angll, the neointima produced a three- to five-fold increase in replication as compared with the underlying vessel wall.(Daemen et al., 1991)

Regeneration of the endothelium inhibits proliferation of the underlying neointimal cells.(Haudenschild and Schwartz, 1979; Clowes et al., 1983a; Clowes et al., 1986) Suppression of neointimal cell proliferation might be due to endothelial production of nitric oxide (NO). Administration of large doses of L-arginine aimed at chronically raising NO levels in animals immediately after balloon catheter-induced endothelial denudation has resulted in significant inhibition of neointimal thickening.(McNamara et al., 1993; Hamon et al., 1994; Tarry and Makhoul, 1994) Hansson et al.(Hansson et al., 1994) have reported that the cytokine-inducible isoform of NO synthase is chronically expressed at high levels by SMCs at the denuded surface of the neointimal lesion in the rat injured carotid artery,(Hansson et al., 1994) an area in which smooth muscle DNA synthesis remains chronically elevated.(Clowes et al., 1986)

\subsection{Vascular Remodeling}

The response to vascular injury not only includes growth of the intima, but also remodeling of the vessel wall. Vascular remodeling is defined as the vascular wall changes from dynamic and trophic stimuli resulting in vascular hypertrophy or rearrangement of vascular wall material without growth.(Heagerty et al., 1993) Several types of vascular remodeling have recently been described by Mulvany et al.(Mulvany et al., 1996) and are depicted in figure 1.1. Inward remodeling describes a decrease in lumen diameter, whereas outward remodeling refers to an increase in lumen diameter. Hypotrophic remodeling describes a decrease in the amount of vascular wall material independent of changes in the lumen diameter, whereas eutrophic remodeling refers to an absence of change in the amount and properties of wall material regardless of changes in lumen diameter. Hypertrophic inward vascular remodeling is the predominant of these processes and is associated with an increase in wall thickness, an increase in wall-to-lumen ratio, and a decrease in lumen diameter.(Korsgaard and Mulvany, 1988) In contrast, hypertrophic outward remodeling is rare; it has been seen in the esophageal veins of rabbits after partial occlusion of the portal vein(Juhl et al., 1989) and during restenosis in human atherosclerotic lesions.(Glagov et al., 1987; Post et al., 1995) In restenosis, the two contributors to lumen renarrowing, i.e. intimal hyperplasia and vascular remodeling, have been identified. Plaque accumulation or neointima formation may progress without reducing the lumen or even with increasing lumen size if the artery enlarges. If compensation is incomplete or if the artery does not remodel, intimal hyperplasia will narrow the lumen. A subset of arteries shrink thus aggravating lumen narrowing by intimal hyperplasia.(Post et al,. 1995; Pasterkamp et al., 1998; Pasterkamp et al., 1999) 


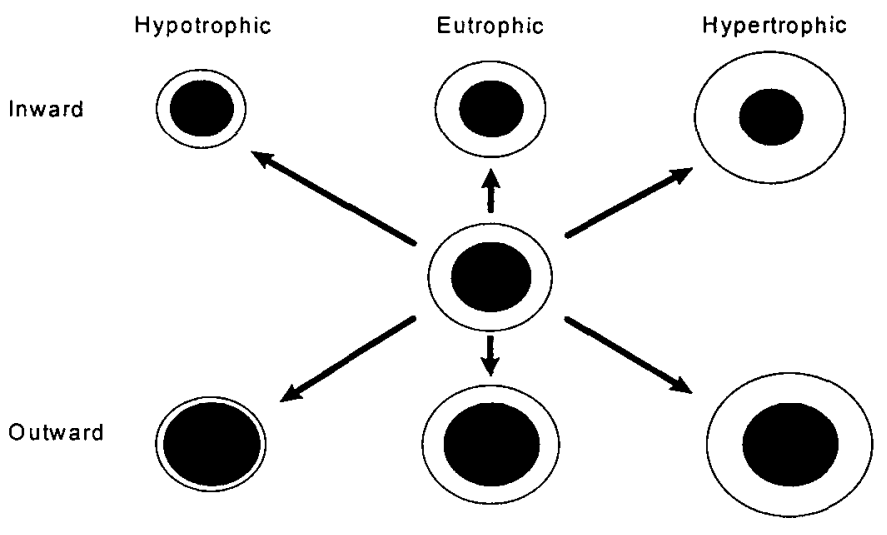

Figure 1.1 Various Types of Vascular Remodeling. Inward hypotrophic, eutrophic, and hypertrophic are associated with decreased lumen diameter and decreased, unchanged, and increased wall thickness, respectively. In contrast, outward hypotrophic, eutrophic, and hypertrophic vascular remodeling are associated with increased lumen diameter and decreased, unchanged, and increased wall thickness, respectively.(Mulvany et al., 1996)

\subsection{Renin Angiotensin System}

\subsubsection{Production and Actions of Angiotensin II}

The renin angiotensin system (RAS) plays an important role in blood pressure regulation. Reduced sodium delivery at the macula densa, decreased renal perfusion pressure, and sympathetic activation all stimulate secretion of renin by the juxtaglomerular cell.(Johnston, 1990) Renin cleaves the inactive decapeptide angiotensin I (Angl) from the prohormone angiotensinogen (figure 1.2). Angll is then cleaved from Angl by the action of angiotensin I converting enzyme (ACE).(Erdos, 1977) Angll is a potent vasoconstrictor, acting directly on vascular SMCs.(Folkow et al., 1961) In addition, Angll interacts with the SNS both peripherally and centrally to increase vascular tone.(Zimmerman et al., 1984) Angll causes volume expansion through sodium retention (via aldosteron(Biron et al., 1961) and renal vasoconstriction) and fluid retention (via antidiuretic hormone).(Padfield and Morton, 1977) At the cellular level, Angll promotes migration, proliferation, and hypertrophy of SMCs.(Bell and Madri, 1990; Daemen et al., 1991; Itoh et al., 1993; Huckle and Earp. 1994; Dostal et al., 1996)

In addition to catalyzing the formation of Angll, ACE catalyzes the degradation of bradykinin.(Erdos, 1977) Bradykinin promotes vasodilatation by stimulating the production of arachidonic acid metabolites, $\mathrm{NO}$ and endothelium derived hyperpolarizing factor in vascular endothelium.(Vanhoutte, 1989) 


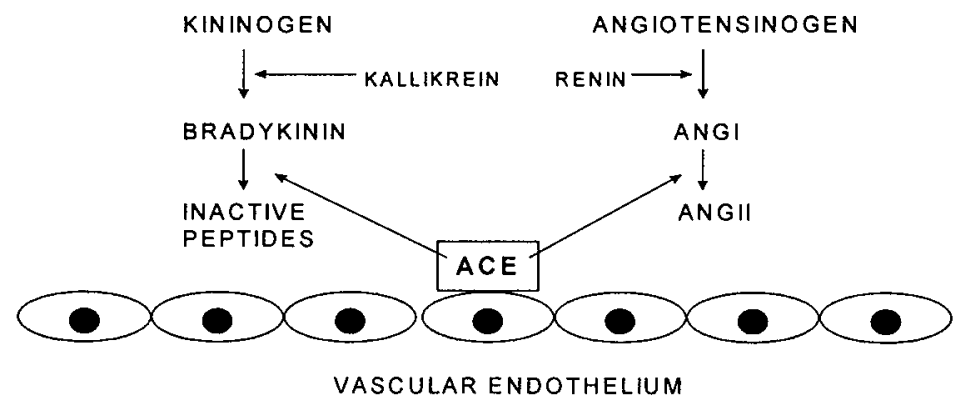

Figure 1.2 Schematic of RAS and Kallikrein-Kinin System. ACE is strategically positioned to regulate the balance between Angll and bradykinin.(Brown and Vaughan, 1998)

\subsubsection{Angiotensin I/ as a Growth Factor}

Angll is a multifunctional hormone with pleiotrophic effects on vascular smooth muscle. It was originally identified as an acute regulator of vasomotor tone(Elliott and Peart, 1956) and has since been shown to promote vascular hypertrophy(Geisterfer et al. 1988; Berk et al., 1989) and in some cases, hyperplasia.(Campbell and Robertson, 1981) It also affects vascular cell migration(Dubey et al., 1995) and extracellular matrix production.(Kato et al., 1991)

In vivo Angll has been shown to induce SMC proliferation, measured by incorporation of bromodeoxyuridine in the balloon injured rat carotid artery.(Daemen et al., 1991) In that same study the effect of Angll was shown to be more marked on neointimal cells. Medial SMC proliferation in response to Angll was shown to be transient in uninjured regions of the vessel compared with the sustained mitogenic action of Angll on the neointima.(deBlois et al., 1996b)

In contrast, Angll was reported to only increase protein, but not DNA synthesis in isolated rat aorta studied using an organ culture technique.(Holycross et al., 1993) This may imply that Angll requires cofactors for expression of its mitogenic potential within the intact blood vessel.

\subsubsection{Angiotensin // Receptors}

The tissue response to Angll is mediated by specific receptors located on the cell surface. As defined by their pharmacological profile, there are two main subtypes of Angll receptors: $A T_{1}$ and $A T_{2}$, blocked by specific antagonists.(de Gasparo et al., 1995) Both $A T_{1}$ and $A T_{2}$ receptors contain a seven transmembrane domain and are coupled to $G$ proteins. The $A T_{1}$ receptor subtype, predominant in the vascular system, mediates most of the actions of Angll such as secretion of aldosteron and catecholamines from the adrenal gland, central nervous responses, release of catecholamines from sympathetic nerve endings, and the regulation of vascular tone by vasoconstriction.(Whitebread et al., 1989; Wong et al., 1990; Gehlert et al., 1991; Timmermans et al., 1991) Treatment with subpressor doses of Angll enhanced the growth of the neointima in wildtype mice but not in $A T_{1 a}$ knockout mice after injury.(Harada et al., 1999) 
The $A T_{2}$ receptor has an antiproliferative effect on neointimal formation after vascular injury(Nakajima et al., 1995) and on coronary endothelial cells.(Stoll et al., 1995) Recent studies have indicated that $A T_{2}$ associates with $G_{i}$ proteins (Zhang and Pratt, 1996) and mediates inhibitory effects on mitogen-activated protein kinase (MAPK) activation in vascular SMCs,(Nakajima et al., 1995) PC12W cells,(Yamada et al., 1996) and neuronal cultures.(Huang et al., 1996) The $\mathrm{AT}_{2}$ receptor subtype also has proapoptotic properties.(Stoll et al., 1995; Yamada et al., 1996) The ability of a tissue to change its expression of $A T_{1}$ to $A T_{2}$ receptors has been described in experimentally-induced vascular injury,(Dzau et al., 1991; Janiak et al., 1992) suggesting that the $A_{2}$ receptor may also play a role in SMC differentiation, proliferation and apoptosis. Indeed, transfection of an $\mathrm{AT}_{2}$ receptor expression vector into the balloon injured rat carotid artery attenuated neointimal formation.(Nakajima et al., 1995)

\subsubsection{Angiotensin // Signaling}

Angll rapidly stimulates multiple phospholipases to hydrolyze membrane phospholipids and generate signaling molecules (figure 1.3). In cultured vascular SMCs, phospholipase $C$ (PLC) is activated within 5 seconds, hydrolyzing phosphatidylinositol 4,5-biphosphate $\left(\mathrm{PiP}_{2}\right)$ to inositol 1,4,5-triphosphate $\left(\mathrm{IP}_{3}\right)$ and diacylglycerol (DAG).(Alexander et al., 1985; Griendling et al., 1986) This response is transient, returning toward baseline levels by 2 minutes. These second messengers in turn release calcium from internal stores and activate protein kinase $C$ (PKC), leading to a cascade of protein phosphorylations that direct the subsequent response of the cell. PKC also serves as a negative-feedback regulator of PLC, since it is apparently responsible, at least in part, for terminating the PLC response.(Brock et al., 1985)

\section{Phospholipases}

While PLC- $\beta$ is generally considered to be involved in mediating responses to Angll in cultured vascular SMCs, (Schelling et al., 1997) recent data has also implicated PLC- $\gamma$ in mediating Angll-induced $\mathrm{PiP}_{2}$ hydrolysis in cultured SMCs.(Marrero et al., 1995a) However, a major role of PLC- $\gamma$ seems inconsistent with reports that tyrosine kinase inhibitors, which would be anticipated to inhibit activation of PLC- $\gamma$, fail to inhibit the rise in $\mathrm{IP}_{3}$ or release of intracellular $\mathrm{Ca}^{2+}$ in response to Angll in cultured rat(Schelling et al., 1997) or human vascular SMCs.(Erdos, 1977)

In addition to PLC, phospholipase D (PLD) may also play a role in activation of PKC by Angll in vascular SMCs.(Ford and Gross, 1989) Activation of PLD is not associated with a rise in $I P_{3}$ but has been reported to be the major source of DAG in cultured rat aortic SMCs.(Lassegue et al., 1993) DAG produced by PLC or PLD stimulates PKC. Activation of PKC by Angll has been reported to be required for Angll-induced growth in several studies using cultured vascular SMCs. (Langan et al., 1994; Malarkey et al., 1996; Liao et al., 1996; Liao et al., 1997) 


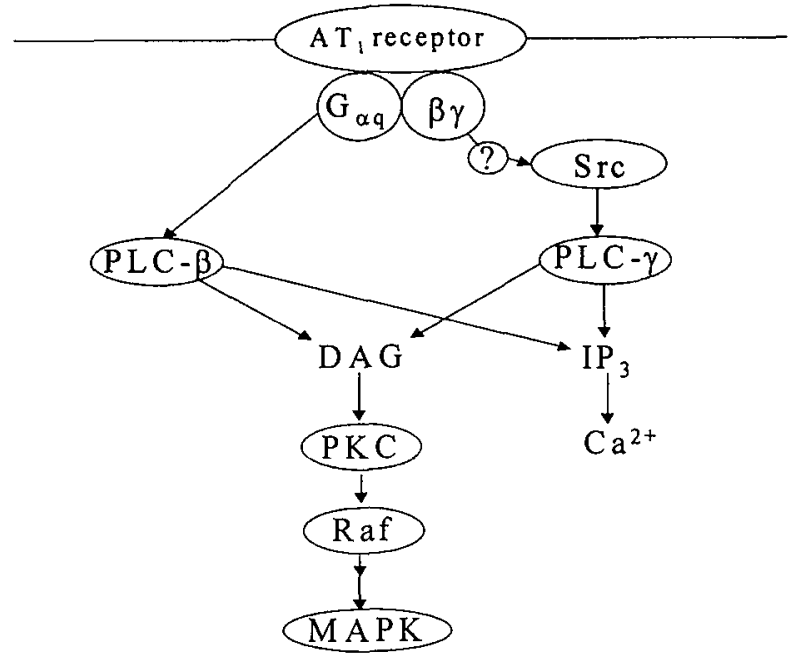

Figure 1.3 Schematic Presentation of the Two Pathways That Couple the AT, Receptor to PKC. ? represents unidentified tyrosine kinases(van Bilsen, 1997)

\section{Tyrosine Phosphorylation}

Angll induces tyrosine phosphorylation of multiple proteins in cultured rat aortic vascular SMCs.(Butcher et al., 1993) Several studies have shown that inhibition of tyrosine kinases blocks protein synthesis(Leduc et al., 1995) or DNA synthesis(Kobayashi et al., 1994) in response to Angll. There is also evidence that a $\mathrm{Ca}^{2+}$-dependent tyrosine kinase may contribute to Angll-induced tyrosine phosphorylation, possibly in conjunction with PKC.(Tsuda et al., 1991) Another class of tyrosine kinases linked to $A T_{1}$ receptor activation is the Janus kinase (JAK) family. The JAK/STAT pathway is a signaling pathway comprising a number of tyrosine kinases and transcription factors. Stimulation of AT, receptors has recently been shown to induce activation of JAK2 and to a lesser extent TYK2 in rat aortic SMCs and in the same studies the AT, receptor was shown to co-immunoprecipitate with JAK2, but not with JAK1 or TYK2.(Marrero et al., 1995b; Berk and Corson, 1997)

\section{Intracellular $\mathrm{Ca}^{2+}$}

A rise in $\left[\mathrm{Ca}^{2+}\right]_{i}$ is the primary signal initiating force production in vascular smooth muscle.(Somlyo and Somlyo, 1994) An increase in $\left[\mathrm{Ca}^{2+}\right]_{i}$ activates calmodulin (CaM) which in turn activates myosin light chain kinase allowing the actin-myosin interaction to proceed with resultant ATP hydrolysis, crossbridge formation and force generation.(Stull et al., 1991) The sensitivity of the contractile process to $\left[\mathrm{Ca}^{2+}\right]_{i}$ can also be influenced by contractile agonists, probably through modulation of myosin phosphatase activity(Kureishi et al., 1997) or by MAPK dependent phosphorylation of thin filament proteins caldesmon and calponin.(Horowitz et al., 1996) There is also evidence that Angll can enhance $\alpha_{1}$-adrenoceptor mediated contraction in rabbit aorta by activation of PKC.(Henrion et al., 1992a; Henrion et al., 1992b) 


\subsection{The Sympathetic Nervous System and the Vascular Response to Injury}

Activation of neurohumoral systems has been implicated in the process of vascular remodeling.(Daemen and De Mey, 1995) Experimental evidence suggests a role for the SNS and circulating catecholamines in the development of vascular remodeling. It has been demonstrated that catecholamines induce proliferation and protein synthesis of cultured vascular SMCs through stimulation of $\alpha_{1}$-adrenoceptors.(Blaes and Boisell, 1983; Yamori et al., 1987; Nakaki et al., 1990; Chen et al., 1995; Siwik and Dale-Brown, 1996) Prolonged infusions of norepinephrine or phenylephrine resulted in significant increases in the cross-sectional area (CSA) of rat carotid arteries.(deBlois et al., 1996a) In spontaneously hypertensive rats, hypertrophic inward vascular remodeling could partially be prevented by neonatal sympathectomy or treatment with an antibody against nerve growth factor.(Lee et al., 1987) This reduction of vascular remodeling was even more pronounced after adrenal demedullectomy or chronic $\alpha_{1}$-adrenoceptor blockade in neonatal rats(Lee et al., 1991; Korner et al., 1993) supporting a role for catecholamines derived from the SNS as well as from the adrenal medulla in vascular remodeling. Also, surgical or chemical denervation results in thickening of the vessel wall, due to vascular SMC hypertrophy. Furthermore, vascular SMCs show important morphological and ultrastructural alterations after sympathectomy including, amongst others, an irregular shape, an increase in the number of organelles and large indented nuclei rich in euchromatin.(Fronek, 1983; Branco et al., 1984; Dimitriadou et al., 1988) These findings suggest that the SNS plays an important role in the regulation of vascular $S M C$ differentiation in neonates, while in the adult it may significantly contribute to the maintenance of the contractile phenotype of vascular SMCs.(Daemen and De Mey, 1995) It remains to be established which neurotransmitter is the actual trophic factor of sympathetic innervation since norepinephrine as well as the sympathetic cotransmitters ATP and NPY have been shown to exert mitogenic effects on vascular SMCs.(Erlinge et al., 1993; Zukowska-Grojec et al., 1993) There is also evidence suggesting adenosine, derived from neurogenically released ATP, as the trophic factor of the SNS.(Osswald, 1991; Osswald and Azevedo, 1991)

\subsubsection{Norepinephrine Transporter}

The biosynthetic pathway of norepinephrine synthesis is shown in figure 1.4. The metabolic precursor of norepinephrine is L-tyrosine, an aromatic amino acid present in body fluids, which is taken up by adrenergic neurons. Tyrosine hydroxylase represents the rate limiting step in the biosynthesis of norepinephrine. Most of the synthesized norepinephrine is contained in vesicles. Depolarization of the nerve terminal membrane promotes the fusion and discharge of synaptic vesicles. Released norepinephrine is metabolized by two enzymes, monoamine oxidase (MAO) and catechol-O-methyl transferase (COMT). MAO occurs within cells, bound to the surface membrane of mitochondria. COMT occurs in both neuronal and non-neuronal tissues and is mainly involved in the metabolism of catecholamines released in the circulation and in the inactivation of norepinephrine in tissues with sparse adrenergic innervation.(Rang et al., 1991) However, degradation of norepinephrine by the catabolizing enzymes MAO and COMT plays only a minor role in comparison to the uptake.

The norepinephrine transporter (NET) is an integral membrane $\mathrm{Na}^{+} /$cotransporter protein that can rapidly move norepinephrine (and $\mathrm{Na}^{+}$) back inside synaptic terminals. In that way it can terminate synaptic transmission and recycle neurotransmitters.(Axelrod, 1971) Recent work by Lu et al. showed that chronic stimulation of norepinephrine uptake by Angll involves stimulation of NET MRNA production in the brain of rats.(Lu et al., 1996) The data presented in that study suggests that Angll binds to the neuronal $A T_{1}$-receptor subtype and stimulates the 
phospholipase C-phosphoinositol hydrolysis system (figure 1.3). This increases the activity of PKC and the transcription of the NET gene. The result is an increase in NETactivity and an increased norepinephrine uptake.(Lu et al., 1996)

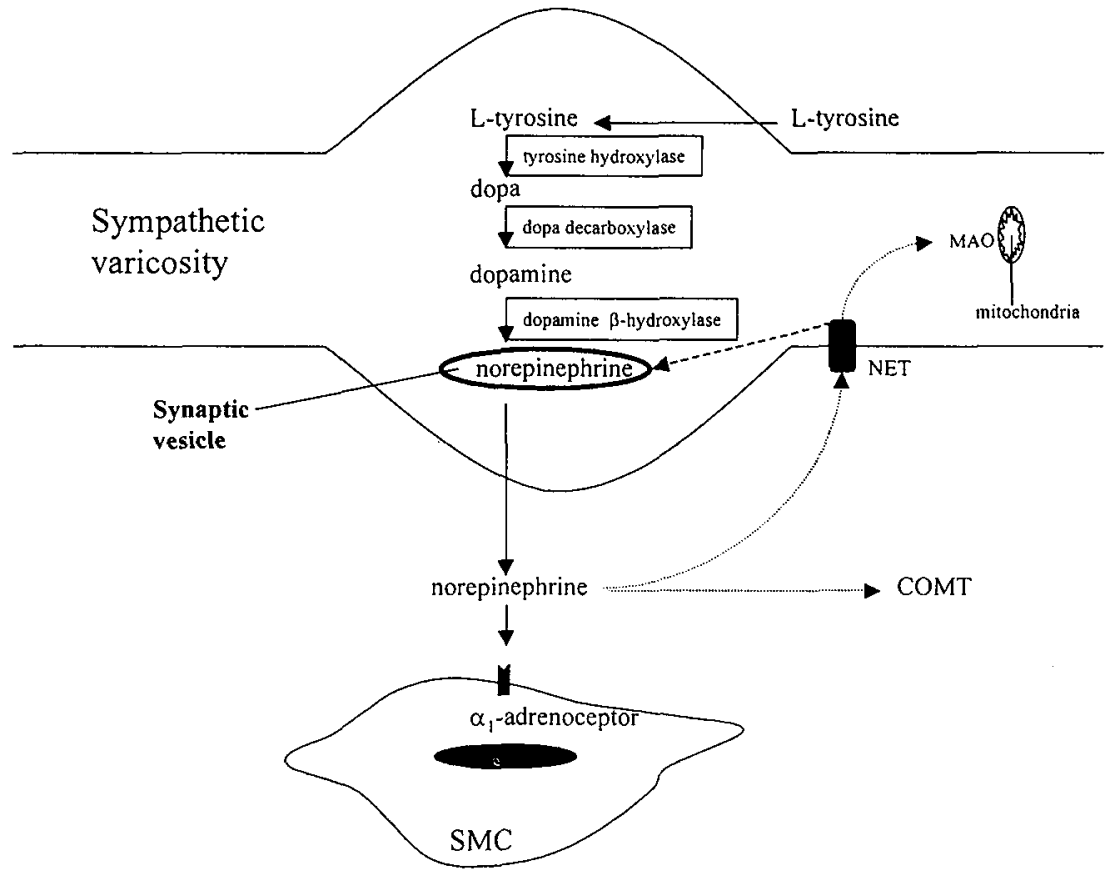

Figure 1.4 Biosynthetic Pathway of Norepinephrine Synthesis at a Varicosity of the Sympathetic Nerve Terminal. Abbreviations are explained in the text.

Analysis of the structure of the NET cDNAs predicts highly hydrophobic, integral membrane proteins with twelve transmembrane domains and cytoplasmatic $\mathrm{NH}_{2}$ and $\mathrm{COOH}$ termini.(Melikian et al., 1994; Brüss et al., 1995)

Interestingly, possible NET coding variants are apparent from divergent bovine NET isolates of adrenal gland,(Jursky et al., 1994; Lingen et al., 1994) involving differential splicing of coding sequences in the $\mathrm{COOH}$ terminus.(Pörzgen et al., 1995) At present it is not known whether the vascular NET system is also activated by Angll.

\section{$1.6 \alpha_{1}$-Adrenergic Receptors}

The work of Ahlquist in 1948 using epinephrine and its metabolites defined the concept of $\alpha$-and $\beta$-adrenoceptors.(Ahlquist, 1948) Ahlquist stated that the receptor mediating vasoconstriction should be termed the $\alpha$-adrenotropic and the receptor mediating vasodilatation and myocardial contraction be termed the $\beta$ adrenoceptor.(Anlquist, 1948) In 1957, Brown and Gillespie noted that $\alpha$-adrenoceptor blockers increased the outflow of norepinephrine following nerve stimulation of the cat spleen.(Brown and Gillespie, 1957) This led to the hypothesis of presynaptic $\alpha$ adrenoceptor that modulates the release of neurotransmitter from the synaptic nerve terminal. The significant difference in the potency of different phenoxybenzamine concentrations for inhibiting vascular effects and transmitter release led Dubocovich and Langer(Dubocovich and Langer, 1974) to suggest that the pre- and postjunctional 
receptors were not identical. Langer(Langer, 1974) suggested that the prejunctional $\alpha$ adrenoceptors be called $\alpha_{2}$, while the postjunctional $\alpha$-adrenoceptors be referred to as $\alpha_{1}$.

However, the concept that the receptors could be classified based on synaptic location proved to be incorrect. With the development of selective ligands for both $\alpha$ adrenoceptor subtypes, the nature of pre- and postjunctional $\alpha$-adrenoceptors could be evaluated. Drew and Whiting(Drew and Whiting, 1979) identified two types of vascular $\alpha$-adrenoceptors, the prazosin sensitive $\alpha_{1}{ }^{-}$and the prazosin insensitive $\alpha_{2^{-}}$ adrenoceptor. Shortly after the subclassification of $\alpha_{1}$ - and $\alpha_{2}$-adrenoceptors, evidence began to emerge that was inconsistent with a single postjunctional vascular $\alpha_{1}$ adrenoceptor.(Ruffolo et al., 1977; Bevan, 1981) Colucci et al.(Colucci et al., 1985) provided evidence of receptor heterogeneity in cultured aortic SMCs. Johnson and Minneman(Johnson and Minneman, 1987) showed that an alkylating analogue of clonidine, chloroethylclonidine (CEC) could only reduce the $\alpha_{1}$-adrenoceptor population of rat brain by approximately $50 \%$. Furthermore, Scatchard plots indicating high- and low-affinity [ $\left.{ }^{3} \mathrm{H}\right]$ prazosin sites in rabbit aorta were made by Piascik et al.(Piascik et al., 1988) Radioligand binding studies provided clear and compelling evidence of $\alpha_{1}$ adrenoceptor subtypes.(Morrow and Creese, 1986) The site at which such ligands as WB 4101, phentolamine, epinephrine, norepinephrine, and phenylephrine interacted with high affinity was termed the $\alpha_{1 A}$-adrenoceptor. The low-affinity site for these ligands was termed the $\alpha_{1 \mathrm{~B}}$-adrenoceptor.

\subsubsection{The $\alpha_{1}$-Adrenergic Receptor Subtypes}

In discussing $\alpha_{1}$-adrenoceptor subtypes, the lower case letters $a, b, c$, and $d$ indicate cloned receptors. When speaking of pharmacologically defined receptors, the upper case letters $A, B$, and $D$ are used. The first $\alpha_{1}$-adrenoceptor was cloned in 1988.(Cotecchia et al., 1988) The cDNA encoded a single polypeptide of 515 amino acids with an apparent molecular weight of approximately $80 \mathrm{kD}$ (table 1.2). This receptor has pharmacological characteristics similar to the $\alpha_{18}$-adrenoceptor. (Morrow and Creese, 1986) The cloned $\alpha_{1 b}$-adrenoceptor has the very familiar structural motif common to the superfamily of $G$ protein coupled seven transmembrane receptors. It possesses seven hydrophobic domains consisting of 20-28 amino acids, which comprise the membrane spanning regions of the receptor. The $\mathrm{N}$-terminus is located in the space. The cytoplasmic carboxyl-terminus and intracellular loops are important for coupling to $G$ proteins and intracellular signaling pathways. The cloned $\alpha_{1 b^{-}}$ adrenoceptor binds norepinephrine and epinephrine in the micromolar range and exhibits the appropriate stereochemistry for an adrenergic receptor. The $\alpha_{1 b^{-}}$ adrenoceptor was further shown to possess low affinity for ligands such as WB 4101, phentolamine, 5-methylurapidil and phenylephrine.(Cotecchia et al., 1988; Lomasney et al., 1991a; Perez et al., 1991) This receptor is sensitive to CEC inactivation. In situ hybridization (ISH), histochemistry and ribonuclease protection assays have also localized mRNA for the $\alpha_{1 b}$-adrenoceptor in a variety of peripheral blood vessels.(Piascik et al., 1994; Guarino et al., 1996) 
Table 1.2 Cloning and Characteristics of $\alpha_{1}$-Adrenoceptor Subtypes (Piascik et al., 1996)

\begin{tabular}{|c|c|c|c|c|}
\hline Current Nomenclature & $\begin{array}{l}\text { Gene } \\
\text { Product }\end{array}$ & $\begin{array}{l}\text { Amino } \\
\text { Acids }\end{array}$ & $\begin{array}{l}\text { Selective Agonists or } \\
\text { Antagonist }\end{array}$ & CEC Sensitivity \\
\hline $\begin{array}{l}\alpha_{1 A} \\
\text { (Schwinn et al., 1990) }\end{array}$ & $\alpha_{1 \mathrm{c}}$ & 466 & $\begin{array}{l}\text { 5-methylurapidil, } \\
\text { (+)-niguldipine, } \\
\text { oxymetazoline, } \\
\text { A61603, cirazoline }\end{array}$ & Low \\
\hline $\begin{array}{l}\alpha_{18} \\
\text { (Cotecchia et al., 1988) }\end{array}$ & $\alpha_{1 \mathrm{~b}}$ & 515 & $\mathrm{AH} 11110 \mathrm{~A}$ & $\begin{array}{l}\text { High ( } 90 \% \\
\text { Inactivated) }\end{array}$ \\
\hline $\begin{array}{l}\alpha_{1 D} \\
\text { (Perez et al., 1991) }\end{array}$ & $\alpha_{1 \mathrm{~d}}$ & 560 & BMY 7378 & $\begin{array}{l}\text { Moderate to } \\
\text { high (70\% } \\
\text { inactivated) }\end{array}$ \\
\hline
\end{tabular}

In the early 90's cDNA isolated from bovine brain encoded a novel peptide of 466 amino acids.(Schwinn et al., 1990) This receptor was $72 \%$ homologous to the $\alpha_{1 \mathrm{~B}^{-}}$ adrenoceptor in the putative membrane spanning regions, and was designated the $\alpha_{1 c^{-}}$ adrenoceptor.(Schwinn et al., 1990) Recent reports have suggested that the cloned $\alpha_{1 c^{-}}$ adrenoceptor in fact may be the pharmacological $\alpha_{1 \mathrm{~A}}$-adrenoceptor.(Forray et al., 1994; Laz et al., 1994; Perez et al., 1994; Price et al., 1994)

In 1991. Perez et al.(Perez et al., 1991) cloned and expressed a novel cDNA. The deduced amino acid sequence from this CDNA was a single polypeptide chain of 560 amino acids, the topology of which was similar to that of $G$ protein coupled receptors. They showed, furthermore, that this receptor was sensitive to CEC inactivation and therefore suggested that this novel receptor represented a new $\alpha_{1}$-adrenoceptor subtype, the $\alpha_{1 d^{-}}$adrenoceptor.(Perez et al., 1991) All subtypes activate PLC and PLA ${ }_{2}$, increase cAMP levels, mediate an $\mathrm{IP}_{3}$-dependent increase in intracellular $\mathrm{Ca}^{2+}$ and stimulate $\mathrm{Ca}^{2+}$ influx through L-type channels.(Piascik et al., 1996)

\subsubsection{Coupling to G Proteins}

The $G$ proteins coupling $\alpha_{1}$-adrenoceptors to their intracellular effectors and the selectivity of the various $\alpha_{1}$-adrenoceptors subtypes for different $G$ proteins have not been clearly defined. $\alpha_{1}$-Adrenoceptors predominantly couple to pertussis toxininsensitive $\mathrm{G}$ proteins of the $\mathrm{G}_{\mathrm{q} / 11}$ family, and there is evidence for selectivity among the various $\alpha_{1}$ subtypes for coupling to the different members of this family.(Wu et al, 1992) For example, $G_{\mathrm{q}}, G_{11}, G_{14}$ and $G_{16}$ can mediate inositol-phosphate turnover by the $\alpha_{1 B^{-}}$ adrenoceptor, but the $\alpha_{10}$-adrenoceptor couples only via $G_{q}$ or $G_{11}$. (Wu et al., 1992) It has also been demonstrated that the various cloned $\alpha_{1}$-adrenoceptor subtypes can activate multiple effectors via coupling to both pertussis toxin-sensitive $\left(G_{i}\right.$ or $G_{0}$ family) and -insensitive $G$ proteins.(Nebigil and Malik, 1992) Moreover, both the $\alpha$ and the $\beta \gamma$ subunits of the pertussis toxin-insensitive $G$ proteins may mediate activation of specific receptor-coupled effectors, such as the $\beta$ isoform of PLC.(Blank et al., 1992)

In addition to activation of PLC- $\beta$ via $G_{q / 11}$, there is evidence that the $\alpha_{18}$-adrenoceptor activates a $69-\mathrm{kD}$ PLC via coupling to a high molecular mass $(74-\mathrm{kD})$ class of pertussis toxin-insensitive $G$ proteins, termed $G_{n}$, that are distinct from the heterotrimeric $G$ proteins.(Nakaoka et al., 1994) These $G_{n}$ proteins are multifunctional proteins with both transglutaminase and receptor signaling functions and are expressed in various tissues, including brain, heart, and liver.(Nakaoka et al., 1994) Interestingly, binding of GTP by $\mathrm{G}_{\mathrm{h}}$ inhibits its transglutaminase activity, whereas binding of $\mathrm{Ca}^{2+}$, which is required for transglutaminase activity, prevents GTP binding.

It is interesting to note that in model cell systems, all three $\alpha_{1}$-adrenoceptor subtypes generate the same diverse array of intracellular second messengers by activating 
similar signaling pathways. If this also occurs in the vasculature, there appears to be redundant control of smooth muscle function by the $\alpha_{1}$-adrenoceptors, with each subtype capable of activating contraction via nearly identical pathways. What may occur in vivo is that receptors may preferentially activate one component of these diverse signaling pathways. Also, there may be differences in $G$ protein expression that could promote a certain type of differential second messenger coupling. (Neer, 1995; Chidiac, 1998)

\subsubsection{Genomic Organization, Promoters and Regulatory Elements}

$\alpha_{1}$-Adrenoceptors all contain a single intron.(Ramarao et al., 1992; Weinberg et al., 1994) Thus, each of the genes for the three $\alpha_{1}$-adrenoceptor subtypes consists of two exons and a single large intron ( 14 to $20 \mathrm{~kb}$ ) that interrupts the coding region at the end of the putative sixth transmembrane domain. In all cases, the exon/intron boundary is situated after the first base of the codon, indicating a type-1 splice phase. This genomic organization is unique among those $G$ protein coupled receptor genes that do contain introns. Given a genomic organization of two exons and only one intron, splicing of nascent transcripts cannot account for different $\alpha_{1}$-adrenoceptor subtypes unless cryptic splice sites are used or unless there is transsplicing of exons. Transsplicing has, as yet, not been convincingly demonstrated for mammalian genes. However, there is evidence for the use of a cryptic splice site in transcription of the $\alpha_{1 c^{-}}$ adrenoceptor.(Hirasawa et al., 1995) This gives rise to two alternate splice variants, which differ in length and sequences of their encoded C-terminal domains.

The $5^{\prime}$ untranslated region of the rat $\alpha_{16}$-adrenoceptor gene has also been sequenced and evaluated for transcriptional control elements.(Gao and Kunos, 1994; Kanasaki et al., 1994; Gao and Kunos, 1993; Gao et al., 1995) Like the human $\alpha_{1 b^{-}}$ adrenoceptor gene, a cAMP response element has been identified in the rat gene.(Gao and Kunos, 1993; Kanasaki et al., 1994) The 5' untranslated region (1621 bp) of the rat $\alpha_{1 b}$-adrenoceptor gene has a high degree of similarity $(87 \%)$ with the nucleotide sequence of the human $\alpha_{16}$-adrenoceptor gene located $500 \mathrm{bp}$ upstream from the translation start site.(Kanasaki et al., 1994) Independently, Gao and Kunos(Gao and Kunos, 1993) found that the overall structure of the rat $\alpha_{1 b}$-adrenoceptor gene is highly conserved with that of the human gene. They identified additional consensus sites for AP-1 and AP-2 binding sites and glucocorticoid and thyroid response elements in the $5^{\prime}$ flanking region, as well as a putative polyadenylation signal (ATTAAA) at the same location in the $3^{\prime}$ flanking region as in the human $\alpha_{1 b}$-adrenoceptor gene.

Although the gene for the $\alpha_{1 \mathrm{c}}$-adrenoceptor has been isolated,(Perez et al., 1994) neither its regulatory elements nor those of the $\alpha_{1 d}$-adrenoceptor gene have been defined. It is possible that transcription of these genes is also under the control of different promoters that are differentially activated in various tissues and species or in response to developmental or hormonal stimuli, since three $\alpha_{1 c}$-transcripts $(5.0,3.9,3.0$ $\mathrm{kb})$ and two $\alpha_{1 \mathrm{~d}}$-transcripts ( 3.0 and $1.7 \mathrm{~kb}$ ) have been identified in the human prostate with the use of cDNA probes that clearly do not cross-hybridize,(Faure et al., 1994) whereas only a single $\alpha_{1 c}$-and $\alpha_{1 d}$-adrenoceptor transcript was observed in rat heart(Perez et al., 1994) and in rat brain.(Perez et al., 1991; Lomasney et al., 1991a) respectively.

It should be mentioned, in this regard, that analysis of $\alpha_{1}$-adrenoceptor regulatory elements and transcripts is particularly problematic, since (1) the $5^{\prime}$ flanking regions are very high in GC content, making primer extension, ribonuclease protection assays, and polymerase chain reaction analyses of those regions difficult, (2) there is a high degree of homology between $\alpha_{1}$-adrenoceptor subtypes, even at the nucleotide level, and (3) in 
many tissues, the abundance of $\alpha_{1}$-adrenoceptor transcripts is extremely low. As a result, relatively large amounts of RNA are required for evaluation of $\alpha_{1}$-adrenoceptor transcripts. This could potentially lead to the identification of unrelated cross-hybridizing species, which may account, in part, for some of the marked variations (e.g. from 2.2 to $11 \mathrm{~kb}$ for the $\alpha_{1 \mathrm{c}}$, from $2.1 \mathrm{~kb}$ to $5.0 \mathrm{~kb}$ for the $\alpha_{1 \mathrm{~b}}$-adrenoceptor, and from 1.7 to $3.0 \mathrm{~kb}$ for the $\alpha_{1 \mathrm{~d}}$-adrenoceptor) in reported transcript sizes.(Perez et al., 1991; Lomasney et al., 1991a; Schwinn et al., 1991; Esbenshade et al., 1993; Hu and Hoffman, 1993; Faure et al., 1994; Stewart et al., 1994)

\subsubsection{Receptor Coupled Effectors}

$\alpha_{1}$-Adrenoceptor-mediated activation of PLC results in the phosphodiesteratic cleavage of a minor component of the membrane phospholipid pool, $\mathrm{PiP}_{2}$, to yield the second messengers, $\mathbb{P}_{3}$ and $\mathrm{DAG}$ (figure 1.5). $\mathbb{I P}_{3}$, thus generated, interacts with specific receptors on intracellular organelles, such as sarcoplasmic reticulum, to release stored $\mathrm{Ca}^{2+}$. DAG activates $\mathrm{PKC}$, which then phosphorylates a variety of cellular substrates, including $\mathrm{Ca}^{2+}$ channels, that may regulate intracellular $\mathrm{Ca}^{2+}$ or activate transcription of various genes. Blockade of $\mathrm{Ca}^{2+}$ channels with dihydropyridines or removal of extracellular $\mathrm{Ca}^{2+}$ was found to inhibit $\alpha_{1 A^{-}}$but not $\alpha_{1 B^{-}}$-mediated contractile responses in isolated vascular smooth muscle or $\mathrm{Ca}^{2+}$ influx in hepatocytes.(Minneman, 1988)

Studies with expressed cloned $\alpha_{1}$-adrenoceptor subtypes demonstrate that all three subtypes can both mobilize intracellular $\mathrm{Ca}^{2+}$ and increase $\mathrm{Ca}^{2+}$ influx via voltageoperated $\mathrm{Ca}^{2+}$ channels.(Schwinn et al., 1991; Perez et al., 1993) These studies also demonstrate that all three subtypes can couple not only to PLC activation but also to activation of PLA ${ }_{2}$ and PLD and can promote CAMP accumulation.(Schwinn et al., 1991; Perez et al., 1993) This latter effect probably occurs via a PKC-mediated potentiation of adenylyl cyclase activity,(Perez et al, 1993) although there is also evidence for $\alpha_{1}-$ adrenoceptor mediated inhibition of cAMP degradation.(Buxton and Brunton, 1985)

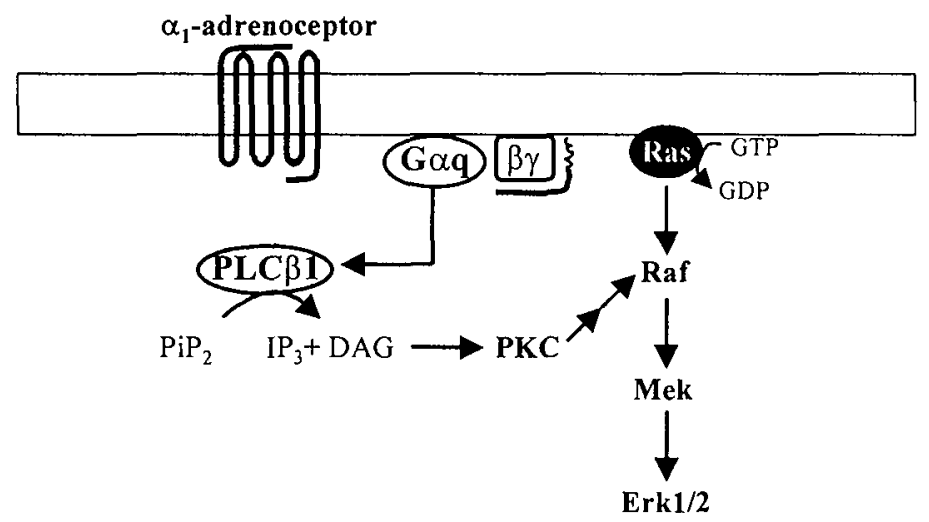

Figure 1.5 ERK1/2 (extracellular signal-regulated kinase) Activation by G Protein-Coupled Receptors Coupled to Pertussis Toxin-Insensitive G Proteins. MEK is MAPK kinase.(Vanbiesen et al., 1996) 


\subsection{The Sympathetic Nervous System of Response to Angll}

Several laboratories have demonstrated that Angll interacts with the SNS at various levels. Angll facilitates the release of norepinephrine from the synaptic sympathetic varicosities via specific Angll-receptors (AT, receptor) and of epinephrine from the chromaffin cells of the adrenal medulla.(Feldberg and Lewis, 1964; Starke, 1977) It also increases smooth vascular tone using the same intracellular second messengers, $I_{3}$ and DAG, as does norepinephrine, thereby enhancing the effects of that catecholamine on vascular SMCs.(Berridge, 1993; Griendling et al., 1997) Angll is known to stimulate the activity of the SNS, not only centrally, but also at the level of the synapse and through stimulation of the adrenal release of catecholamines. These effects are probably mediated by AT, receptors.(Wong et al., 1990) Furthermore, it remains to be established whether the effect of Angll is mediated by a direct effect of the peptide on the vascular wall or by its interaction with the SNS since the mitogenic response of the rat aorta, induced by chronic low-dose Angll infusion, can be blocked by the $\alpha_{1}$-adrenoceptor antagonist prazosin.(van Kleef et al., 1992)

Increased mRNA transcription, without changes in mRNA stability, has also been observed for the $\alpha_{1 b}$-adrenoceptor in response to Angll treatment of cultured rat aortic SMCs. This effect of Angll was associated with increased $\alpha_{1}$-adrenoceptor expression

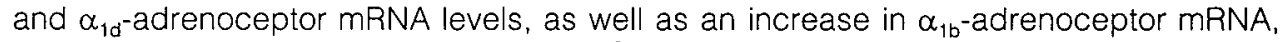
and involved a PKC-dependent, but $\mathrm{Ca}^{2+}$-independent, mechanism.(Hu et al., 1995) However, in rabbit aortic SMCs, activation of PKC as a result of $\alpha_{1 b}$-adrenoceptor stimulation by norepinephrine, although having a permissive effect on $\alpha_{1 \mathrm{~b}}$-adrenoceptor gene transcription, had a greater effect in destabilizing $\alpha_{1 b}$-adrenoceptor mRNA.(Izzo, Jr. et al, 1994)

\subsection{Hypothesis}

Angiotensin II and $\alpha_{1}$-adrenoceptors have prominent effects on vascular growth and particularly on the vascular response after injury. (Jackson et al., 1988; O'Malley et al., 1989; Fingerle et al., 1991; Daemen et al., 1991; Vashisht et al., 1992) However, this response after injury is heterogeneous i.e. medial SMCs are sensitive and the neointimal SMCs are insensitive.(van Kleef et al., 1996a) Also, the precise mechanisms and interactions are still unknown. We therefore further investigated the role of the $\alpha_{1}$ adrenoceptors in the growth regulation in the balloon injured rat carotid artery after stimulation with Angll.

We hypothesized that Angll induces an increase in the release of norepinephrine from the sympathetic nerve endings (neurogenic). This neurogenic release is modulated by the NET, which is also regulated by Angll. Furthermore, we hypothesized that Angll induces an increase in the systemic (humoral) release of (nor)epinephrine from the adrenal medulla. Since both pathways are able to stimulate $\alpha_{1}$-adrenoceptors located on the SMC surface, its difficult to distinguish between them. Therefore, we further hypothesize that the differences in Angll induced growth responses between the uninjured media and the injured neointima comes from differences in sympathetic innervation and/or differences in the presence of $\alpha_{1}$-adrenoceptor subtypes between the media and the neointima in the rat carotid artery.

\subsection{This Thesis}

In the first experimental chapter (chapter 2), mRNA localization and mRNA amount of two $\alpha_{1}$-adrenoceptor subtypes in the balloon injured rat carotid artery was investigated at different time points after injury. In chapter 3 , the possible upregulation of the NET in the balloon injured rat carotid artery after Angll-stimulation was investigated. In chapter 4, the effects of Angll on SMC growth in the injured rat carotid artery after the blockade 
of the release of neuronal norepinephrine were investigated. The release of neuronal norepinephrine from the SNS, was blocked by chemical sympathectomy with 6-OHDA. In chapter 5 , the possible interactions between adrenal medulla derived catecholamines and $\alpha_{1}$-adrenoceptors on Angll induced neointimal growth in the balloon injured rat carotid artery model, were investigated by removal of both adrenal glands and infusion of the $\alpha_{1}$-adrenoceptor antagonist prazosin. Chapter 6 deals with the involvement of the SNS on the regulation of intimal thickening in humans. In that chapter, we investigated sympathetic innervation patterns in human stenotic arteriovenous fistulas. The results of the studies described in the previous chapters are discussed in chapter 7 . 


\section{CHAPTER 2}

Distribution of the mRNAs of the $\alpha_{1}$-Adrenoceptor Subtypes in the Rat Carotid Artery After Balloon Catheter Induced Injury 


\section{Abstract}

To investigate the distribution of the mRNAs of the $\alpha_{1}$-adrenoceptor subtypes in the injured rat carotid artery, a balloon injury of the left carotid artery was performed on male Wistar rats. Subsequently, the mRNAs of the $\alpha_{1 \mathrm{~b}}$-and $\alpha_{1 d^{-}}$-adrenoceptor genes were detected by in situ hybridization (ISH) at 4 and 12 weeks after injury, while the amount of the mRNAs of the $\alpha_{1 b}$-and $\alpha_{1 d^{-}}$adrenoceptors were quantified by a reverse transcriptionpolymerase chain reaction (RT-PCR) on total RNA isolated from carotid arteries at 1, 4, and 12 weeks after balloon injury.

4 Weeks after injury the mRNA levels for both the $\alpha_{1}$-adrenoceptor subtypes was increased $\left(\alpha_{1 \mathrm{~b}}: 147.5 \pm 39.1 \mathrm{fg} / 250 \mathrm{ng}\right.$ total RNA; $\alpha_{1 \mathrm{~d}}: 390.7 \pm 61.9 \mathrm{fg} / 250 \mathrm{ng}$ total RNA) as compared to 12 weeks after injury $\left(\alpha_{1 \mathrm{~b}}: 41.0 \pm 9.3 \mathrm{fg} / 250 \mathrm{ng}\right.$ total RNA; $\alpha_{1 \mathrm{~d}}: 52.3 \pm$ $11.4 \mathrm{fg} / 250 \mathrm{ng}$ total RNA). The amount of mRNA of the $\alpha_{1 b^{-}}$and $\alpha_{1 \mathrm{~d}}$-adrenoceptor of the uninjured rat carotid artery did not change in time after injury.

The ISH data show that transcription of the two $\alpha_{1}$-adrenoceptor genes at 4 weeks after injury, occurs throughout the adventitia, media and neointima of injured carotid arteries. Both the smooth muscle cells in the media and the neointima, as the vasa vasorum and nerves in the adventitia, showed positivity for the $\alpha_{1}$-adrenoceptor subtypes mRNAs. This positive signal showed a gradient increasing from the adventitia towards the lumen of the vessel and was higher as compared to the ISH data 12 weeks after injury, which showed almost no signal for the $\alpha_{1}$-adrenoceptor subtypes mRNAs. With ISH no obvious differences between the distribution of the $\alpha_{1}$-adrenoceptor subtypes could be detected.

These data show that the amount and distribution of the mRNA for the $\alpha_{1}$ adrenoceptor subtypes changes in time after balloon injury of the rat carotid artery. 
Introduction

$\alpha_{1}$-Adrenergic receptors in vascular smooth muscle exert trophic actions to regulate the phenotype of vascular smooth muscle celis, in addition to their dynamic regulation of vascular contractility in response to stimulation of the sympathetic nervous system. While sympathetic denervation of the rabbit ear artery inhibits normal vessel wall development in young animals,(Bevan, 1984) acute injection of the $\alpha_{1}$-selective adrenergic agonist phenylephrine or the infusion of catecholamines increases protein, mRNA synthesis and cellular polyploidy, but not cellular proliferation, in rat aorta.(Yamori et al., 1987; Majesky et al., 1990) Conversely, $\alpha_{1}$-adrenoceptor blockade with prazosin inhibits neointimal thickening in models of vascular injury in the rat and rabbit.(O'Malley et al., 1989; Fingerle et al., 1991) The $\alpha_{1}$-adrenoceptor antagonist doxazosin however, did not reduce SMC DNA synthesis in the media and neointima of the injured rat carotid artery when infused together with Angll two weeks after balloon injury. It did, however, decrease SMC DNA synthesis in the media of the uninjured carotid artery.(van Kleef et al., 1996a)

One possible explanation for this relative insensitivity of the neointima to $\alpha_{1}$ adrenergic blockade is a relative loss of $\alpha_{1}$-adrenoceptors in the neointima. An alternative explanation is a shift in $\alpha_{1}$-adrenoceptor subtypes which may result in different effects.

Although there are some studies about the tissue and vascular distribution of the $\alpha_{1}$ adrenoceptor subtypes in different species,(Piascik et al., 1994; Kohno et al., 1994; Alonso-Llamazares et al., 1995; Piascik et al., 1997; Suzuki et al., 1997) there is no data on the distribution of $\alpha_{1}$-adrenoceptors subtypes in the rat carotid artery after balloon injury.

We report here the analysis of the mRNA amount in the injured and uninjured rat carotid artery at 1, 4, and 12 weeks after injury. The quantitative RT-PCR, of total RNA isolated from injured rat carotid artery, revealed that the amount of both the $\alpha_{1 b^{-}}$and $\alpha_{1 d^{-}}$ adrenoceptor mRNAs were increased at 4 weeks after balloon injury of the rat carotid artery as compared to 12 weeks after injury. The mRNA levels in the uninjured carotid artery remained unchanged.

In situ hybridization showed that both receptor subtypes were present throughout the entire vessel wall, with a gradient from the adventitia to the lumen. No obvious changes in receptor distribution pattern over time were found after injury.

These data show that the neointima, that develops after balloon injury of the rat carotid artery, contains $\alpha_{1}$-adrenoceptor mRNAs. Their quantities, but not subtype or distribution changes over time.

Materials \& Methods

Animals

Male Wistar rats obtained from Iffa Credo (Someren, the Netherlands) were used (body weight, 275-325 $\mathrm{g} ; \mathrm{n}=15$ ). They had free access to standard rat chow (Hope Farms, Woerden, the Netherlands) and tap water. The experiments were performed according to institutional guidelines.

\section{Balloon Injury}

All rats were anaesthetized with pentobarbital $(60 \mathrm{mg} / \mathrm{kg}$ body weight) by intraperitoneal (i.p.) injection. The left common carotid artery was injured by introduction of a 2F balloon catheter (Baxter, Maarsen, the Netherlands) into the left external carotid artery. After inflation, the catheter was withdrawn through the common carotid artery. This procedure was repeated three times after which the catheter was removed and the 
external carotid artery ligated. The right carotid artery was not traumatized and served as a control.(Clowes et al., 1983a; Clowes et al., 1983b)

\section{Tissue Processing}

After 1, 4, and 12 weeks after balloon injury 3 animals per time-point were anaesthetized with sodium pentobarbital ( $80 \mathrm{mg} / \mathrm{kg}$ i.p.) and the left and right carotid artery, the vas deferens and the heart were rapidly removed and dissected in ice-cold saline $(0.9 \% \mathrm{NaCl})$ containing 2 units $/ \mathrm{ml}$ of recombinant ribonuclease inhibitor (RNasin, Promega Corp., Madison, WI). The tissues were frozen in liquid nitrogen and then stored at $-70^{\circ} \mathrm{C}$ until extraction of RNA.

After $4(n=3)$ and 12 weeks $(n=3)$ after injury of the left carotid artery rats received 0.5 $\mathrm{ml} 0.5 \%$ Evans blue (Chroma Gesellschaft, Stuttgart, Germany) in $0.9 \% \mathrm{NaCl}$ by intravenous (i.v.) injection, to stain non-endothelialized tissue in the left common carotid artery. One hour later the animals were killed by pentobarbital overdose $(80 \mathrm{mg} / \mathrm{kg}$ body weight i.p.) and the arterial system was perfused with phosphate buffered saline (PBS)

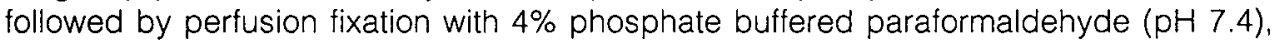
at a pressure of $100 \mathrm{mmHg}$. Maximal vasodilatation was ensured by adding nitroprusside $(0.1 \mathrm{mg} / \mathrm{ml}$, Sigma Chemical Co., St. Louis, Mo., USA) to the perfusate.

One circular segment $(2-3 \mathrm{~mm}$ long) was taken from the center of the blue stained non-endothelialized part of the left carotid artery. Heart $\left(\alpha_{1 b}\right)$ and vas deferens $\left(\alpha_{1 d}\right)$ served as positive controls for the ISH.(Scofield et al., 1995) All tissues were fixed overnight in $4 \%$ phosphate buffered paraformaldehyde, routinely processed and embedded in paraffin (Para Clean, Klinipath, Duiven, the Netherlands).

\section{Total RNA Isolation}

Injured left and uninjured right carotid arteries were homogenized in $4 \mathrm{M}$ guanidine isothiocyanate solution using a Polytron P1200 homogenizer (Kinematica AG). The homogenized samples were loaded onto $5.7 \mathrm{M}$ cesium chloride containing ultracentrifuge tubes. Total-RNA was pelleted by centrifugation at 35,000 rounds per minute for 18 hours at room temperature. After removal of the supernatant the RNA pellet was resuspended in $0.3 \mathrm{M}$ sodium acetate, $\mathrm{pH} 6.0$ and ethanol. Precipitation was performed for 1 hour at $-70^{\circ} \mathrm{C}$. After centrifugation the pellet was washed with $70 \%$ ethanol, centrifuged again, and the resulting pellet was dissolved in $15 \mu_{\mathrm{l}} \mathrm{H}_{2} \mathrm{O}$. The integrity of the RNA was checked by agarose gel electrophoresis, while the total RNA content of each individual sample was determined by optical density at $260 \mathrm{~nm}$.

\section{Polymerase Chain Reaction Primer Selection}

Primers used in the PCR reaction were designed in such a way that the PCR product would span the nucleotide sequence of the third intracellular loop, specifically amplifying transmembrane region 5 to transmembrane region 6 of the rat $\alpha_{10}$-(Voigt et al., 1990) and $\alpha_{1 d}$-adrenergic receptor.(Lomasney et al., 1991a; Perez et al., 1991) Previous results indicated that these two $\alpha_{1}$-adrenoceptor subtypes are present in rat tissues.(Lomasney et al., 1991b) The $\alpha_{1 \mathrm{~A}}$-adrenoceptor could not be detected in large muscular arteries(Stassen et al., 1997a; Muramatsu, 1991) and was therefore not investigated. For the rat $\alpha_{1 b}$-adrenoceptor cDNA, a 300 bp PCR product was formed using the sense, primer 5'-GCTCCTTCTACATCCCGCTCG-3' and the corresponding anti-sense primer 5'-AGGGGAGCCAACATAAGATGA-3'. For the $\alpha_{1 \mathrm{~d}}$-adrenoceptor the sense primer was 5'-CGTGTGCTCCTTCTACCTACC-3', and the corresponding antisense primer was 5'-GCACAGGACGAAGACACCCAC-3'. The predicted CDNA amplification product of the $\alpha_{1 d}$-adrenergic receptor was $304 \mathrm{bp}$ long. 


\section{Reverse Transcription-Polymerase Chain Reaction}

Total RNA was transcribed to cDNA with the use of the 'Ready-To-Go You-Prime FirstStrand Beads' (Pharmacia, Uppsala, Sweden). Briefly, $250 \mathrm{ng}$ of total RNA and 100 pmol of random hexanucleotide primer were denaturated at $65^{\circ} \mathrm{C}$ for 10 minutes, then chilled on ice for 2 minutes. The RNA solution was transferred to the tube of 'First-Strand Reaction Mix Beads' and brought to a final volume of $33 \mu \mathrm{l}$ with DEPC-treated water. After gentle mixture of the tube, cDNA was transcribed at $37^{\circ} \mathrm{C}$ for 60 minutes. Of this RT solution, $3.3 \mu \mathrm{l}$ was subjected to PCR with the use of the above described specific primers for the $\alpha_{1 \mathrm{~b}}$-and $\alpha_{1 \mathrm{~d}}$-adrenergic receptor cDNA.

The PCR reaction mix contained $20 \mathrm{mM}$ Tris $-\mathrm{HCl}, \mathrm{pH} 8.3,10 \mathrm{mM} \mathrm{KCl}, 10 \mathrm{mM}$ $\left(\mathrm{NH}_{4}\right)_{2} \mathrm{SO}_{4}, 2 \mathrm{mM} \mathrm{MgSO}, 50 \mu \mathrm{M}$ of each dNTP, $20 \mathrm{pmol}$ of sense and anti-sense primers, and $2 U$ Taq DNA polymerase in a total volume of $25 \mu \mathrm{l}$. PCR was performed during $35 \mathrm{cycli}$, with each cycle at $94^{\circ} \mathrm{C}$ for 30 seconds, $58^{\circ} \mathrm{C}$ for 1 minute, and $72^{\circ} \mathrm{C}$ for 1 minute.

\section{Agarose Gel Electrophoresis of RT-PCR Products}

$10 \mu \mathrm{l}$ Of the PCR product was mixed with $2 \mu \mathrm{l} 6 \times$ gel loading buffer $(0.25 \%$ Orange $\mathrm{G}$, $40 \%(\mathrm{~W} / \mathrm{V})$ sucrose) and loaded on a $3 \%$ agarose gel prepared in $1 \times$ TBE buffer ( $89 \mathrm{mM}$ Tris base, $89 \mathrm{mM}$ boric acid, and $2 \mathrm{mM}$ EDTA, $\mathrm{pH}$ 8.0) and containing $0.5 \mu \mathrm{g} / \mathrm{ml}$ ethidium bromide. PCR products were electrophoresed for 45 minutes at $100 \mathrm{~V}$ in a BioRad Mini-Gel System (Bio-Rad Laboratories, Hercules, CA). After electrophoresis, fragments were visualized by UV light.

\section{In Situ Hybridization}

The PCR fragments were ligated in the PCR2.1-vector (Invitrogene, molar ratio 3:1, 1:1 and 1:3), containing a 3' thymidine overhang and a T7 and Sp6 RNA polymerase site. The specificity of these products were checked by sequencing (Sanger method). A ${ }^{35}$ S-UTP-labeled anti-sense riboprobe was created by transcription using T7 RNA polymerase (Riboprobe System II, Promega). Plasmid DNA was removed by RQ1 DNase (Promega) treatment and the probe was precipitated after phenol/chloroform extraction. Sections $(4 \mu \mathrm{m})$ of paraformaldehyde fixed, paraffin embedded tissues (see Tissue Processing section) were cut, mounted on silane-coated slides and dried for 48 hours at $37^{\circ} \mathrm{C}$. Pre-treatment consisted of 10 minutes fixation in $4 \%$ paraformaldehyde, followed by proteinase $\mathrm{K}(2 \mu \mathrm{g} / \mathrm{ml})$ treatment for 10 minutes at room temperature. Hereafter, the sections were incubated for 1 hour in a prehybridization buffer $(50 \%$ formamide, $0.3 \mathrm{M} \mathrm{NaCl}, 20 \mathrm{mM}$ Tris $\mathrm{pH} 8.0,5 \mathrm{nM}$ EDTA, $0.02 \%$ polyvinyl-pyrrolidone, $0.02 \%$ Ficoll, $0.02 \%$ BSA, $10 \%$ dextran sulphate, and $10 \mathrm{mMDTT}$ ) at $37^{\circ} \mathrm{C}$. Hybridization was performed overnight at $55^{\circ} \mathrm{C}$ after addition of $600.000 \mathrm{cpm}$ of the ${ }^{35} \mathrm{~S}$ labeled probe per slide. After hybridization the slides were washed in $2 \times$ SSC $(2 \times S S C=0.3 \mathrm{M} \mathrm{NaCl}$, $30 \mathrm{mM}$ sodium citrate, $\mathrm{pH} 7.0$ ), $1 \mathrm{mM}$ EDTA and $10 \mathrm{mM}$ B-mercaptoethanol for 10 minutes (2X), RNase treatment and washed for 2 hours in $0.1 \times$ SSC at $55^{\circ} \mathrm{C}$. This was followed by a wash in $0.5 \times$ SSC without EDTA/B-mercaptoethanol and dehydration by immersion in increasing alcohol grades. After dehydration and drying, the slides were dipped in G5 photo emulsion (Ilford, Leiden, The Netherlands) at $42^{\circ} \mathrm{C}$, and exposed at $4^{\circ} \mathrm{C}$. Depending on message abundance the exposure time varied between 2-6 weeks. The slides were developed with Kodak Dektol developer (Eastman Kodak Company, Rochester, USA) and fixed in $0.8 \mathrm{M}$ sodium thiosulphate and $0.09 \mathrm{M}$ potassium disulphate. The sections were counterstained with hematoxylin and examined by brightand dark-field microscopy. 


\section{Quantitative Reverse Transcription-Polymerase Chain Reaction}

The technique of quantitative RT-PCR with the use of internal standards was performed as described previously.(Passier et al., 1995; Passier et al., 1996)

\section{Internal Standards Formation}

The pCR2.1-plasmid containing the $\alpha_{1 \mathrm{~b}}$ and $\alpha_{1 d}$ PCR-fragments used for the ISH, were digested with specific restriction enzymes. The $\alpha_{1 \mathrm{~b}}$-adrenoceptor PCR fragment ( $300 \mathrm{bp}$ ) was digested by BspH1 (New England Biolabs) and the $\alpha_{1 \mathrm{~d}}$-adrenoceptor PCR fragment (304 bp) was digested by Dpnll (New England Biolabs). Digestion of the PCR fragments resulted in three fragments of different lengths. The 5' and 3' fragments of each PCR fragment were separately isolated by gel electroelution and consequently ligated with $1 \cup$ of $T 4$ DNA ligase (Promega) at $15^{\circ} \mathrm{C}$ overnight. After amplification (35 cycles), the deletion fragment was checked by agarose gel electrophoresis for length and purity. Subsequently, the deletion fragment was ligated for 15 hours at $15^{\circ} \mathrm{C}$ with 2 U T4 DNA ligase in the presence of the pCR2.1-vector (Invitrogene, San Diego, USA). After linearizing the plasmid with Sacl (Promega), RNA was transcribed with $1 \cup$ T7 RNA polymerase (Promega), 1 hour at $37^{\circ} \mathrm{C}$. Plasmid DNA was removed by electroelution, followed by DNase treatment with $5 \mathrm{U}$ of RQ1 DNase (Promega), 30 minutes at $37^{\circ} \mathrm{C}$. The concentration of the internal standard RNA was measured by spectrophotometry at 260 $\mathrm{nm}$ and integrity was checked on a $1 \%$ agarose gel. Possible plasmid DNA contamination was ruled out by amplification of the RNA. For stabilizing the standard RNA, $30 \mu \mathrm{g} / \mathrm{ml}$ tRNA was added. The lengths of the internal standards for the $\alpha_{1 b^{-}}$ adrenoceptor and the $\alpha_{1 \mathrm{~d}}$-adrenoceptor were $242 \mathrm{bp}$ and $196 \mathrm{bp}$, respectively.

\section{Reverse Transcription}

In the same tube total RNA isolated from the carotid artery was mixed together with increasing amounts of the standard RNA ( $5 \mathrm{fg}$ to $20 \mathrm{pg} \alpha_{1 b}$-adrenoceptor or $5 \mathrm{fg}$ to 20 pg $\alpha_{1 d}$-adrenoceptor standard RNA per $250 \mathrm{ng}$ total RNA, 12 concentrations/total RNA sample) and transcribed to cDNA with the use of the 'Ready-To-Go You-Prime FirstStrand Beads' (Pharmacia, Uppsala, Sweden). Briefly, tubes containing total RNA and increasing amounts of the standard RNA and $100 \mathrm{pmol}$ of random hexanucleotide primer were denaturated at $65^{\circ} \mathrm{C}$ for 10 minutes, then chilled on ice for 2 minutes. The RNA solution was transferred to the tube of 'First-Strand Reaction Mix Beads' and brought to a final volume of $33 \mu \mathrm{l}$ with DEPC-treated water. After gentle mixture of the tube, cDNA was transcribed at $37^{\circ} \mathrm{C}$ for 60 minutes.

\section{Polymerase Chain Reaction}

The cDNA fragments from each reverse transcription reaction were amplified in duplicate. $5 \mu \mathrm{l}$ Of the reverse transcription mixture was added to $20 \mu \mathrm{l}$ of a PCR-mix, containing $20 \mathrm{mM}$ Tris- $\mathrm{HCl}, \mathrm{pH} 8.3,50 \mathrm{mM} \mathrm{KCl}, 20 \mathrm{pmol}$ of both the sense and antisense $\alpha_{1 \mathrm{~b}}$-adrenoceptor primers and $1.25 \cup$ AmpliTaq DNA polymerase (Perkin \& Elmer). For the $\alpha_{10}$-adrenoceptor PCR, $10 \mu$ of the reverse transcription mixture was added to $15 \mu \mathrm{l}$ of a PCR-mix, containing $20 \mathrm{mM}$ Tris- $\mathrm{HCl}, \mathrm{pH} 8.3,50 \mathrm{mM} \mathrm{KCl}, 20 \mathrm{pmol}$ of both the sense and anti-sense $\alpha_{10}$-adrenoceptor primers and $1.25 \mathrm{U}$ AmpliTaq DNA polymerase. The final $\mathrm{MgCl}_{2}$ concentration in the PCR-mix was $2.0 \mathrm{mM}$.

The primers used were:

$\alpha_{1 \mathrm{~b}}$-adrenoceptor sense: 5'-GCTCCTTCTACATCCCGCTCG-3'

$\alpha_{1 b^{-}}$-adrenoceptor anti-sense: 5'-AGGGGAGCCAACATAAGATGA-3'

$\alpha_{1 d}$-adrenoceptor sense: 5'-CGTGTGCTCCTTCTACCTACC-3'

$\alpha_{1 d^{-}}$-adrenoceptor anti-sense: 5'-GCACAGGACGAAGACACCCAC-3' 
The PCR reaction for both the $\alpha_{1 b^{-}}$and the $\alpha_{1 d^{-}}$-adrenoceptor cDNA was performed during $40 \mathrm{cycli}$, with each cycle at $94^{\circ} \mathrm{C}$ for 30 seconds, $58^{\circ} \mathrm{C}$ for 1 minute, and $72^{\circ} \mathrm{C}$ for 1 minute.

\section{Quantification of the PCR Fragments}

After amplification, $10 \mu$ of the PCR fragments were separated by electrophoresis on a $3 \%$ agarose gel, containing ethidium bromide. Two fragments were detected by UV light and the image was captured by a digital camera. The optical density of the two fragments was measured by the Gelpro Analyzer software (Version 2.0, Media Cybernetics). The value of the optical density of the internal standard was multiplied by the ratio of target DNA bp/standard bp, thereby correcting for the difference in ethidium bromide density, caused by the difference in length between the target fragment and the internal standard. The mean values of the duplicate samples were plotted as the logarithm of the ratio of the internal standard to the target fragment against the logarithm of the known amount of internal standard RNA in each tube. The line of best fit and the correlation coefficient $(r)$ were calculated. If $r^{2}$ was below 0.95 data were discarded. The logarithm value of zero on the $y$-axis represents the equivalence point, indicating the equal amount of internal standard RNA and target RNA.

\section{Statistics}

The mean values of the RNA samples were related to the mean of the standard total RNA. The mRNA amount is expressed in femto (f)g/250 $\mathrm{ng}$ total RNA. The mean mRNA amounts ( \pm SEM) of 3 animals are given. The mRNA amounts in the injured and the noninjured rat carotid artery at the different time points after injury are evaluated. Statistical differences were calculated using one way ANOVA followed by the Newman-Keuls test for multiple comparisons. Statistical significance was assumed at $p<0.05$.

Results

$\alpha_{16}$-Adrenoceptor mRNA Levels in the Injured and Uninjured Rat Carotid Artery

Quantitative RT-PCR revealed that the mRNA amount of the $\alpha_{15}$-adrenoceptor in the injured rat left carotid artery was $67.9 \pm 22.8 \mathrm{fg} / 250 \mathrm{ng}$ total RNA at 1 week, and $147.5 \pm$ $39.1 \mathrm{fg} / 250 \mathrm{ng}$ total RNA at 4 weeks after balloon injury. This difference however, was not statistically significant $(p=0.45)$. The mRNA concentration in the injured left carotid artery at 12 weeks after injury decreased to $41.0 \pm 9.3 \mathrm{fg} / 250 \mathrm{ng}$ total RNA as compared to 4 weeks after injury $\left(p=0.04\right.$; table 2.1). There was no difference between the $\alpha_{1 b}$ adrenoceptor mRNA amount of the injured left carotid artery at 1 week as compared to 12 weeks after injury.

No differences were detected between the mRNA amounts of the $\alpha_{16}$-adrenoceptor in the uninjured right carotid artery. Basal levels were $249.1 \pm 53.2 \mathrm{fg} / 250 \mathrm{ng}$ total RNA and remained unchanged over time.

\section{$\alpha_{10}$-Adrenoceptor mRNA Levels in the Injured and Uninjured Rat Carotid Artery}

The mRNA level of the $\alpha_{1 d}$-adrenoceptor in the injured rat left carotid artery was 155.1 $\pm 59.0 \mathrm{fg} / 250 \mathrm{ng}$ total RNA at 1 week and $390.7 \pm 61.9 \mathrm{fg} / 250 \mathrm{ng}$ total RNA at 4 weeks after balloon injury $(p=0.39)$. Quantitative RT-PCR showed that the mRNA concentrations in the injured left carotid artery at 12 weeks after injury decreased to $52.3 \pm 11.4 \mathrm{fg} / 250$ ng total RNA as compared to 4 weeks after injury ( $p=0.03$; table 2.1). There was no statistical difference between the $\alpha_{1 d}$-adrenoceptor mRNA amount of the injured left carotid artery at 1 week after injury as compared to the $\alpha_{1 d}$-adrenoceptor mRNA amount of the injured left carotid artery at 12 weeks after injury. 
In the uninjured rat carotid artery the levels of $\alpha_{1 d}$-adrenoceptor mRNA did not differ throughout the experiment and was $413.5 \pm 57.8 \mathrm{fg} / 250 \mathrm{ng}$ total RNA.

Table 2.1 The Amount of mRNA For the $\alpha_{1}$-Adrenoceptor Subtypes $\left(\alpha_{1 b}\right.$ and $\left.\alpha_{1 d}\right)$ in the Injured Left Carotid (LC) and the Uninjured Right Carotid (RC) Artery at Different Time Points After Balloon Injury

\begin{tabular}{|c|c|c|c|c|}
\hline \multirow{2}{*}{ Time After Injury } & \multicolumn{2}{|c|}{$\alpha_{1 b}$} & \multicolumn{2}{|c|}{$\alpha_{10}$} \\
\hline & LC & $\mathrm{RC}$ & LC & $\mathrm{RC}$ \\
\hline 7 Days & $67.9 \pm 22.8$ & $124.8 \pm 48.0$ & $155.1 \pm 59.0$ & $397.5 \pm 65.4$ \\
\hline 28 Days & $147.5 \pm 39.1$ & $328.5 \pm 56.4$ & $390.7 \pm 61.9$ & $469.8 \pm 28.0$ \\
\hline 12 Weeks & $41.0 \pm 9.3^{*}$ & $257.3 \pm 43.2$ & $52.3 \pm 11.4^{*}$ & $385.4 \pm 47.6$ \\
\hline
\end{tabular}

The mRNA amount is expressed in femto $(f) g / 250 \mathrm{ng}$ of total RNA. Data represent mean \pm SEM.

*) Statistically different from 28 days.

\section{In Situ Hybridization}

With the use of mRNA riboprobes designed to recognize specific regions of the $\alpha_{1 \mathrm{~b}}$ and $\alpha_{10}$-adrenoceptors, we were able to localize the mRNAs of both adrenoceptor subtypes in the injured carotid artery at 4 weeks after balloon injury. The mRNAs of both $\alpha_{1}$-adrenoceptor subtypes were located on SMCs in the media and neointima, and on the vasa vasorum and nerves in the adventitia (figure 2.1). Furthermore, the mRNA levels of both $\alpha_{1}$-adrenoceptor subtypes seemed to gradually increase from the adventitia towards the lumen of the vessel (figure 2.1).

On the other hand, no increased mRNA signals for the $\alpha_{1}$-adrenoceptor subtypes could be detected in the injured carotid artery at 12 weeks after injury. This lack of specific signal was, however, not due to sampling error or technical difficulties since both the vas deferens $\left(\alpha_{1 \mathrm{~d}}\right)$ and the heart $\left(\alpha_{\mathrm{bb}}\right)$ showed a positive signal (data not shown).

\section{Discussion}

Adrenergic receptors are a family of $\mathrm{G}$ protein-linked signaling proteins that can be functionally and structurally classified into three subfamilies, designated $\alpha_{1}, \alpha_{2}$ and $B$. Three subtypes of $\alpha_{1}$-adrenergic receptors $\left(\alpha_{1 \mathrm{~A}}, \alpha_{1 \mathrm{~B}}\right.$ and $\left.\alpha_{1 \mathrm{D}}\right)$ have been identified and characterized pharmacologically,(Minneman and Esbenshade, 1994; Minneman, 1988; Minneman et al, 1988) whereas four subtypes $\left(\alpha_{1 \mathrm{a}}, \alpha_{1 \mathrm{~b}}, \alpha_{1 \mathrm{c}}\right.$ and $\left.\alpha_{1 \mathrm{~d}}\right)$ have been identified through molecular cloning.(Cotecchia et al., 1988; Schwinn et al., 1990; Voigt et al., 1990; Perez et al., 1991; Lomasney et al., 1991a; Forray et al., 1994; Laz et al., 1994; Perez et al., 1994) However, the $\alpha_{1 \mathrm{a}}$ and $\alpha_{1 \mathrm{~d}}$ cDNA appeared to be the same and are now simply called $\alpha_{10}$-adrenoceptor.(Hieble et al., 1995)

Recent studies have led several investigators to conclude that the cloned $\alpha_{1 d^{-}}$and

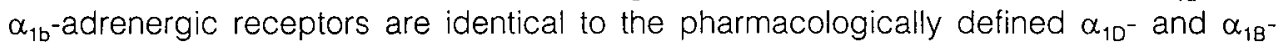
adrenergic receptors, respectively, and that the cloned $\alpha_{1 \mathrm{c}}$-adrenergic receptor is the $\alpha_{1 \mathrm{~A}}$-adrenoceptor.(Ford et al., 1994; Forray et al., 1994; Price et al., 1994; Perez et al., 1994; Laz et al., 1994) Evidence for additional subtypes has been reported from radio ligand binding studies,(Abel et al., 1995; Ford et al., 1994; Muramatsu et al., 1990) but it remains uncertain whether these novel binding sites represents distinct gene products. 


$$
\alpha_{1 b}
$$
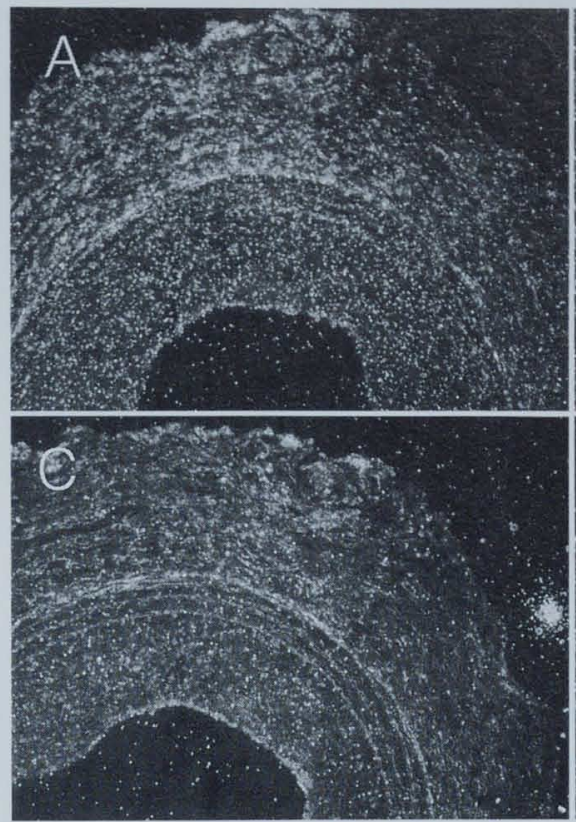

$\alpha_{1 d}$

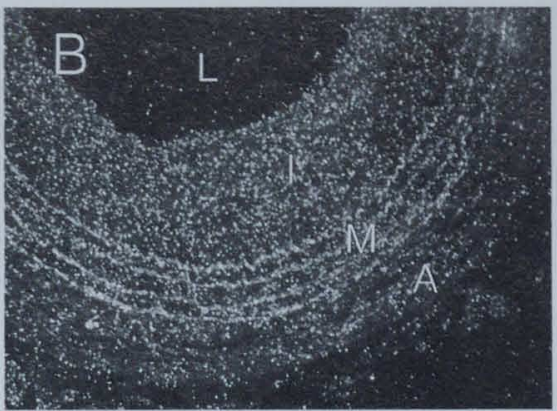

4 weeks

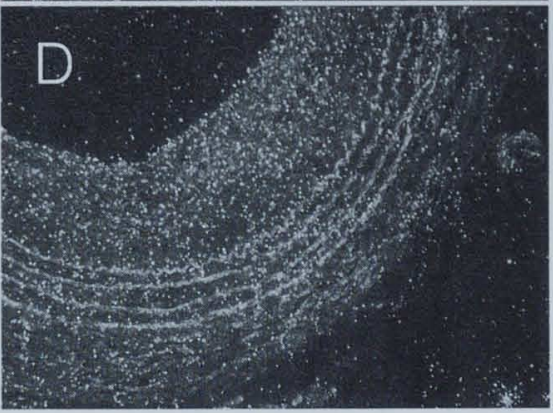

12 weeks

Figure 2.1 Photomicrograph (200x) of a cross-section of a balloon injured left carotid artery hybridized with $\left[{ }^{35} \mathrm{~S}\right.$-labeled $\alpha_{1 b^{-}}\left(\mathrm{A}\right.$ and $\mathrm{C}$ ) and $\alpha_{10^{-}}$-adrenoceptor probe (B and D). Upper panels represent 4 weeks and lower panels 12 weeks after balloon injury. $L=$ lumen, $I=$ intima, $M=$ media, $A=$ adventitia

Although there are only two endogenous ligands, epinephrine and norepinephrine, the physiological responses to catecholamines vary widely. One level of control that may be important in mediating different tissue responses is at the level of the receptors; where different receptor subtypes may regulate very different responses.(Chen et al., 1995) Therefore, tissue or organ differences in receptor subtype expression may represent an important factor in determining adrenoceptor physiology.(Scofield et al., 1995) Furthermore, we do not know whether $\alpha_{1}$-adrenoceptors are present in the neointima of the rat carotid artery. We do know, however, that the neointima is insensitive to blockade with $\alpha_{1}$-adrenoceptor antagonists(van Kleef et al., 1996a) and that there are less $\alpha_{1}$-adrenoceptors present in the vascular wall after injury (see chapter 4). This may suggest that the lack of an adequate number of $\alpha_{1}$-adrenoceptors in the neointima is responsible for the insensitivity for $\alpha_{1}$-adrenoceptor blockade.

This study shows, with the use of competitive RT-PCR, that the MRNA amount of the $\alpha_{1 b^{-}}$and $\alpha_{1 d^{-}}$adrenoceptors in the injured rat carotid artery were significantly decreased at 12 weeks as compared to 4 weeks after balloon injury. Furthermore, there were no differences detected between the $\alpha_{1}$-adrenoceptor subtypes mRNA levels of the uninjured carotid artery at 1,4 , and 12 weeks after injury. $\alpha_{1}$-Adrenoceptor mRNA levels in the injured carotid artery were lower than in the control vessel. Since mRNA levels are expressed per $250 \mathrm{ng}$ total RNA, one explanation is an increase in total RNA levels after injury. Indeed, mRNA levels of for instance proelastin and $\alpha_{1}$ procollagen (type I) are dramatically increased after balloon injury.(Majesky et al., 1992) 
This study further showed that ISH, with complementary RNA probes capable of differentiating between the $\alpha_{1 b}$ and $\alpha_{1 d}$-adrenoceptor subtypes, detected mRNA for $\alpha_{1}$ adrenoceptors in injured rat carotid arteries at 4 weeks, but not at 12 weeks after balloon injury. The $\alpha_{1}$-adrenoceptor subtypes were present throughout the adventitial, medial and neointimal layer of the carotid arteries and showed an increase in mRNA expression from the adventitia towards the lumen of the vessels. Therefore, it can be concluded that the neointima does contain at least the mRNA of two $\alpha_{1}$-adrenoceptor subtypes. The presence of the $\alpha_{1 \mathrm{~b}}$ and $\alpha_{1 \mathrm{~d}}$-adrenoceptor mRNAs have been reported earlier in cultured rat vascular smooth muscle cells. ( $\mathrm{Hu}$ et al., 1995) Furthermore, ISH on the intact rat aorta clearly showed the presence of mRNA for the $\alpha_{1 \mathrm{~b}}$ and $\alpha_{1 \mathrm{~d}}$-adrenoceptor in the media.(Piascik et al., 1994) This is in accordance with the data presented in this study which also indicates that mRNA for the $\alpha_{1 b}$ - and $\alpha_{1 d^{-}}$-adrenoceptor can be found in the media of the carotid artery.

Infusion of phenylephrine during the 3rd and 4th week after injury showed no increase in DNA labeling fraction in the neointima of injured rat carotid artery.(deBlois et al., 1996a) This is in accordance with the receptor binding studies showing less specific binding of $\left[{ }^{3} \mathrm{H}\right]$-prazosin at two weeks after injury (chapter 4 ). Furthermore, this study shows that $\alpha_{1}$-adrenoceptor mRNA amounts decrease after injury as compared with uninjured vessels. This is in accordance with the data on receptor binding presented in chapter 4 and may explain the relative insensitivity of $\alpha_{1}$-adrenoceptors for stimulation(deBlois et al., 1996a) and blockade(van Kleef et al., 1996a) on DNA synthesis.

When we review the data at 12 weeks after injury there was almost no mRNA production for the $\alpha_{1}$-adrenoceptors in the injured vessels. However, infusion of phenylephrine at this time point significantly increased the neointimal SMC DNA synthesis.(deBlois et al., 1996a) This indicates that at 12 weeks after injury enough functional $\alpha_{1}$-adrenoceptors may be present on the vessel wall. The low levels of the $\alpha_{1 b^{-}}$ and $\alpha_{1 d^{-}}$adrenoceptor mRNA in the injured vessels measured at 12 weeks after injury may be explained by the normalized protein levels with subsequent downregulation of the mRNA.

In summary this study shows i) that the amount of $\alpha_{1}$-adrenoceptor mRNA decreases after carotid injury when compared to the uninjured carotid artery ii) that the injured carotid artery shows a transient increase in $\alpha_{1}$-adrenoceptor mRNA iii) that at least the mRNAs of two $\alpha_{1}$-adrenoceptor subtypes are present in the injured and uninjured rat carotid artery iv) that the neointima contains the mRNA of at least two subtypes $v$ ) that there is no clear switch in subtype after injury.

We conclude that the relative insensitivity of the rat carotid artery to $\alpha_{1}$-adrenoceptor stimulation and blockade is not due to an absence of $\alpha_{1}$-adrenoceptors in the neointima, not due to a subtype switch, but may be due to a lack of sufficient $\alpha_{1}$-adrenoceptors after injury. 


\section{CHAPTER 3}

Detection of Norepinephrine Transporter mRNA in the Balloon Injured Rat Carotid Artery After Stimulation With Angiotensin II 


\begin{abstract}
Previous results indicated that the $\alpha_{1}$-adrenoceptor plays an important role in the angiotensin II (Angll) induced increase in medial, but not in neointimal vascular smooth muscle cell (SMC) DNA synthesis. One of the possible explanations for this difference in growth response between medial and neointimal SMCs during Angll infusion is the amount of norepinephrine in the synaptic cleft, which depends, amongst others, on the balance of release and uptake of the neurotransmitter. The norepinephrine transporter (NET) is a transmembrane protein mediating the uptake of norepinephrine from the synaptic cleft into the sympathetic nerves endings. In doing so it terminates synaptic transmission. In the brain stimulation of norepinephrine uptake by Angll involves NET gene transcription.

To investigate a possible role of the NET in the vascular wall, we have used the reverse transcription-polymerase chain reaction (RT-PCR) technique to detect the mRNA of the NET gene in both balloon-injured and uninjured rat carotid arteries after chronic Angll infusions. In the injured rat carotid artery NET MRNA levels could be detected at eight and twenty-four hours after continuous infusion with Angll $(2.81 \pm 0.08$ and $2.66 \pm 0.10$ optical density (O.D.), respectively). In the uninjured carotid artery however, NET mRNA levels were only detected at twenty-four hours $(7.37 \pm 0.48$ O.D.) after chronic Angll infusion. NET mRNA could neither be detected in the injured nor in the uninjured rat carotid artery after $\mathrm{NaCl}$ infusion.

These data show i) that the NET gene transcription is upregulated in the vascular wall after Angll infusion and ii) that injured vessels are more susceptible to this Angllinduced increase in NET gene transcription than uninjured vessels. These data suggest that the NET could play an important role in the difference in growth response between injured and uninjured rat carotid arteries upon stimulation with Angll.
\end{abstract}




\section{Introduction}

Although the involvement of the sympathetic nervous system in the mitogenic response of vascular smooth muscle cells (SMC)s to angiotensin $\|$ (Angll) is well established the mechanism remains to be elucidated. Previous data from our lab showed that the Angll induced increase in medial SMC DNA synthesis of the carotid artery was decreased, not only after co-infusion with the $\alpha_{1}$-adrenoceptor antagonist doxazosin,(van Kleef et al,, 1996a) but also after chemical sympathectomy with 6-OHDA (chapter 4). However, the Angll induced increase in neointimal SMC DNA synthesis two weeks after balloon injury of the left carotid artery was insensitive to pharmacological $\alpha_{1}$ adrenoceptor blockade(van Kleef et al, 1996a) or chemical sympathectomy with 6OHDA (chapter 4). Thus, the Angll induced increase in rat carotid SMC DNA synthesis is mediated by the sympathetic nervous system in the media, but not in the neointima formed after balloon catheter induced injury. This suggests a differential regulation of Angll induced SMC growth in injured and uninjured vessels, at least as far as the involvement of the sympathetic nervous system is concerned.

One of the explanations for the difference in Angll induced SMC growth in injured and uninjured vessels may be the differential involvement of the norepinephrine transporter (NET). The NET is an integral membrane $\mathrm{Na}^{+} /$cotransporter protein that can rapidly move norepinephrine (and $\mathrm{Na}^{+}$) back inside sympathetic nerve endings (figure 1.4, chapter 1) which ends synaptic transmission. (Axelrod, 1971)

Recent work by Lu et al. showed that chronic stimulation of norepinephrine uptake by Anglt involves stimulation of NET mRNA production in the rat brain.(Lu et al., 1996) The data presented in that study suggests that Angll binds to the neuronal angiotensin type $1\left(A T_{1}\right)$ receptor and stimulates the phospholipase C-phosphoinositol hydrolysis system (figure 1.3, chapter 1). This increases the activity of phosphokinase $C$ and the transcription of the NET gene which results in a chronic increase in NET-activity and an increase in norepinephrine uptake.(Lu et al., 1996)

In analogy with the findings in the rat brain, we hypothesized that Angll infusion would also increase the transcription of the NET gene in the vessel wall. Furthermore, we hypothesized that elevated transcription is only apparent in the balloon injured artery and not in the uninjured artery. This difference in NET mediated uptake of norepinephrine would therefore explain the difference in growth response between injured and uninjured rat carotid arteries upon stimulation with Angll.

\section{Materials \& Methods}

Animals

Male Wistar rats obtained from Iffa Credo (Someren, the Netherlands) were used (body weight, 275-325 g). They had free access to standard rat chow (Hope Farms, Woerden, the Netherlands) and tap water. Rats were randomly divided into two groups. Group A $(n=15)$ received Angll ten weeks after balloon injury while group $N(n=15)$ received $\mathrm{NaCl}$. All experiments were performed according to institutional guidelines.

\section{Balloon Denudation}

All rats were anaesthetized with pentobarbital (60 mg/kg bodyweight) by intraperitoneal (i.p.) injection. The left common carotid artery was injured by introduction of a 2F balloon catheter (Baxter, Maarsen, the Netherlands) into the left external carotid artery. After inflation, the catheter was withdrawn through the common carotid artery. This procedure was repeated three times after which the catheter was removed and the external carotid artery ligated. The right carotid artery served as a control and was not traumatized.(Clowes et al., 1983a) 


\section{Drug Infusion}

Human [Val ${ }^{5}$-Angll (Saxon Biochemicals GMBH, Hannover, Germany) was continuously infused using osmotic minipumps (Alzet, model 2001, Alza Corp., Palo Alto, Ca., USA) implanted subcutaneously between the shoulder blades under ether anaesthesia. Angll was dissolved in $0.9 \% \mathrm{NaCl}$ and infused at a rate of $250 \mathrm{ng} / \mathrm{kg} / \mathrm{min}$. Previous results in rat brain neuronal cultures showed an upregulation of NET mRNA between 2-8 hours after Angll stimulation, with peak levels at 8 hours, which remained elevated for up to 24 hours.(Lu et al., 1996) Since phenylephrine infusion in the first few weeks after balloon injury has no effect on neointimal SMC growth, but increases neointimal SMC growth when infused at ten weeks after balloon injury,(deBlois et al., 1996a) all infusions were started ten weeks after balloon injury. Thus, infusions with Angll or $\mathrm{NaCl}$ started ten weeks after balloon denudation and were given for 8 hours (group $A 8(n=5), N 8(n=5)$ ), 24 hours (group $A 24(n=5), N 24(n=5)$ ), and 7 days (group $A 7(n=5), N 7(n=5))$.

\section{Tissue Processing}

At the end of the infusion period animals were killed by ether anaesthesia. From all animals both the injured left and the uninjured right carotid artery as well as the brain and adrenal glands, which served as positive controls for the NET primer set used (see RT-PCR section), were quickly excised, snap-frozen in liquid nitrogen and stored at $70^{\circ} \mathrm{C}$ until they were used for total RNA isolation.

\section{Total RNA /solation}

Tissue samples were homogenized in $4 \mathrm{M}$ guanidine isothiocyanate solution using a Polytron P1200 homogenizer (Kinematica AG). The homogenized samples were loaded onto 5.7 $\mathrm{M}$ cesium chloride containing ultracentrifuge tubes. Total-RNA was pelleted by centrifugation at 35,000 rounds per minute for 18 hours at room temperature. After removal of the supernatant the RNA pellet was resuspended in $0.3 \mathrm{M}$ sodium acetate, $\mathrm{pH} 6.0$ and ethanol. Precipitation was performed for 1 hour at $-70^{\circ} \mathrm{C}$. After centrifugation the pellet was washed with $70 \%$ ethanol, centrifuged again, and the resulting pellet was dissolved in $15 \mu \mathrm{l} \mathrm{H}_{2} \mathrm{O}$. The integrity of the RNA was checked by agarose gel electrophoresis, while the total RNA content of each individual sample was determined by optical density at $260 \mathrm{~nm}$.

\section{Reverse Transcription-Polymerase Chain Reaction}

Since it is not known whether the NET gene is present in the vessel wall of rats, a reverse transcription-polymerase chain reaction (RT-PCR), with a primer set selected from the human NET CDNA sequence(Pacholczyk et al., 1991) was performed. This primer set was also used by Cubells et al.(Cubells et al., 1995a) to detect the NET mRNA levels in the rat adrenal medulla and locus ceruleus in the rat brain.

Total RNA was transcribed to CDNA with the use of the 'Ready-To-Go You-Prime FirstStrand Beads' (Pharmacia, Uppsala, Sweden). Briefly, $250 \mathrm{ng}$ of total RNA and 100 pmol of random hexanucleotide primer were denaturated at $65^{\circ} \mathrm{C}$ for 10 minutes, then chilled on ice for 2 minutes. The RNA solution was transferred to the tube of 'First-Strand Reaction Mix Beads' and brought to a final volume of $33 \mu$ with DEPC-treated water. After gentle mixture of the tube, cDNA was transcribed at $37^{\circ} \mathrm{C}$ for 60 minutes. Of this RT solution, $3.3 \mu \mathrm{l}$ was subjected to PCR with the use of the NET primers. Equal sample loading was checked by PCR with GAPDH-primers.

The primers used were:

NET-sense: 5'-CAGTTACCAACAAATTTGACAACAACTGT-3'

NET-anti-sense: 5'-GTCGTTTCGGAACCTGTCCACTCC-3' 
GAPDH-sense: 5'-TCCGCCCCTTCCGCTGATGCC-3'

GAPDH-anti-sense: 5'-TAGTGGGCCCTCGGCCGCCTG-3'

The PCR reaction contained $20 \mathrm{mM}$ Tris- $\mathrm{HCl}, \mathrm{pH} 8.75,10 \mathrm{mMKCl}, 10 \mathrm{mM}\left(\mathrm{NH}_{4}\right)_{2} \mathrm{SO}_{4}$, $2 \mathrm{mM} \mathrm{MgSO}_{4}, 50 \mu \mathrm{M}$ of each dNTP, 20 pmol of sense and anti-sense primers, and $2 \mathrm{U}$ Taq DNA polymerase in a total volume of $25 \mu \mathrm{l}$. PCR was performed during 35 cycli, with each cycle at $94^{\circ} \mathrm{C}$ for 30 seconds, $54^{\circ} \mathrm{C}$ for 1 minute, and $72^{\circ} \mathrm{C}$ for 1 minute.

Agarose Gel Electrophoresis of RT-PCR Products.

After PCR, $10 \mu \mathrm{l}$ of samples were mixed with $2 \mu \mathrm{l} 6 \times$ gel loading buffer $(0.25 \%$ Orange $\mathrm{G}, 40 \%$ (w/v) sucrose) and loaded on a $3 \%$ agarose gel prepared in $1 \times$ TBE buffer ( 89 $\mathrm{m} M$ Tris base, $89 \mathrm{mM}$ boric acid, and $2 \mathrm{mM}$ EDTA, pH 8.0) and containing $0.5 \mu \mathrm{g} / \mathrm{ml}$ ethidium bromide. PCR products were electrophoresed for 45 minutes at $100 \mathrm{~V}$ in a BioRad Mini-Gel System (Bio-Rad Laboratories, Hercules, CA). After electrophoresis, fragments were visualized by UV light.

\section{Quantification of RT-PCR products}

After amplification, $10 \mu$ of the PCR fragments were separated by electrophoresis on a $3 \%$ agarose gel, containing ethidium bromide. The fragment was detected by UV light and the image was captured by a digital camera. The optical density of the fragment was measured by the Gelpro Analyzer software (Version 2.0, Media Cybernetics). The value of the optical density of the sample was multiplied by the GAPDH-correction factor of the same sample to correct for equal sample loading. The mRNA amounts in the injured and the non-injured rat carotid artery at the different time points after injury are evaluated.

\section{Statistics}

Data are presented as mean \pm SEM. Statistical differences were calculated using one way ANOVA followed by the Newman-Keuls test for multiple comparisons. Statistical significance was assumed at $p<0.05$.

Results

Effects of NaCl Infusion on the NET MRNA Levels of the Carotid Arteries

mRNA signals for the NET could neither be detected in the injured nor in the uninjured rat carotid artery after all three $\mathrm{NaCl}$ infusion periods (table 3.1). However, RTPCR performed on total RNA isolated from the brain and the adrenal glands of rats after seven days of chronic $\mathrm{NaCl}$-infusion, showed a signal for the NET mRNA in both tissues and validated the RT-PCR procedure used (data not shown).

Table 3.1 The Amount of mRNA For the Norepinephrine Transporter in the Injured Left Carotid (LC) and the Uninjured Right Carotid (RC) Artery at Different Time Points After Infusion

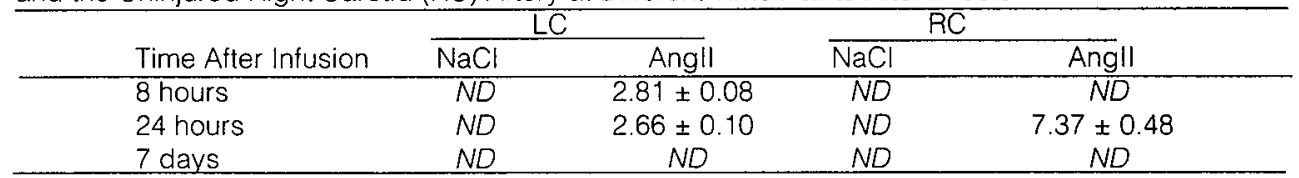

The mRNA amount is expressed in optical density. Data represent mean \pm SEM. ND; Non Detectable. 


\section{Effects of Angll Infusion on the NET MRNA Levels of the Carotid Arteries}

Rat NET mRNA was detected in the injured left carotid artery after Angll infusion (table 3.1). The NET mRNA level in the injured left carotid artery was $2.81 \pm 0.08$ optical density (O.D.) at eight hours after Angll infusion and $2.66 \pm 0.10$ O.D. at twenty-four hours after Angll-infusion and was not significantly different $(p=0.45)$.

In the uninjured right carotid artery, no NET mRNA could be detected eight hours after Angll infusion (table 3.1). However, NET mRNA levels of the uninjured right carotid artery increased to $7.37 \pm 0.48$ O.D. at twenty-four hours after chronic Angll infusion.

NET MRNA could neither be detected in the injured nor in the uninjured rat carotid artery after chronic Angll infusion for seven days (table 3.1).

\section{Discussion}

In the present study, mRNA expression of the NET in both the injured and the uninjured rat carotid arteries was observed after chronic Angll infusion, while no NET mRNA could be detected after $\mathrm{NaCl}$ infusion. These findings do support our hypothesis that Angll infusion may increase the uptake of norepinephrine into the sympathetic nerve endings through the NET, which will result in decreased levels of norepinephrine in the synapse. However, the NET mRNA not only increased in the injured but also in the uninjured rat carotid artery after Angll infusion, albeit that the time course was different. While NET mRNA levels in the injured arteries were elevated at eight and twenty-four hours after Angll infusion, we found a peak at twenty-four hours in uninjured arteries. The question therefore arises whether the observed shift in the time course of NET mRNA upregulation can explain the difference in the mitogenic response between injured and uninjured rat carotid arteries upon Angll stimulation, since previous data from our laboratory indicate that sympathetic innervation or more exactly $\alpha_{1}{ }^{-}$ adrenoceptors, (van Kleef et al., 1992; van Kleef et al., 1996a) mediate the Angllinduced replication of SMCs, but only in the uninjured rat carotid artery. Therefore, it could be possible that the increase in NET MRNA in uninjured arteries may not be sufficient to decrease the amount of norepinephrine, leaving them susceptible to $\alpha_{1}$ adrenoceptor blockade, whereas the early increase of NET mRNA in injured arteries may have been sufficient to make them insensitive to $\alpha_{1}$-adrenoceptor blockade.

Another possibility is that not only the uptake of norepinephrine in the carotid artery is increased after Angll infusion, but that enhanced metabolic degradation of norepinephrine may explain the presumed lowering of norepinephrine concentrations in the synaptic cleft. However, the effect of injury and Angll infusion on the catecholamines metabolizing enzymes monoamine oxidase and catechol-O-methyl transferase is not known.

NET cDNAs predict highly hydrophobic, integral membrane proteins with 12 transmembrane domains and cytoplasmatic $\mathrm{NH}_{2}$ and $\mathrm{COOH}$ termini.(Melikian et al., 1994; Brüss et al., 1995) Recently, Pörzgen and co-workers(Pörzgen et al., 1995) cloned and characterized the human NET gene, revealing a highly dispersed locus with $\sim 2 \mathrm{~kb}$ of coding exons spread across $45 \mathrm{~kb}$ of genomic DNA. The gene is single copy in humans and located at chromsome 16q12.2.(Brüss et al., 1993) Although sites of NET gene expression(Pacholczyk et al., 1991; Ramamoorthy et al., 1993; Lorang et al., 1994; Cubells et al., 1995a) match expectations from norepinephrine biosynthesis and uptake studies in the rat brain and adrenal gland, full-length rodent cDNAs suitable for regulatory studies in vitro and in vivo have yet to be reported. However, all amino acid residues that are presently considered essential for the function and specificity in the mono-amino transporters(Borowsky and Hoffman, 1995) are conserved between the mouse, human, and bovine NET species variants. 
The recent cloning and sequencing of the human NET gene allowed investigation of factors that modulate NET gene expression. The data presented here indicate that Angll is one of these factors and that Angll also modulates the NET in the vessel wall. In general, agents that increase sympathetic activity, such as reserpine or insulin, decrease NET mRNA levels.(Figlewicz et al., 1993; Cubells et al., 1995b; Cubells et al., 1995a) In contrast, desipramine, which decreases neuronal firing rates, increases NET mRNA.(Shores et al., 1994) Angll, which facilitates sympathetic activity, also seems to increase NET mRNA levels.

The data presented in this study further show that the NET gene transcription is differentially upregulated by Angll, i.e. injured vessels are more susceptible to this Angil-induced increase in NET gene transcription than uninjured vessels. The data suggest that the NET could play an important role in the regulation of the mitogenic responses of injured and uninjured rat carotid arteries as seen after Angll stimulation. To our knowledge this is the first study which detects the presence of MRNA of the NET in the vessel wall. 



\section{CHAPTER 4}

Effects of Chemical Sympathectomy on Angiotensin IIInduced Neointimal Growth in the Balloon Injured Rat Carotid Artery 


\section{Abstract}

To investigate the role of the sympathetic nervous system in angiotensin II (Angll) stimulated medial and neointimal smooth muscle cell (SMC) replication, we sympathectomized rats with 6-hydroxydopamine (6-OHDA) in which the left carotid artery was injured by a balloon catheter. Angll $(250 \mathrm{ng} / \mathrm{kg} / \mathrm{min})$, infused two weeks after balloon injury of the rat left carotid artery, increased systolic blood pressure by approximately $70 \mathrm{mmHg}$. There was no effect of 6-OHDA on this pressor response. Angll increased the cumulative 5-bromo-2'-deoxyuridine (BrdU) labeling fraction (LF) in the uninjured right carotid media and the injured left carotid neointima as compared to controls $(5.7 \pm 1.6 \%$ vs. $0.4 \pm 0.1 \%, p<0.05 ; 10.6 \pm 0.9 \%$ vs. $5.0 \pm 0.8 \%, p<0.05$; respectively). 6-OHDA decreased the Angll induced increase in LF in the media of the uninjured right carotid artery (Angll/6-OHDA: $0.9 \pm 0.2 \%$ vs. Angll: $5.7 \pm 1.6 \%, p<0.05$ ). 6-OHDA did not decrease the Angll induced increase in LF in both the injured left carotid media and neointima at 4 weeks after balloon injury. The effects of chemical sympathectomy were comparable with those obtained 12 weeks after balloon injury. Thus, data show that the sympathetic nervous system mediates the Angll induced increase in SMC DNA synthesis, but only in the uninjured carotid media. This indicates a differential regulation of Angll induced SMC replication in injured and uninjured vessels. 


\section{Introduction}

The sympathetic nervous system plays an important role in the regulation of vascular smooth muscle cell (SMC) DNA synthesis. For instance, surgical sympathetic denervation of the rabbit ear artery reduces SMC proliferation,(Bevan, 1975) and chemical sympathectomy with 6-OHDA, which destroys the sympathetic nerve endings leaving vessels denervated,(Aprigliano and Hermsmeyer, 1976) reduces the number of SMCs in the growing aortic media.(Fronek et al., 1978) in contrast, stimulation of $\alpha_{1}$ adrenoceptors by phenylephrine increases the expression of growth related factors such as PDGF-A.(Majesky et al., 1990) an effect which may be mediated via mitogen activated protein kinases.(Yu et al., 1996) $\alpha_{1}$-Adrenoceptor antagonists, when administered immediately after balloon injury, reduce SMC DNA synthesis and neointima formation in the rat carotid artery and rabbit abdominal aorta.(Jackson et al., 1988; O'Malley et al., 1989; Fingerle et al., 1991; Vashisht et al., 1992) Angil also stimulates SMC DNA synthesis in the media and the neointima after balloon injury, (Daemen et al., 1991) an effect which may be partly mediated through $\alpha_{1}$ adrenoceptors since Angll facilitates sympathetic transmission by potentiating neurotransmitter release and inhibiting norepinephrine uptake,(Starke, 1977) and stimulates the humoral release of catecholamines from the adrenal medulla.(Feldberg and Lewis, 1964) The $\alpha_{1}$-adrenoceptor antagonist doxazosin however, did not reduce SMC DNA synthesis in the media and neointima of the injured rat carotid artery when infused together with Angll two weeks after balloon injury. It did however, decrease SMC DNA synthesis in the media of the uninjured carotid artery.(van Kleef et al., 1996a) Furthermore, if the $\alpha_{1}$-adrenoceptor agonist phenylephrine was infused two weeks after balloon injury of the rat common carotid artery SMC DNA synthesis in the neointima was not affected.(deBlois et al., 1996a) If, however, phenylephrine was infused ten weeks after injury neointimal SMC DNA synthesis did increase.(deBlois et al., 1996a) These results indicate that in the uninjured vessel the mitogenic effects of Angll are mediated by $\alpha_{1}$-adrenoceptors. The role of $\alpha_{1}$-adrenoceptors in the growth regulation of injured vessels appears to be limited and restricted to the late phase of neointimal growth.(deBlois et al., 1996a)

A limitation of the $\alpha_{1}$-adrenoceptor antagonists studies is that it is not possible to distinguish between the Angll induced increase in release of norepinephrine from the sympathetic nerve endings (neurogenic) or the Angll induced increase in systemic (humoral) release of (nor)epinephrine from the adrenal medulla. Therefore we decided to remove neuronal norepinephrine but not adrenal medulla norepinephrine by chemical sympathectomy using 6-OHDA(Aprigliano and Hermsmeyer, 1976; Yamaguchi and Nakada, 1992) at 4 and at 12 weeks after balloon injury of the left carotid artery. Based on the lack of effect of phenylephrine infusion on neointima SMC growth in the first few weeks after balloon injury(deBlois et al., 1996a) we hypothesized that removal of the neurogenic input during Angll infusion would not decrease neointimal SMC growth 4 weeks after balloon denudation, but would decrease Angll induced neointimal SMC growth at 12 weeks after balloon denudation as phenylephrine infusion during that period established an increase in neointimal SMC growth.(deBlois et al., 1996a)

\section{Materials \& Methods}

\section{Animals}

Male Wistar-Kyoto rats obtained from a local inbred strain (University of Maastricht), were used (body weight, $275-325 \mathrm{~g} ; \mathrm{n}=74$ ). They had free access to standard rat chow (Hope Farms, Woerden, the Netherlands) and tap water.

Rats were randomly divided into eight groups: group A ( 4 weeks: $n=9$ ) received $0.9 \%$ $\mathrm{NaCl}$; group B ( 4 weeks: $n=9$ ) was treated with Angll; group $C$ (4 weeks: $n=9$ ) received 
Angll and was sympathectomized with $6-\mathrm{OHDA}$, and group $D(4$ weeks: $n=10$ ) received only 6-OHDA. Group $E(12$ weeks: $n=8$ ) received $0.9 \% \mathrm{NaCl}$; group $F(12$ weeks: $n=9)$ received Angll; group $G$ (12 weeks: $n=11$ ) received Angll and 6-OHDA, and group $H$ (12 weeks: $n=9$ ) received only $6-O H D A$. The experiments were performed according to institutional guidelines.

\section{Balloon injury}

All rats were anaesthetized with pentobarbital $(60 \mathrm{mg} / \mathrm{kg}$ body weight) by intraperitoneal (i.p.) injection. The left common carotid artery was injured by introduction of a 2F balloon catheter (Baxter, Maarsen, the Netherlands) into the left external carotid artery. After inflation, the catheter was withdrawn through the common carotid artery. This procedure was repeated three times after which the catheter was removed and the external carotid artery ligated. The right carotid artery was not traumatized and served as a control.(Clowes et al., 1983a; Clowes et al., 1983b)

\section{Blood Pressure Measurement}

Systolic blood pressures were measured by tail cuff plethysmography (ITTC inc. Woodland Hills. Ca., USA) in slightly restrained, conscious rats. After a training period of seven days, blood pressure measurements started two days before 6-OHDA treatment and were performed three times a week.

\section{Chemical Sympathectomy}

6-OHDA (Sigma Chemical Co., St. Louis, Mo.,USA) was dissolved in $0.9 \% \mathrm{NaCl}(50$ $\mathrm{mg} / \mathrm{kg}$ ) and brought to $\mathrm{pH} 4.7$ with gluthation (Merck, Darmstadt, Germany). 6-OHDA was injected $2 x$ i.p. with 2 hours intervals. This procedure results in complete sympatholysis for 9-10 days.(Aprigliano and Hermsmeyer, 1977) To establish complete sympatholysis during the entire two weeks of Angll infusions, 6-OHDA was repeated eight days after the first treatment. Controls received only vehicle.

\section{Drug Infusion}

Human $\left[\mathrm{Val}^{5}\right]$-Angll (Saxon Biochemicals GMBH, Hannover, Germany) and BrdU (Serva, Heidelberg, Germany) were continuously infused using osmotic minipumps (Alzet model 2002, Alza Corp., Palo Alto, Ca.,USA) implanted subcutaneously between the shoulder blades under ether anaesthesia. Angll was dissolved in $0.9 \% \mathrm{NaCl}$ and infused at a rate of $250 \mathrm{ng} / \mathrm{kg} / \mathrm{min}$. BrdU was also dissolved in $0.9 \% \mathrm{NaCl}(30 \mathrm{mg} / \mathrm{ml})$ and infused at a rate of $714 \mathrm{ng} / \mathrm{kg} / \mathrm{min}$. All infusions started two (groups $A, B, C, D$ ) or ten (groups $E, F, G, H$ ) weeks after balloon injury and lasted for two weeks.

\section{Tissue Processing}

At the end of the experiment all rats received $0.5 \mathrm{ml} 0.5 \%$ Evans blue (Chroma Gesellschaft, Stuttgart, Germany) in $0.9 \% \mathrm{NaCl}$ by intravenous (i.v.) injection, to stain non-endothelialized tissue in the left common carotid artery. One hour later the animals were killed by pentobarbital overdose ( $80 \mathrm{mg} / \mathrm{kg}$ body weight i.p.) and the arterial bed was perfused during 5 minutes with phosphate buffered saline (PBS) followed by perfusion fixation with $4 \%$ phosphate buffered paraformaldehyde $(\mathrm{pH} 7.4)$ during 5 minutes, at a pressure of $100 \mathrm{mmHg}$, by a catheter advanced retrogradely in the abdominal aorta. Maximal vasodilatation was ensured by the addition of nitroprusside $(0.1 \mathrm{mg} / \mathrm{ml}$, Sigma Chemical Co.) to the perfusate.

One circular segment $(2-3 \mathrm{~mm}$ long) was taken from the center of the blue stained non-endothelialized part of the left carotid artery. For comparison, one segment was taken at a similar location from the noninjured right carotid artery. 
Hearts were excised, blotted dry and weighed after removal of the atria. All tissues were fixed overnight in $4 \%$ phosphate buffered paraformaldehyde, routinely processed and embedded in paraffin (Para Clean, Klinipath, Duiven, the Netherlands).

\section{Evaluation of Innervation}

Prior to perfusion fixation the right femoral artery was ligated, excised, and placed in freshly prepared $2 \%$ glyoxylic acid (monohydrate, ICN Biomedicals Inc., Aurora, Ohio, USA) in $0.1 \mathrm{M}$ phosphate buffer at $\mathrm{pH} 7.2$ supplemented with $10 \%$ sucrose. After 30 minutes vessels were stretched on slides and dried for 30 minutes under an airstream at room temperature. Subsequently, the slides were heated for 4 minutes at $100^{\circ} \mathrm{C}$, mounted on entallan, and stored in the dark. The preparations were evaluated with a Leitz Dialux 20 microscope (Rijswijk, the Netherlands) equipped with orthomat camera and filterblock $D$ by an observer blinded for the different groups. With this method nerves that contain norepinephrine stain bright green whereas norepinephrine depleted nerves show no staining.(Cowen and Burnstock, 1980)

Since femoral arteries are densely innervated they served as a control to assess sympatholysis by $6-$ OHDA.(Rosenblum and Chen, 1976) We assumed that if the femoral artery was denervated by 6-OHDA, the lesser innervated carotid artery would also be denervated. Femoral arteries of groups $A, B, E$, and $F$ (not-6-OHDA treated groups) showed strong staining with glyoxylic acid indicating intact sympathetic innervation (data not shown). Femoral arteries of 6-OHDA treated rats (groups C, D, G and H, 6OHDA treated groups) showed no staining with glyoxylic acid at the end of the experimental period indicating effective denervation.

\section{Morphometric Analysis}

Cross-sectional areas of the media, defined as the area between the externat and internal elastic lamina, and the neointima, defined as the area between the internal elastic lamina and the lumen of the artery, were measured using a computerized morphometric system (Quantimet 570, Leica), on 4 um Lawson (Boom B.V., Meppel, the Netherlands) stained cross-sections of the carotid arteries. Measurements were performed on two cross-sections taken from each ring.

\section{Immunohistochemistry}

The cumulative labeling fractions of BrdU positive cells in the media of both carotid arteries and in the neointima of the left carotid artery were determined after immunostaining of $4 \mu \mathrm{m}$ cross-sections with a monoclonal antibody directed against BrdU using methods published earlier. (van Kleef et al., 1992; van Kleef et al., 1996a) The cumulative labeling fraction ([BrdU-positive cells/total number of cells] $\times 100 \%$ ) was determined by one observer, blinded for the different groups, who counted the number of labeled cells and the total number of cells in the media or neointima.

\section{Ligand Binding}

Analysis of specific binding of $\alpha_{1}$-adrenoceptors in the presence of $0.3 \cap M\left[{ }^{3} \mathrm{H}\right.$ ]prazosin in injured left carotid arteries and uninjured right carotid control arteries was performed essentially as described by Stassen et al.(Stassen et al., 1997a) Segments $\left(5-10 \mathrm{~mm}\right.$ long) of carotid artery were incubated for 60 minutes at $37^{\circ} \mathrm{C}$ in $250 \mu \mathrm{l} 50 \mathrm{mM}$ Tris- $\mathrm{HCl}, 5 \mathrm{mM} \mathrm{MgCl}_{2}$ (pH 7.4) (incubation buffer) containing $0.3 \mathrm{nM}\left[{ }^{3} \mathrm{H}\right]$-prazosin. Non-specific binding was determined in parallel incubations in the continuous presence of phentolamine (25 $\mu \mathrm{M})$. After incubation the arterial segments were gently blotted and rinsed during vortexing for 30 seconds with $1 \mathrm{ml}$ incubation buffer at $37^{\circ} \mathrm{C}$. They were then filtered over Whatman filters (GF/C) 5 times with $5 \mathrm{ml}$ ice-cold incubation buffer. 
Arterial segments were recovered from the filters and solubilized in $200 \mu l 1 \mathrm{~N} \mathrm{NaOH}$. To $100 \mu \mathrm{l}$ of this, $5 \mathrm{ml}$ scintillation solution (Formula 989, Packard) was added and the radioactivity determined in a liquid scintillation counter (Beckman). To the remaining 100 $\mu \mathrm{l}, 900 \mu \mathrm{H}_{2} \mathrm{O}$ was added and the protein and DNA content were determined as described by Bradford(Bradford, 1976) and by Labarca and Paigan,(Labarca and Paigen, 1980) using bovine serum albumin and calf thymus DNA as internal standards, respectively.

\section{Statistics}

Data are presented as mean \pm SEM. Comparisons between the groups were made by non-parametric multiple comparison using the Kruskal-Wallis H-test. Statistical significance was assumed at $p<0.05$.

Results

\section{Effects of Angll and 6-OHDA on Body Weight and Heart Weight}

The body weights of the animals in the different groups did not differ neither at the start of the experiment nor at the start of the infusions/injections. In the 4 weeks experiment (group A-D) body weights decreased during infusion with Angll (group B: $10 \pm 3 \mathrm{~g}$ ), whereas animals in the control group increased their body weight (group A: $20 \pm 3 \mathrm{~g}$, table 4.1). When 6-OHDA was given together with Angll (group C) there was no further decrease in body weight as compared to the group that received Angll alone. The increase in body weight during administration of 6-OHDA alone did not differ from the increase in the $\mathrm{NaCl}$ alone group. The heart-to-body-weight ratio in the Angll group (group B: $3.3 \pm 0.1 \mathrm{~g} / \mathrm{kg}$ ) was increased as compared to the $\mathrm{NaCl}$ group (group A: $2.8 \pm$ $0.1 \mathrm{~g} / \mathrm{kg}$ ), which was mainly due to the loss in body weight during the 2 weeks infusion period (table 4.1). There was no effect of the addition of 6-OHDA on the heart-to-bodyweight ratio neither when given alone nor when given together with Angll.

Body weights of the animals in the different groups in the 12 weeks experiment (group E-H) did not differ neither at the start of the experiment nor at the start of the infusions/injections. Due to normal growth, the body weight at the start of the infusions/injections had increased with approximately $50 \mathrm{~g}$ as compared to the animals in the 4 weeks experiment. The changes in body weight after the infusions/injections were comparable to those described above for the 4 weeks experiment (table 4.1).

Table 4.1 Effects of Ang II and 6-OHDA on Body Weight and Heart Weight at 4 and 12 Weeks After Balloon Injury of the Left Carotid Artery.

\section{WEEKS}

\begin{tabular}{|c|c|c|c|c|}
\hline Groups & $\stackrel{\mathrm{A}}{\mathrm{NaCl}}$ & $\begin{array}{c}\text { B } \\
\text { Angll }\end{array}$ & $\begin{array}{c}\mathrm{C} \\
\text { Angll/6-OHDA }\end{array}$ & $\begin{array}{c}\mathrm{D} \\
\mathrm{NaCl} / 6-\mathrm{OHDA}\end{array}$ \\
\hline $\begin{array}{l}\text { Change in } \\
\text { body weight } \\
\text { (g) }\end{array}$ & $+20 \pm 3$ & $-10 \pm 3^{*}$ & $-9 \pm 5$ & $+19 \pm 4$ \\
\hline $\begin{array}{l}\text { Heart weight } \\
\text { (mg) }\end{array}$ & $993 \pm 25$ & $1101 \pm 23$ & $1066 \pm 36$ & $959 \pm 23$ \\
\hline $\begin{array}{l}\text { Heart-to-body- } \\
\text { weight }\left(10^{-3}\right)\end{array}$ & $2.8 \pm 0.1$ & $3.3 \pm 0.1^{*}$ & $3.4 \pm 0.1$ & $2.9 \pm 0.1$ \\
\hline
\end{tabular}




\begin{tabular}{lcccc}
\hline Groups & $\begin{array}{c}E \\
\mathrm{NaCl}\end{array}$ & $\begin{array}{c}F \\
\text { Angll }\end{array}$ & $\begin{array}{c}\mathrm{G} \\
\text { Angll/6-OHDA }\end{array}$ & $\begin{array}{c}\mathrm{H} \\
\text { NaCl/6-OHDA }\end{array}$ \\
\hline $\begin{array}{l}\text { Change in } \\
\text { body weight } \\
(\mathrm{g})\end{array}$ & $+7 \pm 3$ & $-16 \pm 6^{*}$ & $-35 \pm 7$ & $-5 \pm 3$ \\
$\begin{array}{l}\text { Heart weight } \\
(\mathrm{mg})\end{array}$ & $1217 \pm 66$ & $1388 \pm 30$ & $1162 \pm 39$ & $1158 \pm 55$ \\
$\begin{array}{l}\text { Heart-to-body- } \\
\text { weight (10-3) }\end{array}$ & $3.1 \pm 0.1$ & $3.8 \pm 0.1^{*}$ & $3.4 \pm 0.1$ & $3.0 \pm 0.2$ \\
\hline
\end{tabular}

Changes in body weight and heart weight are given
S.E.M. *) Significantly different from $\mathrm{NaCl}, 0<0.05$.

\section{Effects of Angll and 6-OHDA on Systolic Blood Pressure}

The systolic blood pressure (SBP) of Angll infused animals increased from $136 \pm 11$ $\mathrm{mmHg}$ five days prior to infusion of Angll to $201 \pm 19 \mathrm{mmHg}$ at the end of the two weeks infusion period (figure 4.1A). Injection of 6-OHDA (groups C \& D) had a small but transient blood pressure lowering effect. As compared to the $\mathrm{NaCl}$ and Angll groups, SBPs in the 6-OHDA groups were not different.

The rise in SBP of Angll infused animals in the 12 weeks experiment was comparable with the 4 weeks experiment (figure 4.1B). Injections of 6-OHDA (groups $G$ \& H) had, as in the 4 weeks experiment, no effect on the final outcome of blood pressure as compared to the $\mathrm{NaCl}$ and Angll groups (figure 4.1B).
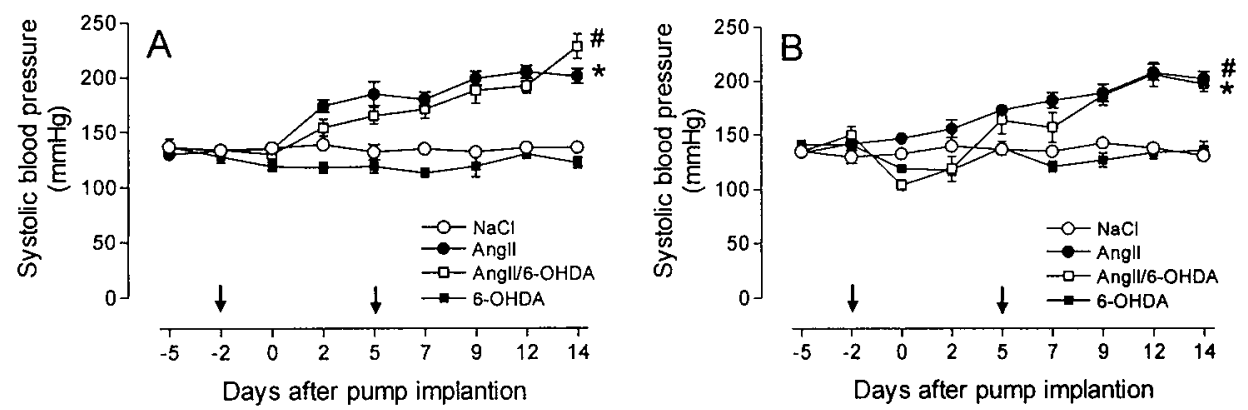

Figure 4.1 The Development of Systolic Blood Pressure ( $\mathrm{mmHg}$ ) During the A) 4 Weeks Experiment and B) During the 12 Weeks Experiment. Data represent mean \pm S.E.M. *) Significantly different from $\mathrm{NaCl}$ over time, $p<0.05$. \#) Significantly different from $6-\mathrm{OHDA}$ over time, $p<0.05$. Arrows indicate days of injections with 6-OHDA.

\section{Effects of Angll and 6-OHDA on Uninjured Right Carotid Artery Medial Structure and Lumen}

In the 4 weeks experiment Angll infusion increased the LF of SMCs (figure 4.2A) in the media of the non-injured right carotid arteries from $0.4 \pm 0.1 \%$ in the $\mathrm{NaCl}$ control group to $5.7 \pm 1.6 \%$ in the Angll group. Addition of 6-OHDA reduced the Angll induced increase in medial LF as compared to the group which received Angll alone $(0.9 \pm 0.2 \%$ vs. $5.7 \pm 1.6 \%$ ). Angll also increased the medial CSA (table 4.2). When 6-OHDA was given together with Angll (group C) there was no decrease in medial CSA as compared 
to animals receiving Angll alone. Also 6-OHDA alone (group D) did not affect the medial CSA. The lumen area after Angll infusion was comparable to the lumen area of animals receiving $\mathrm{NaCl}$ (table 4.2). Neither administration of 6-OHDA during Angll infusion nor 6OHDA alone had an effect on lumen area as compared to administration of Angll alone or $\mathrm{NaCl}$.

In the 12 weeks experiment largely similar findings were obtained (figure $4.2 \mathrm{~B}$ and table 4.2) as compared to the 4 weeks experiment.

\section{Effects of Angll and 6-OHDA on Injured Left Carotid Artery Medial Structure}

In the 4 weeks experiment, the labeling fraction (LF) in the media of the injured left carotid artery was slightly increased during Angll infusion from $0.8 \pm 0.3 \%$ in group $A$ to $1.8 \pm 0.4 \%(p=0.10)$ in group $B$ (figure $4.2 \mathrm{C}$ ). Addition of $6-\mathrm{OHDA}$ did not affect the LF during Angll infusion as compared to the group receiving Angll alone. When 6-OHDA was given alone (group D) the LF was $0.3 \pm 0.1 \%$. This result was not significantly different from the $\mathrm{NaCl}$ group (group A). During the 2 weeks infusion with Angll the CSA of the media did not increase (table 4.2). There was no effect of 6-OHDA when given alone, nor when given during Angll infusion.

In the 12 weeks experiment largely similar findings were obtained (figure $4.2 \mathrm{D}$ and table 4.2) as compared to the 4 weeks experiment.

Table 4.2 Effects of Angll and 6-OHDA on Cross-Sectional Area (CSA) and Lumen Area (LA) at 4 and 12 Weeks After Balloon Injury of the Left Carotid Artery

\begin{tabular}{|c|c|c|c|c|}
\hline Groups & $\begin{array}{c}\mathrm{A} \\
\mathrm{NaCl}\end{array}$ & $\begin{array}{c}B \\
\text { Angll }\end{array}$ & $\begin{array}{c}\mathrm{C} \\
\text { Angll/6-OHDA }\end{array}$ & $\begin{array}{c}\mathrm{D} \\
\mathrm{NaCl} / 6-\mathrm{OHDA}\end{array}$ \\
\hline $\begin{array}{l}\operatorname{CSA}\left(\mathrm{mm}^{2}\right) \\
\text { right media } \\
\text { left media } \\
\text { left neointima }\end{array}$ & $\begin{array}{l}0.09 \pm 0.01 \\
0.11 \pm 0.01 \\
0.11 \pm 0.01\end{array}$ & $\begin{array}{l}0.12 \pm 0.01^{*} \\
0.12 \pm 0.01 \\
0.16 \pm 0.01^{*}\end{array}$ & $\begin{array}{l}0.11 \pm 0.01 \\
0.12 \pm 0.01 \\
0.15 \pm 0.01\end{array}$ & $\begin{array}{l}0.09 \pm 0.01 \\
0.11 \pm 0.01 \\
0.10 \pm 0.01\end{array}$ \\
\hline $\begin{array}{l}\mathrm{LA}\left(\mathrm{mm}^{2}\right) \\
\text { right artery } \\
\text { left artery }\end{array}$ & $\begin{array}{l}0.29 \pm 0.02 \\
0.19 \pm 0.02\end{array}$ & $\begin{array}{r}0.29 \pm 0.01 \\
0.16 \pm 0.01 \\
12 \text { WEEK }\end{array}$ & $\begin{array}{l}0.30 \pm 0.02 \\
0.17 \pm 0.01\end{array}$ & $\begin{array}{l}0.28 \pm 0.01 \\
0.18 \pm 0.01\end{array}$ \\
\hline Groups & $\begin{array}{c}\mathrm{E} \\
\mathrm{NaCl}\end{array}$ & $\begin{array}{c}\mathrm{F} \\
\text { Angll } \\
\end{array}$ & $\begin{array}{c}\mathrm{G} \\
\text { Angl//6-OHDA }\end{array}$ & $\begin{array}{c}\mathrm{H} \\
\mathrm{NaCl} / 6-\mathrm{OHDA}\end{array}$ \\
\hline $\begin{array}{l}\mathrm{CSA}\left(\mathrm{mm}^{2}\right) \\
\text { right media } \\
\text { left media } \\
\text { left neointima }\end{array}$ & $\begin{array}{l}0.10 \pm 0.01 \\
0.11 \pm 0.01 \\
0.13 \pm 0.01\end{array}$ & $\begin{array}{l}0.12 \pm 0.01^{*} \\
0.12 \pm 0.01 \\
0.17 \pm 0.01^{*}\end{array}$ & $\begin{array}{l}0.12 \pm 0.01 \\
0.12 \pm 0.01 \\
0.18 \pm 0.02\end{array}$ & $\begin{array}{l}0.10 \pm 0.01 \\
0.11 \pm 0.01 \\
0.11 \pm 0.01\end{array}$ \\
\hline $\begin{array}{l}\mathrm{LA}\left(\mathrm{mm}^{2}\right) \\
\text { right artery } \\
\text { left artery }\end{array}$ & $\begin{array}{l}0.23 \pm 0.03 \\
0.19 \pm 0.02\end{array}$ & $\begin{array}{l}0.24 \pm 0.02 \\
0.16 \pm 0.01\end{array}$ & $\begin{array}{l}0.22 \pm 0.02 \\
0.16 \pm 0.01\end{array}$ & $\begin{array}{l}0.22 \pm 0.02 \\
0.20 \pm 0.02\end{array}$ \\
\hline
\end{tabular}

Data represent mean \pm S.E.M. ${ }^{*}$ ) Significantly different from $\mathrm{NaCl}, \mathrm{p}<0.05$. 


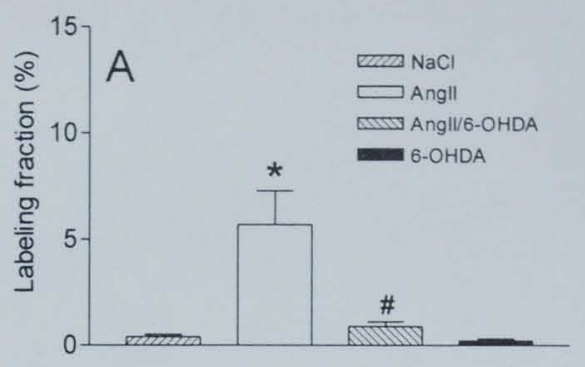

Media

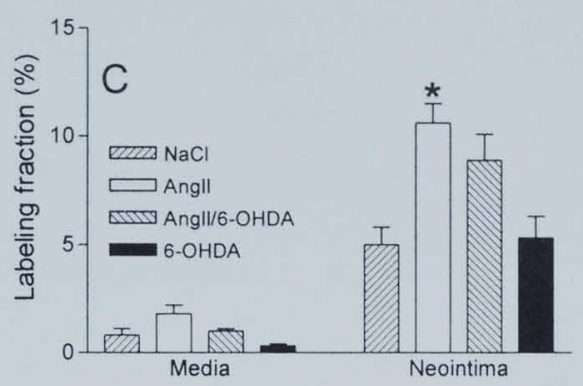

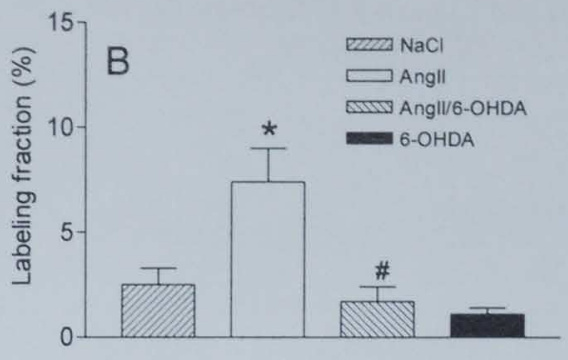

Media

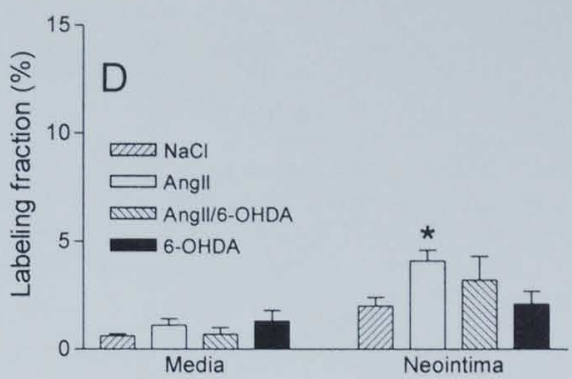

Figure 4.2 Effects of Angll and 6-OHDA on labeling fraction of uninjured right carotid media A) 4 weeks after balloon denudation and B) 12 weeks after balloon denudation. C) represents the effects of Angll and 6-OHDA on labeling fraction of injured left carotid media and neointima 4 weeks after balloon denudation and D) 12 weeks after balloon denudation. Data represent mean \pm S.E.M. *) Significantly different from $\mathrm{NaCl}, p<0.05$. \#) Significantly different from Angll, $p<0.05$.

Effects of Angll and 6-OHDA on Injured Left Carotid Artery Neointimal Structure and Lumen

In the neointima of the injured left carotid artery the LF increased during infusion with Angll as compared to the group receiving $\mathrm{NaCl}$ alone (figure $4.2 \mathrm{C} ; 10.6 \pm 0.9 \%$ vs. 5.0 $\pm 0.8 \%$ ). Most labeling was found at the luminal side of the vessel. Sympathectomy did not affect the LFs in saline (group A and D) and Angll (group B and C) treated animals. Angll caused a significant increase in neointimal CSA as compared to animals receiving $\mathrm{NaCl}\left(0.16 \pm 0.01\right.$ vs. $0.11 \pm 0.01 \mathrm{~mm}^{2}$, table 4.2). Addition of 6-OHDA did not affect the Angll induced increase in neointimal CSA. Also 6-OHDA alone had no effect on CSA. Balloon injury decreased the lumen area. Addition of Angll further decreased this parameter ( $p=0.09$, table 4.2). Administration of 6-OHDA together with Angll infusion had no effect on lumen area as compared to administration of Angll alone. 6-OHDA alone had no effect on lumen area as compared to the $\mathrm{NaCl}$ group.

In the 12 weeks experiment largely similar findings were obtained (figure $4.2 \mathrm{D}$ and table 4.2) as compared to the 4 weeks experiment.

\section{$\left[{ }^{3} \mathrm{H}\right]$-Prazosin Binding}

To evaluate whether the lack in response to Angll was due to a reduction of $\alpha_{1}$ adrenoceptor number, the amount of $\alpha_{1}$-adrenoceptors in the carotid artery at several time points after balloon injury was measured with $0.3 \cap M\left[{ }^{3} \mathrm{H}\right]$-prazosin. Balloon injury decreased the specific $\alpha_{1}$-adrenoceptor binding from day 3 up to 10 weeks after injury when expressed relative to the total protein content (figure $4.3 \mathrm{~A}$ ) as compared to 
controls, and from day 3 up to 20 weeks after injury when expressed relative to the total DNA content (figure 4.3B).
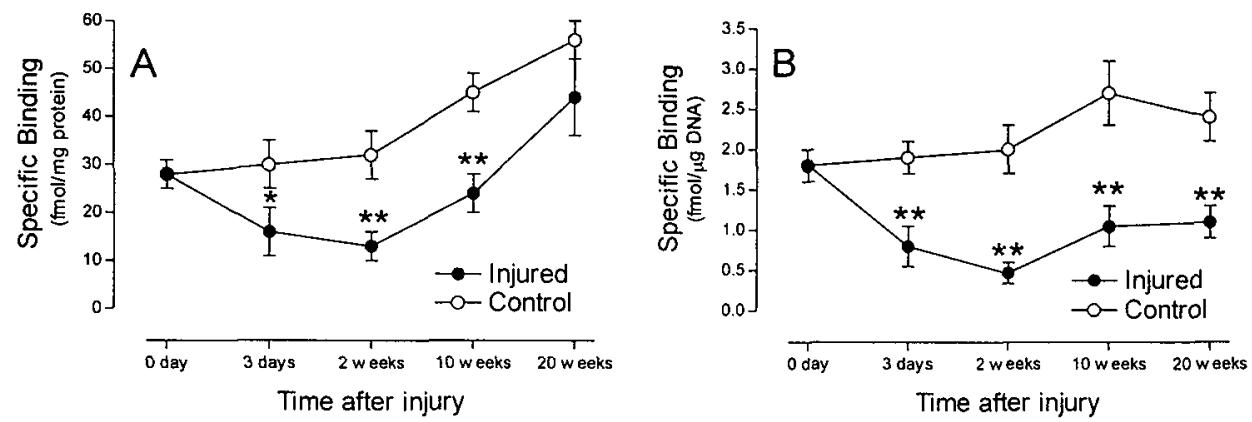

Figure 4.3 Specific binding of $\alpha_{1}$-adrenoceptors in the presence of $0.3 \mathrm{nmol}^{-1}\left[{ }^{3} \mathrm{H}\right]$-prazosin in injured left carotid arteries and uninjured right carotid control arteries at different time points after balloon denudation and $A$ ) expressed relative to total protein content and $B$ ) relative to DNA content. Data represent mean \pm S.E.M. *) Significantly different from control, $p<0.05 .{ }^{* *}$ ) Significantly different from control, $p<0.01$.

\section{Discussion}

The main findings of this study are that balloon injury modifies the effects of chemical sympathectomy with 6-OHDA on Angll induced SMC DNA synthesis. While 6-OHDA did reduce the Angll induced SMC DNA synthesis in the media of uninjured carotid arteries, it had no effects on Angll induced SMC DNA synthesis in injured carotid arteries neither at 4 nor at 12 weeks after injury. Moreover, 6-OHDA had no effects on Angll induced changes in CSA or lumen area.

Our observation that 6-OHDA induced sympathectomy inhibits the mitogenic response of Angll in uninjured vessels is in agreement with earlier findings that $\alpha_{1}$ antagonists blunt the proliferative effect of Ang II. (van Kleef et al., 1992; van Kleef et al., 1996a) Indeed, Angll is known to stimulate the activity of the sympathetic nervous system, not only centrally, but also at the level of the synapse and through stimulation of the adrenal release of catecholamines. These effects are probably mediated by AT, receptors.(Wong et al., 1990)

The fact that 6-OHDA treatment did not reduce blood pressure suggests that effects of 6-OHDA on arterial mitogenic responses are not due to an effect on blood pressure. Since all Angll infused animals became hypertensive it is possible that the stimulatory effect of Angll on smooth muscle cell replication is due at least in part to its hypertensive effect or to a direct effect of Angll on the SMC. The argument against an indirect blood pressure mediated effect of Angll is found in in vitro data where Angll has been shown to stimulate SMC protein and DNA synthesis in cell culture,(Geisterfer et al., 1988; Schelling et al., 1991) and by in vivo data where Angll has been shown to stimulate vascular hypertrophy through a non-pressor pathway. (Griffin et al., 1991) Moreover, also in the present study 6-OHDA was able to reduce the Angll-induced increase in DNA synthesis in the media of the carotid artery without an effect on the blood pressure. 


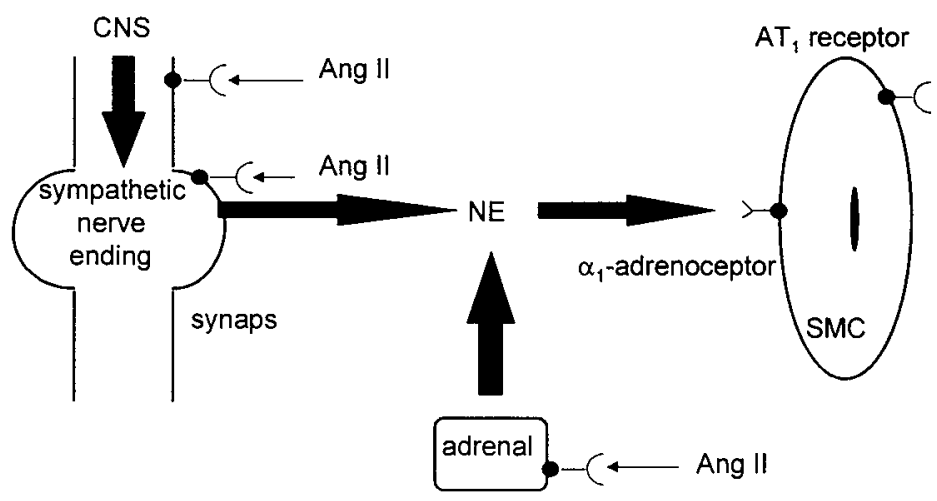

Figure 4.4 Schematic Drawing of the Systemic and Sympathetic Actions on $\alpha_{1}$-Adrenoceptor After Ang II Stimulation. Angll binds to the AT, receptors on the sympathetic nervous endings triggering the release of norepinephrine (NE) from the synapses. NE binds to the $\alpha_{1}$-adrenoceptors which increases the SMC DNA synthesis. The same events can be triggered by binding of Angll at AT, receptors located on the adrenals. This binding will trigger the release of NE directly in the system where it can bind to the $\alpha_{1}$-adrenoceptors located on SMCs and trigger the increase in SMC DNA synthesis.

Since 6-OHDA is known to leave the catecholamine content of the adrenal medulla intact(Mueller et al., 1969) the data presented here suggest that the adrenal medulla may not be an important factor in the pathway that controls medial SMC replication in response to Angll. As indicated in figure 4.4, this leaves open the possibility of an interaction at the level of the central nervous system or at the level of the synapse.(Starke et al., 1969; Zimmerman and Whitmore, 1967; Wong et al., 1990; Lu et al., 1996)

In the uninjured media, where 6-OHDA reduced SMC replication, no effect on lumen area or CSA were found, indicating no effect of 6-OHDA on vessel growth or remodeling. This is in accordance with previous results which showed that $\alpha_{1}$ adrenoceptor blockade with doxazosin decreased Angll induced DNA synthesis but had no effect on CSA.(van Kleef et al., 1996a) When, however, the AT, receptor blocker losartan was infused together with Angll the CSA decreased.(van Kleef et al., 1996b) Angll stimulates collagen synthesis in cultured rat thoracic SMCs.(Kato et al., 1991) Furthermore, treatment of young ( 4 or 10 weeks old) normotensive rats with the ACE inhibitor enalapril caused a marked decrease in both large (aorta, renal and carotid artery) and smaller arteries (mesenteric) in elastin and collagen protein content(Keeley et al., 1992) suggesting stimulatory effects of Angll on elastin and collagen protein deposition. The lack of effect of 6-OHDA on medial CSA, but not on SMC replication, may suggest that the $\alpha_{1}$-adrenoceptors are involved in the regulation of SMC replication but not in (Angll stimulated) matrix growth.

Balloon injury increased the CSA and decreased the lumen area of the carotid artery indicating hypertrophic inward remodeling (table 4.2; figure 1.1, chapter 1).(Mulvany et al., 1996) Interestingly, no such relation between an increased neointimal area and a smaller lumen area was found in a pig coronary artery injury model.(Andersen et al., 1996) Administration of Angll further increased the vessel CSA, without an effect on lumen area, supporting the idea that Angll stimulates vessel growth in the rat carotid neointima.(Daemen et al., 1991) 
Although infusion of the $\alpha_{1}$-agonist phenylephrine 10 weeks after injury increased neointimal SMC DNA synthesis,(deBlois et al., 1996a) sympathetic denervation 10 weeks after injury did not reduce the Angll induced neointimal SMC replication. An explanation for this apparent discrepancy is that we might not have succeeded to completely denervate the injured vessel for the entire 2 weeks. This possibility is, however, very unlikely since glyoxylic acid fluorescence staining was still absent in the highly innervated femoral artery (data not shown) indicating successful catecholamine depletion(Cowen and Burnstock, 1980) at the end of the experiment.

The Angil induced SMC replication in the neointima was not only insensitive to sympathetic denervation (this study), but also to pharmacological $\alpha_{1}$-adrenoceptor blockade.(van Kleef et al., 1996a) One possibility that may explain this phenomenon is a loss of $\alpha_{1}$-adrenoceptors after balloon injury. To test this hypothesis, we measured the amount of $\alpha_{1}$-adrenoceptors in the carotid artery at several time points after balloon injury. As is shown in this study, balloon injury is associated with a loss of specific [ $\left.{ }^{3} \mathrm{H}\right]$ prazosin binding. Even at 20 weeks after balloon injury the amount of $\alpha_{1}$-adrenoceptors is lower in the injured than in the uninjured carotid artery. The loss of $\alpha_{1}$-adrenoceptors after injury may also explain why a two weeks infusion of the $\alpha_{1}$-adrenoceptor agonist phenylephrine failed to increase SMC replication in the rat carotid neointima.(deBlois et al., 1996a) It is not clear why the density of $\alpha_{1}$-adrenoceptors is decreased after injury. One possible explanation may be the increased exposure of the vessel to neurogenic and circulating catecholamines after balloon injury that may down regulate $\alpha_{1}$ adrenoceptors. Indirect evidence for this possibility is provided in the rabbit iliac artery injury model where the increase in local facilitation of adrenergic neurotransmission after injury resulted in decreased contractile responses to exogenous catecholamines.(Candipan et al., 1994) However, in contrast to $\beta_{2}$-adrenoceptors, $\alpha_{1}$ adrenoceptors have been reported to be rather resistant to homologous downregulation.(Colucci et al., 1981) Other possibilities include heterologous downregulation of $\alpha_{1}$-adrenoceptors as a result of increased intra-arterial levels of Angll.(Clements and Faber, 1997)

The most likely explanation for the apparent paradox between the stimulatory effect of phenylephrine(deBlois et al., 1996a) and the lack of effect of sympathetic denervation is the humoral release of catecholamines from the adrenal medulla which is stimulated by Angll,(Feldberg and Lewis, 1964) and not affected by 6-OHDA.(Mueller et al., 1969) Previous results from our laboratory(Stassen et al., 1997b) and from Henegar et al.(Henegar et al., 1995) indicated a rise in norepinephrine plasma levels after chronic Angll infusion. Thus, the release of catecholamines from the adrenal medulla may have overruled the effect of sympathetic denervation on SMC replication by stimulation of non-innervated $\alpha_{1}$-adrenoceptors on the vascular SMCs.

In conclusion, the data presented here help to unravel the pathways that control SMC replication in vivo in response to Angll, in which the AT, receptor(van Kleef et al., 1996b) and factors like IGF(Delafontaine and Lou, 1993) have been shown to be involved. Our data indicate that sympathetic innervation or more exactly $\alpha_{1}$-adrenoceptors(van Kleef et al., 1992; van Kleef et al., 1996a) mediate the Angll induced replication, but only in the uninjured vessel. 


\section{CHAPTER 5}

Angiotensin II Modifies the Contribution of Adrenal Medulla Derived Catecholamines to the Regulation of Neointimal Growth After Balloon Injury of the Rat Carotid Artery 


\begin{abstract}
In this study, we investigated the possible interactions between adrenal medulla derived catecholamines on angiotensin II (Angll) induced neointimal growth in the balloon injured rat carotid artery model. To this purpose, the left carotid artery of male Wistar rats, from which both adrenal medullas were removed, was injured by a balloon catheter. From 10-12 weeks after injury animals received Angll to stimulate intimal smooth muscle cell growth and/or the $\alpha_{1}$-adrenoceptor antagonist prazosin to block $\alpha_{1}{ }^{-}$ adrenoceptors in the vascular wall.

Body weights and systolic blood pressures in the demedullation-prazosin groups were not different from those in the demedullation groups. Demedullation decreased adrenal medulla derived plasma epinephrine concentrations, but did not change neuronal plasma norepinephrine concentrations. Addition of prazosin did not affect these plasma catecholamine concentrations. In the Angll infused groups, coinfusion of prazosin after demedullation had no effect on neointimal or lumen CSA as compared to the demedullation alone group. Also, prazosin by itself did not affect neointimal CSA. However, demedullation tended to increase neointimal growth by sensitization of the $\alpha_{1}$ adrenoceptors since this increase in neointimal growth was affected by prazosin.

These data show that neointimal growth after a balloon catheter induced injury is $\alpha_{1}$ adrenoceptor regulated, but that neither the adrenal medulla derived catecholamines nor the $\alpha_{1}$-adrenoceptors contribute to the Angil-induced neointimal growth.
\end{abstract}


Introduction

The sympathetic nervous system plays an important role in the regulation of vascular smooth muscle cell (SMC) growth. Chronic administration of catecholamines not only accelerates the progression of atherosclerosis in several animal species,(Kukreja et al., 1981: Majesky et al., 1985) but also induces significant DNA replication in SMCs in both the normal and injured rat arterial wall.(deBlois et al., 1996a) $\alpha_{1}$-Adrenoceptor antagonists, when administered immediately after balloon injury, reduce SMC DNA synthesis and neointima formation in the rat carotid artery and rabbit abdominal aorta.(Jackson et al., 1988; O'Malley et al., 1989; Fingerle et al., 1991; Vashisht et al., 1992) Angll also stimulates SMC DNA synthesis in the media and the neointima after balloon injury. (Daemen et al., 1991) This effect may be partly mediated through $\alpha_{1^{-}}$ adrenoceptors, since Angll facilitates sympathetic transmission by potentiating neurotransmitter release and inhibiting norepinephrine uptake,(Starke, 1977) and stimulates the humoral release of catecholamines from the adrenal medulla.(Feldberg and Lewis, 1964) The $\alpha_{1}$-adrenoceptor antagonist doxazosin however, did not reduce SMC DNA synthesis in the media and neointima of the injured rat carotid artery, when infused together with Angl! two weeks after balloon injury. On the other hand, it did however, decrease SMC DNA synthesis in the media of the uninjured carotid artery.(van Kleef et al., 1996a) Furthermore, when the $\alpha_{1}$-adrenoceptor agonist phenylephrine was infused two weeks after balloon injury of the rat common carotid artery, SMC DNA synthesis in the neointima was not affected.(deBlois et al., 1996a) In contrast, if phenylephrine was infused ten weeks after injury, neointimal SMC DNA synthesis did increase.(deBlois et al., 1996a)

When neuronal norepinephrine, but not adrenal medulla derived (nor)epinephrine, was removed by chemical sympathectomy using 6-OHDA(Aprigliano and Hermsmeyer, 1976; Yamaguchi and Nakada, 1992) it became apparent that balloon injury modifies the effects of chemical sympathectomy with 6-OHDA on Angll induced SMC DNA synthesis (chapter 4). While 6-OHDA did prevent the Angll induced SMC DNA synthesis in the media of uninjured carotid arteries, it had no effects on Angll induced SMC DNA synthesis in injured carotid arteries neither at 4 nor at 12 weeks after injury. Moreover, 6OHDA had no effects on Angll induced changes in intimal cross-sectional area or lumen area (chapter 4). One explanation for the apparent paradox between the stimulatory effect of phenylephrine(deBlois et al., 1996a) and the lack of effect of sympathetic denervation is the humoral release of catecholamines from the adrenal medulla, which is stimulated by Angll,(Feldberg and Lewis, 1964; Henegar et al., 1995; Stassen et al., 1997b) but not affected by 6-OHDA.(Mueller et al., 1969) This Angll stimulated release of humoral catecholamines may have overruled the effects of sympathetic denervation on neointimal growth and in that way may have obscured a possible inhibiting effect of sympathetic denervation on neointimal growth (figure 4.4, chapter 4).

In the present investigation, we have studied the role of the adrenal medulla in the control of neointimal growth of balloon catheter induced vascular injury in more detail. Moreover, we investigated the effects of possible modifiers such as Angll and $\alpha_{1^{-}}$ adrenoceptor blockade.

\section{Materials \& Methods}

Animals

Male Wistar rats obtained from Iffa Credo (Someren, the Netherlands) were used (body weight, 275-325 g; $n=46$ ). They had free access to standard rat chow (Hope Farms, Woerden, the Netherlands) and tap water. The experiments were performed according to institutional guidelines. 
Rats in which the left common carotid artery had been injured by a balloon catheter (see below) were randomly divided into six groups (figure 5.1): group $A(n=8)$ was treated only with Angll. Group $B(n=8)$ received Angll and a bilateral adrenal demedullation; group $C(n=8)$ received Angll, prazosin $(\alpha$, -adrenoceptor antagonist) and a bilateral adrenal demedullation. Group $D(n=7)$ received $0.9 \% \mathrm{NaCl}$. Group $E$ $(n=7)$ received $0.9 \% \mathrm{NaCl}$, and a bilateral adrenal demedullation; group $F(n=8)$ received $\mathrm{NaCl}$, prazosin and a bilateral adrenal demedullation.

\section{Balloon injury}

All rats were anaesthetized with pentobarbital $(60 \mathrm{mg} / \mathrm{kg}$ body weight) by intraperitoneal (i.p.) injection. The left common carotid artery was injured by introduction of a 2F balloon catheter (Baxter, Maarsen, the Netherlands) into the left external carotid artery. After inflation, the catheter was withdrawn through the common carotid artery. This procedure was repeated three times after which the catheter was removed and the external carotid artery ligated. The right carotid artery was not traumatized and served as a control.(Clowes et al., 1983a; Clowes et al., 1983b)
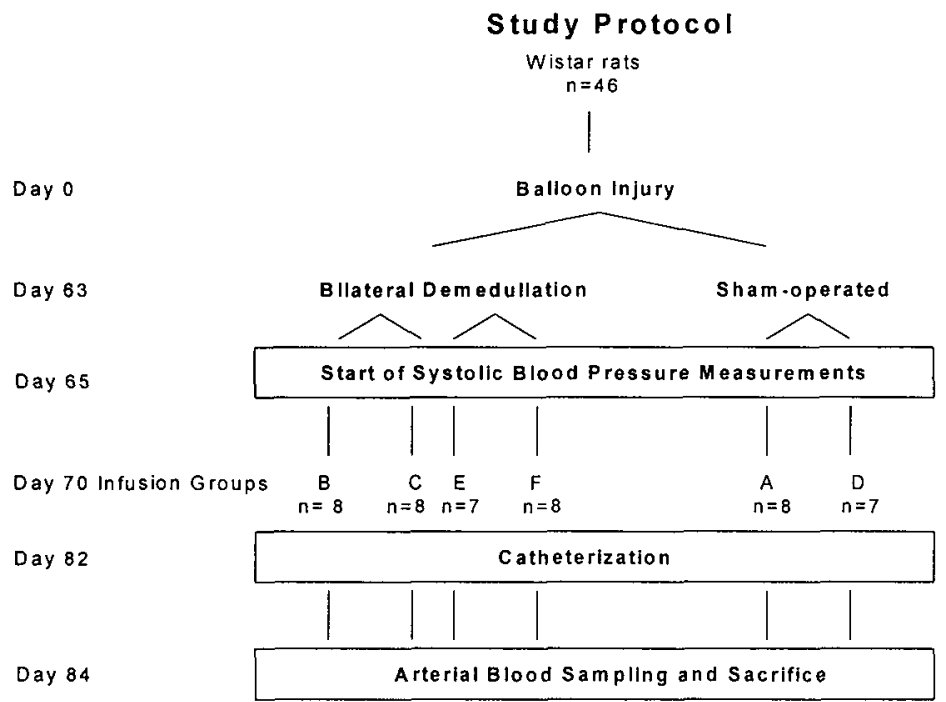

Figure 5.1 Outline of the Research Protocol With Randomization Scheme.

\section{Bilateral Adrenal Demedullation}

Bilateral adrenal demedullation was performed under ether anaesthesia via flank incisions one week before the start of the infusions (figure 5.1). After exposing the adrenal gland, a small incision was made in the adrenal cortex. Enucleation of the adrenal medulla was performed by gentle squeezing with a forceps. A sham operation, consisting of the same procedure described above without the enucleation of the adrenal medulla, was performed on control animals (group $\mathrm{C}$ and $\mathrm{F}$ ).

\section{Blood Pressure Measurement}

Systolic blood pressures were measured by tail cuff plethysmography (ITTC inc. Woodland Hills. Ca., USA) in slightly restrained, conscious rats. After a training period of 
seven days, blood pressure measurements started five days before drug infusions and were performed three times a week until sacrifice.

\section{Drug Infusion}

Human [Val $\left.{ }^{5}\right]$-Angll (Saxon Biochemicals GMBH, Hannover, Germany) was continuously infused using osmotic minipumps (Alzet model 2002, Alza Corp., Palo Alto, Ca.,USA) implanted subcutaneously between the shoulder blades under ether anaesthesia. Angll was dissolved in $0.9 \% \mathrm{NaCl}$ and infused at a rate of $250 \mathrm{ng} / \mathrm{kg} / \mathrm{min}$. Prazosin (Sigma Chemical Co., St. Louis, Mo., USA) was dissolved in $50 \%$ dimethyl sulphoxide $(7.3 \mathrm{mg} / \mathrm{ml})$ and infused at a rate of $1.23 \mu \mathrm{g} / \mathrm{min}(0.35 \mu \mathrm{g} / 100 \mathrm{~g}$ per minute $)$ in an Alzet model $2 \mathrm{ml1}$ osmotic minipump.(Theeuwes and Yum, 1976) Since phenylephrine infusion in the first few weeks after balloon injury has no effect on neointima SMC growth, but increases neointimal SMC growth when infused at ten weeks after balloon injury,(deBlois et al., 1996a) all infusions were started ten weeks after balloon injury and lasted for two weeks.

\section{Catecholamine Analysis}

Two days before sacrifice, rats were anaesthetized with pentobarbital (60 mg/kg i.p.). A polyethylene (PE 10) catheter was implanted under aseptic conditions into the femoral artery and advanced into the abdominal artery. The saline-filled catheter was guided subcutaneously to the base of the neck, exteriorized, and sealed with a metal plug.

Two hours before sacrifice arterial blood samples were obtained for determination of catecholamine plasma levels. Blood $(1.2 \mathrm{ml})$ was withdrawn from quietly resting conscious rats and put into chilled tubes containing $1 \mathrm{mg}$ glutathion (Merck, Darmstadt, Germany) and $10 \mu \mathrm{l}$ heparin (Leo Pharmaceutical Products, $5000 \mathrm{u} / \mathrm{ml}$ ). The blood samples were centrifuged at $3000 \mathrm{~g}$ for 15 minutes, and the plasma was stored at $20^{\circ} \mathrm{C}$. Catecholamines were determined by fluorescence high performance liquid chromatography as described earlier.(van der Hoorn et al., 1989)

\section{Tissue Processing}

At the end of the experiment all rats received $0.5 \mathrm{ml} 0.5 \%$ Evans blue (Chroma Gesellschaft, Stuttgart, Germany) in $0.9 \% \mathrm{NaCl}$ by intravenous (i.v.) injection, to stain non-endothelialized tissue in the left common carotid artery. One hour later the animals were killed by pentobarbital overdose $(80 \mathrm{mg} / \mathrm{kg}$ body weight i.p.) and the arterial system was perfused with phosphate buffered saline (PBS) followed by perfusion fixation with $4 \%$ phosphate buffered paraformaldehyde $(\mathrm{pH} 7.4)$, at a pressure of 100 $\mathrm{mmHg}$. Maximal vasodilatation was ensured by adding nitroprusside $(0.1 \mathrm{mg} / \mathrm{ml}$, Sigma Chemical Co., St. Louis, Mo., USA) to the perfusate.

One circular segment $(2-3 \mathrm{~mm}$ long) was taken from the center of the blue stained non-endothelialized part of the left carotid artery. For comparison one segment was taken at a similar location from the uninjured right carotid artery. All tissues were fixed overnight in $4 \%$ phosphate buffered paraformaldehyde, routinely processed and embedded in paraffin (Para Clean, Klinipath, Duiven, the Netherlands).

\section{Morphometric Analysis}

Cross-sectional areas of the media, defined as the area between the external and internal elastic lamina, and the neointima, defined as the area between the internal elastic lamina and the lumen of the artery, and the lumen area were measured using a computerized morphometric system (Quantimet 570, Leica), on 4 mm Lawson (Boom B.V., Meppel, the Netherlands) stained cross-sections of the carotid artery rings. Measurements were performed on two cross-sections taken from each ring. 


\section{Statistics}

Data are presented as mean \pm SEM. Comparisons between groups for blood pressure and body weight were made by two-way analysis of variance (ANOVA). Comparisons between groups for catecholamine content and morphometry were made by Kruskal-Wallis $\mathrm{H}$-test. Statistical significance was assumed at $\mathrm{p}<0.05$.

\section{Results}

\section{Body Weight}

Body weights of the animals in the different groups did not differ, neither at the start of the experiment nor at the start of the infusions. Body weight decreased during infusion with Angll (table 5.1) and animals in the $\mathrm{NaCl}$ group increased their body weight. Neither demedullation nor prazosin did affect body weight changes in the Angll groups or the $\mathrm{NaCl}$ infused groups.

Table 5.1 Effects of Angiotensin II, Demedullation and Prazosin on Body Weight and Systolic Blood Pressure 12 Weeks After Balloon Injury of the Left Carotid Artery

\begin{tabular}{llllll}
\hline \multirow{2}{*}{ Treatment } & \multicolumn{2}{c}{ body weight, } & & \multicolumn{2}{c}{ blood pressure, $\mathrm{mmHg}$} \\
\cline { 2 - 3 } & start & change & & start & change \\
\hline Angll & $425 \pm 8$ & $-41 \pm 8^{*}$ & $109 \pm 3$ & $+78 \pm 6^{*}$ \\
Angll/demedullation & $411 \pm 7$ & $-42 \pm 8 \#$ & $111 \pm 7$ & $+94 \pm 7 \#$ \\
Angll/demedullation/prazosin & $436 \pm 12$ & $-20 \pm 7 \$$ & $118 \pm 6$ & $+90 \pm 10 \$$ \\
\hline $\mathrm{NaCl}$ & $428 \pm 9$ & $+11 \pm 3$ & $115 \pm 5$ & $-10 \pm 3$ \\
$\mathrm{NaCl} /$ demedullation & $409 \pm 7$ & $0 \pm 6$ & $114 \pm 2$ & $-9 \pm 5$ \\
$\mathrm{NaCl} /$ demedullation/prazosin & $418 \pm 4$ & $+11 \pm 2$ & & $112 \pm 4$ & $+2 \pm 3$ \\
\hline
\end{tabular}

Starting values of body weight Changes in body weight and systolic blood pressure are given over the infusion period. Data represent mean \pm SEM. ${ }^{*}$ ) Significantly different from $\mathrm{NaCl}: 0<0.05$. \#) Significantly different from NaCl/demedullation: $p<0.05$. \$) Significantly different from $\mathrm{NaCl} /$ demedullation/prazosin: $\mathrm{p}<0.05$.

\section{Systolic Blood Pressure}

The systolic blood pressures (SBP) of the animals in the different groups were comparable at the start of the infusions. Angll infusion increased the SBP regardless of the interventions performed (table 5.1). Also in $\mathrm{NaCl}$ infused animals neither demedullation nor prazosin did affect SBP.

\section{Plasma Epinephrine Concentrations}

Demedullation decreased the plasma epinephrine concentration in both $\mathrm{NaCl}$ - and Angll infused animals to almost zero, indicating the efficacy of the procedure. In both the $\mathrm{NaCl}$ - and the Angll infused groups prazosin infusion had no effect on the plasma epinephrine concentration of demedullated animals (table 5.2). 
Table 5.2 Effects of Angiotensin II. Demedullation and Prazosin on Plasma Epinephrine and Norepinephrine Levels 12 Weeks After Balloon injury of the Left Carotid Artery

\begin{tabular}{llc}
\hline Treatment & epinephrine, nmol/l & norepinephrine, nmol/l \\
\hline Angll & $1.02 \pm 0.65$ & $2.38 \pm 0.83$ \\
Angll/demedullation & $0.02 \pm 0.01 \#$ & $1.97 \pm 0.43$ \\
Angll/demedullation/prazosin & $0.03 \pm 0.01 \#$ & $1.62 \pm 0.27$ \\
\hline $\mathrm{NaCl}$ & $0.85 \pm 0.42$ & $0.89 \pm 0.18$ \\
$\mathrm{NaCl} /$ demedullation & $0.09 \pm 0.03^{*}$ & $0.87 \pm 0.09$ \\
$\mathrm{NaCl} /$ demedullation/prazosin & $0.06 \pm 0.02^{*}$ & $1.82 \pm 0.38^{*}$
\end{tabular}

Plasma epinephrine and norepinephrine levels after the infusion period. Data represent mean \pm SEM. *) Significantly different from $\mathrm{NaCl}: p<0.05$. \#) Significantly different from Angll: $p<0.05$.

\section{Plasma Norepinephrine Concentrations}

No significant differences in plasma norepinephrine concentrations were found between the three Angll infused groups (A-C). In the $\mathrm{NaCl}$ groups (D-F) prazosin increased the plasma norepinephrine concentration in the prazosin-demedullated animals (group F) to $1.82 \pm 0.38 \mathrm{nM}$ as compared to $0.87 \pm 0.09 \mathrm{nM}$ in the demedullated animals (Group $E, p=0.04$, table 5.2).

\section{MORPHOMETRY}

Uninjured Right Carotid Artery

Medial CSA

Removal of both adrenal medullas before infusion of Angll did not change medial cross-sectional area (CSA) as compared to infusion of Angll alone. Infusion of prazosin together with Angll in demedullated animals (group C) did not change the medial CSA of the right carotid artery as compared to Angll infusion after demedullation alone (group B). The medial CSA of the right carotid artery however, increased from $0.10 \pm$ $0.01 \mathrm{~mm}^{2}$ in the control $\mathrm{NaCl}$ group to $0.13 \pm 0.01 \mathrm{~mm}^{2}$ in the Angll group $(p=0.03$, table 5.3). There were no significant differences in the medial CSA of the right carotid artery between the different $\mathrm{NaCl}$ infused groups (D-F).

\section{LumenArea}

The lumen area of the right carotid artery in demedullated animals receiving Angll did not differ from the lumen area of the right carotid artery in animals infused with Angll. There were no effects of prazosin in combination with demedullation on lumen area, neither in the Angll- nor in the $\mathrm{NaCl}$ infused groups (table 5.3). In fact, lumen area was not changed in any of the experimental groups.

\section{Injured Left Carotid Artery Medial CSA}

Demedullation had no effect on the medial CSA of the left carotid artery in Angll infused animals. Coinfusion of prazosin and Angll after demedullation (group C) had also no effect on the medial CSA of the left carotid artery. Infusion of Angll did increase the medial CSA of the left carotid artery from $0.10 \pm 0.01 \mathrm{~mm}^{2}$ after $\mathrm{NaCl}$ infusion 100.12 $\pm 0.01 \mathrm{~mm}^{2}(p=0.04$, table 5.4). In the $\mathrm{NaCl}$ infused groups (D-F) the CSA of the media of the left carotid artery was not affected, neither by demedullation nor by prazosin (table 5,4). 
Table 5.3 Effects of Angiotensin II, Demedullation and Prazosin on Uninjured Medial CSA and Lumen Area 12 Weeks After Balloon Injury of the Left Carotid Artery

\begin{tabular}{lll}
\hline Treatment & media CSA, $\mathrm{mm}^{2}$ & $\mathrm{LA}, \mathrm{mm}^{2}$ \\
\hline Angll & $0.13 \pm 0.01$ & $0.38 \pm 0.04$ \\
Angll/demedullation & $0.12 \pm 0.01$ & $0.36 \pm 0.03$ \\
Angl//demedullation/prazosin & $0.12 \pm 0.01$ & $0.38 \pm 0.02$ \\
\hline $\mathrm{NaCl}$ & $0.10 \pm 0.01$ & $0.35 \pm 0.02$ \\
$\mathrm{NaCl} /$ demedullation & $0.10 \pm 0.01$ & $0.35 \pm 0.04$ \\
$\mathrm{NaCl} /$ demedullation/prazosin & $0.10 \pm 0.01$ & $0.44 \pm 0.04$
\end{tabular}

Cross-sectional area (CSA) and lumen area (LA) of the uninjured right carotid artery after the infusion period. Data represent mean \pm SEM.

\section{Neointimal CSA}

Demedullation of animals receiving Angll did not change neointimal CSA of the left carotid artery. In the Angll infused groups, coinfusion of prazosin after demedullation had no effect on neointimal CSA as compared to the demedullation group. The neointimal CSA of the injured left carotid artery tended to increase during infusion with Angll as compared to the group receiving $\mathrm{NaCl}$ alone $\left(0.20 \pm 0.04 \mathrm{~mm}^{2}\right.$ vs. $0.17 \pm 0.02$ $\mathrm{mm}^{2}, p=0.15$, table 5.4). The neointimal CSA of the left carotid artery of demedullated animals receiving $\mathrm{NaCl}$ (group $\mathrm{E}$ ) decreased from $0.22 \pm 0.02 \mathrm{~mm}^{2}$ to $0.15 \pm 0.01 \mathrm{~mm}^{2}$ after infusion of prazosin ( $p=0.04$, table 5.4). Demedullation alone increased neointimal CSA from $0.17 \pm 0.02 \mathrm{~mm}^{2}$ in $\mathrm{NaCl}$ infused control animals to $0.22 \pm 0.02 \mathrm{~mm}^{2}$ after demedullation. However, this increase was not significant $(p=0.13$, table 5.4$)$. In other words, without additional Angll present, adrenal demedulation sensitizes $\alpha_{1}$ adrenoceptors which promotes vessel growth.

Table 5.4 Effects of Angiotensin II, Demedullation and Prazosin on Injured Medial and Neointimal CSA and Lumen Area 12 Weeks After Balloon Injury of the Left Carotid Artery

\begin{tabular}{llll}
\hline treatment & \multicolumn{3}{c}{ CSA, $\mathrm{mm}^{2}$} \\
\cline { 2 - 3 } & media & neointima & LA, mm ${ }^{2}$ \\
\hline Angll & $0.12 \pm 0.01$ & $0.20 \pm 0.04$ & $0.25 \pm 0.03$ \\
Angll/demedullation & $0.11 \pm 0.01$ & $0.20 \pm 0.01$ & $0.27 \pm 0.04$ \\
Angll/demedullation/prazosin & $0.10 \pm 0.01 \#$ & $0.21 \pm 0.03$ & $0.27 \pm 0.04$ \\
\hline $\mathrm{NaCl}$ & $0.10 \pm 0.01$ & $0.17 \pm 0.02$ & $0.16 \pm 0.01$ \\
$\mathrm{NaCl} /$ demedullation & $0.11 \pm 0.01$ & $0.22 \pm 0.02$ & $0.27 \pm 0.03^{*}$ \\
$\mathrm{NaCl} /$ demedullation/prazosin & $0.10 \pm 0.01$ & $0.15 \pm 0.01 \$$ & $0.27 \pm 0.02^{*}$
\end{tabular}

Cross-sectional area (CSA) and lumen area (LA) of the injured left carotid artery after the infusion period. Data represent mean \pm SEM. Significantly different from $\mathrm{NaCl}:{ }^{*} p<0.05$. Significantly different from Angll: $\# p<0.05$. Significantly different from NaCl/demedullation: $\$ p<0.05$.

\section{Lumen Area}

Infusion of Angll increased the lumen area from $0.16 \pm 0.01 \mathrm{~mm}^{2}$ in the $\mathrm{NaCl}$ group to $0.25 \pm 0.03 \mathrm{~mm}^{2}$ in the Angll group $(p=0.01$, table 5.4$)$. There were no significant differences between the three Angll infusion groups with regard to lumen area of the injured left carotid artery. Demedullation in the $\mathrm{NaCl}$ groups increased lumen area as 
compared to the $\mathrm{NaCl}$ infusion alone group indicating hypertrophic outward remodeling. This increase in lumen area of the left carotid artery by demedullation was not affected by infusion of prazosin (table 5.4).

\section{Discussion}

The studies described here further dissect the mechanism of Angll-induced neointimal growth in the injured rat carotid artery. The major findings are that i) removal of the adrenal medulla increases the response of the neointima to balloon catheter induced vascular injury, ii) this effect is sensitive to $\alpha_{1}$-adrenoceptor blockade and iii) this effect is absent during infusion with Angll.

Since there is no effect of demedullation on Angll stimulated neointimal growth, the data presented in this study indicate that the Angll-induced increase in neointimal growth in the balloon injured rat carotid artery is not mediated by the release of catecholamines from the adrenal medulla. Previous results from our laboratory have shown that this increase is also not mediated by stimulation of $\alpha_{1}$-adrenoceptors on the neointimal SMCs through the release of catecholamines from the sympathetic nervous system (chapter 4). Thus, the data suggest that Angll-induced SMC growth in the neointima of the rat carotid artery is mediated by a direct effect of Angll on the AT, receptor and not by indirect effects involving catecholamines. Indeed, coinfusion of the $A T_{1}$ receptor antagonist losartan and Angll after balloon injury in the rat showed a significant decrease in neointimal CSA as compared to controls.(van Kleef et al., 1996b) This decrease in neointimal CSA after AT, receptor blockade,(van Kleef et al, 1996b) but not after $\alpha_{1}$-adrenoceptor blockade or demedullation (this study) of animals receiving Angll, also suggests that there is a lack of cross-talk between the $\alpha_{1}$ adrenoceptors and the AT, receptors on neointimal SMCs as observed in neuronal cultures of Wistar-Kyoto rats.(Yang et al,, 1996) in those cells stimulation of $\alpha_{1}$ adrenoceptors by norepinephrine causes a down regulation of $A T_{1}$ receptors. Interestingly, norepinephrine does not decrease AT, receptors in neuronal cultures of spontaneously hypertensive rat brains.(Yang et al., 1996)

The fact that demedullation, and the combination of prazosin and demedullation had no effect on the Angll-induced increase in systolic blood pressure (SBP), suggests that also the increase in SBP after Angll is not $\alpha_{1}$-adrenoceptor mediated. These results are in agreement with previous results showing that the Angll-induced increase in SBP is an $A T_{1}$ receptor mediated phenomenon.(van Kleef et al., 1996b) Furthermore, infusion of prazosin (this study) and doxazosin(van Kleef et al., 1996a) do not decrease the Angllinduced increase in SBP. Bilateral adrenal demedullation did also not affect vascular smooth muscle reactivity since the pressor responses to bolus injections of phenylephrine were remarkably similar in demedullated and sham-operated animals.(Borkowski and Quinn, 1983)

Demedullation increases the turnover of norepinephrine in peripheral sympathetic nerves.(Micalizzi and Pals, 1979; de Champlain and van Ameringen, 1975) However, in the present study bilateral adrenal demedullation depleted plasma epinephrine concentrations, but did not reduce norepinephrine concentrations, as might be expected if a facilitatory stimulus is removed. We can however, not exclude that an increased neuronal uptake of norepinephrine prevented plasma norepinephrine concentrations from rising. The implications of changes in plasma norepinephrine levels related to peripheral sympathetic nervous system activity must be interpreted with caution. Absolute levels of norepinephrine may not reflect true body and organ turnover or activity, especially when release and clearance of norepinephrine are unknown.

In the present studies the most striking results were found in the $\mathrm{NaCl}$ infused animals, where i) demedullation increased neointimal CSA after injury and ii) addition of 
prazosin to $\mathrm{NaCl}$ animals prevented this increase in neointimal CSA. Since, demedullation increases sympathetic activity, (de Champlain and van Ameringen, 1975; Micalizzi and Pals, 1979) one explanation could be that more norepinephrine is released from the sympathetic nerve terminals which could increase stimulation of the $\alpha_{1}$ adrenoceptors present on the neointimal SMCs (figure 4.4, chapter 4). The suggestion that $\alpha_{1}$-adrenoceptors were sensitized is supported by our findings that blockade of the $\alpha_{1}$-adrenoceptors prevented this effect of demedullectomy on neointimal CSA. As can be concluded from the data presented in table 5.1, this effect of $\alpha_{1}$-adrenoceptor blockade is not mediated through the blood pressure. These data are in contrast with data published earlier that show that the rat carotid neointima was insensitive to infusion of the $\alpha_{1}$-adrenoceptor agonist phenylephrine during the ninth and tenth week after injury.(deBlois et al., 1996a)

Not only the neointimal CSA of $\mathrm{NaCl}$ animals increases after demedullation of the injured rat carotid artery, but also the lumen area, indicating hypertrophic outward remodeling (figure 1.1, chapter 1). (Mulvany et al., 1996) However, previous data from our laboratory showed no effects of 6-OHDA on arterial remodeling (chapter 4). An explanation for the apparent discrepancy between the present study and the previous chapter, is a regain of responses of neointimal SMCs to $\alpha_{1}$-adrenoceptor agonists in the eleventh and twelfth week after injury. This explanation is supported by data presented in the previous chapter, where we showed that balloon injury decreased the specific $\alpha_{1}$ adrenoceptor binding capacity from day 3 up to 10 weeks after injury when expressed relative to the total protein content, and from day 3 up to 20 weeks after injury when expressed relative to the total DNA content (chapter 4). However, $\alpha_{1}$-adrenoceptor specific binding started to increase from week 10 after injury (see figure 4.3). We propose therefore, that in the present study, in which infusions were performed during the eleventh and twelfth week after injury, some neointimal SMCs could have regained enough $\alpha_{1}$-adrenoceptors to respond to $\alpha_{1}$-adrenoceptor stimulation.(Orlandi et al., 1994; Kocher et al., 1991)

In conclusion, this study shows that neointimal growth after balloon catheter induced injury is $\alpha_{1}$-adrenoceptor sensitive and that there seems to be no apparent role for catecholamines and $\alpha_{1}$-adrenoceptors in this response to injury during Angll infusion. 


\section{CHAPTER 6}

Anastomotic Innervation in Peripheral Bypasses and Graft Arteriovenous Fistulas in Humans 


\begin{abstract}
Vascular interventions are often complicated by the development of intimal thickening, leading to stenosis. Vascular smooth muscle cell (SMC) proliferation and extracellular matrix deposition is considered to be one of the key events in the development of intimal thickening. One of the regulators of intimal thickening, at least in animal studies, is the sympathetic nervous system. However, information on the importance of the sympathetic nervous system on the regulation of intimal thickening in humans is scarce. To determine a possible correlation between sympathetic (re)innervation and the development of vascular stenosis we determined the immunoreactivity of the anastomotic region of 10 human stenotic vessels, derived from either peripheral bypasses $(n=5)$ or haemodialysis arteriovenous (AV)-fistulas $(n=5)$ with the use of antibodies directed against antigens in sympathetic nerves. The antibodies used were directed against $\mathrm{S100}$, protein gene product 9.5 (PGP-9.5), tyrosine hydroxylase (TH), neurofilament (NF) and neuropeptide tyrosine (NPY). In addition, 5 saphenous vein control specimens were stained with the same antibodies

S100 and PGP-9.5 containing nerve bundles were present in the adventitia of normal saphenous veins, peripheral bypasses and AV-fistulas. Nerve fibers positive for TH were located around small blood vessels in the adventitia of all vessels examined. Neither the media nor the intima stained positive with the forementioned antibodies. This was true for control vessels, peripheral bypasses and AV-fistulas. Nerve fibers positive for NF or NPY were not detected.

We conclude that the adventitia of human peripheral bypasses and AV-fistulas contain S100, PGP-9.5 and TH positive, but NF and NPY negative sympathetic nerves. Both the media and intima of stenosed human peripheral bypass grafts, AV-shunts and the media of non-diseased saphenous veins lack sympathetic nerves. The data thus suggests that (re)innervation does not contribute to intimal growth and vascular stenosis in human stenotic tissue derived from AV-fistulas and peripheral bypass grafts.
\end{abstract}




\section{Introduction}

The replacement or bypass of sections of diseased arteries with autologous vein segments has become firmly established. The transplanted vein segment shows some degree of endothelial denudation, but rapidly becomes 'arterialized' by the establishment of an endothelial lining derived from arterial sources and the development of a new smooth muscle layer in the wall.(Dilley et al., 1988) However, this muscle layer is unlike the media of the normal muscular artery. It develops subendothelially in the intimal region, without a clear anatomic distinction from the pre-existing media. Thus the terms neointima, intimal thickening, and intimal hyperplasia have been used to describe this new muscle layer in a vein graft.(Fuchs et al., 1978) In some cases the arterialized vein develops an excessively thick intimal muscle layer that may ultimately obliterate the lumen and cause graft failure.(Motwani and Topol, 1998) Indeed, the long-term patency of arteriovenous (AV)-fistulas created for haemodialysis treatment of patients with endstage renal-failure is limited. In particular, those fistulas created with prosthetic graft materials such as polytetrafluoroethylene (PTFE) have patency rates that are usually measured in months only.(Swedberg et al., 1989) Although some failures are due to acute perioperative thrombosis, a significant proportion of graft stenosis is due to the development of an intimal hyperplastic lesion in the anastomosis of the graft with the vein.(Swedberg et al., 1989; Sottiurai, 1990)

The sympathetic nervous system may be one of the regulators of this intimal hyperplasia. The importance of the sympathetic nervous system in the regulation of smooth muscle cell (SMC) growth is underlined by the following examples which are derived from animal studies. Surgical sympathetic denervation of the growing rabbit ear artery reduces SMC proliferation,(Bevan, 1975) and chemical sympathectomy with 6hydroxydopamine (6-OHDA), which destroys the sympathetic nerve endings leaving vessels denervated,(Aprigliano and Hermsmeyer, 1976) reduces the number of SMCs in the growing aortic media.(Fronek et al., 1978) Stimulation of $\alpha_{1}$-adrenoceptors by phenylephrine increases the expression of growth related factors such as platelet derived growth factor-A.(Majesky et al., 1990) Previous results from our laboratory indicate that angiotensin II induces SMC proliferation in both the media and neointima of rat carotid arteries. This response could be blocked by both $\alpha_{1}$-adrenoceptor blockers and by sympathetic denervation with 6-hydroxydopamine, but only in the media (chapter 4).(van Kleef et al., 1992; van Kleef et al., 1996a) The intima was insensitive to both interventions. This indicates that the sympathetic nervous system may act as a trophic factor in the media, but does not seem to be important in the regulation of neointimal growth. Also, in arteries of adult animals, surgical denervation and 6-OHDA induced an increase in SMC size and ultrastructural changes compatible with increased synthetic activity.(Fronek et al., 1978; Branco et al, 1984; Bevan and Tsuru, 1981; Dimitriadou et al., 1988; Fronek, 1983) Thus, although sympathetic nerves seem to exert a trophic action on vascular SMCs during development and disease, they may help stabilize the contractile phenotype of the SMC in the non-diseased adult vessel.

Although we know a lot of the contribution of the sympathetic nervous system in animals, the extent of sympathetic (re)innervation and the role of the sympathetic nervous system in the regulation of intimal growth in human vein grafts has received scant attention. Human saphenous veins have a dense plexus network at the adventitiamedia border consisting of catecholamine and cholinergic nerves.(Herbst et al., 1992; Amenta et al., 1983) Prior to grafting, human saphenous veins are cut and stripped of their adventitia, which renders them denervated.(Kraiss and Clowes, 1997; Holme et al., 1990) Reinnervation of the vasa vasorum of vein grafts does not become established until two to four weeks after grafting.(Waris et al., 1984; Meagher et al., 1984) Also, neuromodulin positivity, a phosphoprotein transported anterogradely from the somata to 
the axon terminals of neurons, that is present in neurons that are capable of regenerative responses,(Benowitz and Perrone-Bizzozero, 1991) was strongly decreased or had disappeared almost completely in areas where intimal thickening was prominent.(De Meyer et al., 1997) Furthermore, in regions of the human carotid artery where intimal thickening occurred, the perivascular nerve network was degenerated.(Fuchs et al., 1978)

Thus, although several animal studies implicate that sympathetic nerves may act as a trophic factor of vascular growth, the few data in human vein grafts suggests a lack of re-(innervation), that may contribute to the development of intimal hyperplasia. To gain further insights in the innervation of human vein grafts and to determine the possible role of sympathetic nerves in the regulation of intimal growth, we evaluated the innervation status of the anastomotic region of stenosed human vein graft using a panel of antibodies directed against different epitopes present in sympathetic nerves.

\section{Materials \& Methods}

Patient Clinical Profile

\section{Patients With AV Fistulas}

This group consisted of 3 men and 2 women, with a mean age of 52 years (range, 40 to 66 years). The AV-fistula was repaired after an average time of 14.2 months (range, 8 to 20 months). The diagnosis of the stenosis was based on duplex ultrasound and confirmed by fistulography.(Tordoir et al., 1987) In all patients, the occurrence of a stenosis was associated with an increase in venous pressure and/or a decrease in flow of the fistula during haemodialysis necessitated reintervention. The stenotic sample was derived from the venous anastomosis of a PTFE interposition graft.

\section{Patients With a Peripheral Bypass}

This group of patients consisted of 2 men and 3 women, with a mean age of 66 years (range, 40 to 87 years). Reintervention was performed after an average time of 5.2 months (range, 1 to 21 months). The diagnosis of a stenosis was based on generally accepted duplex criteria and confirmed by angiography.(Buth et al., 1991) Patients with a graft at risk underwent repair of the stenotic segment. The stenotic tissue was derived from the proximal anastomosis of reversed saphenous vein grafts.

\section{Control Vessels}

This group of patients consisted of 2 men and 3 women whose mean age was 64 years (range, 50 to 78 years). Saphenous veins, which were left over after coronary artery bypass grafting was established, officiated as control vessels in this study.

\section{Immunohistochemistry}

All tissue specimens were fixed overnight in 10\% phosphate buffered formalin, processed according to routine histological procedures and paraffin-embedded. The distribution of the innervation markers used (TH: Chemicon, U.S.A. (1:5000); PGP-9.5: Ultraclone, U.K. (1:500); NPY: Boehringer Ingelheim, Germany (1:250); S100: Dako, Denmark (1:5000); NF: Euro-diagnostics, the Netherlands (1:250), table 6.1) was visualized in both AV-fistulas, peripheral bypass grafts and in control vessels. Four $\mu \mathrm{m}$ thick sections were deparaffinized and incubated in $0.3 \% \mathrm{H}_{2} \mathrm{O}_{2}$ in methanol to block endogenous peroxidase activity. After rinsing in tris-buffered saline (TBS) sections were incubated with each respective primary antibody, followed by incubation with biotinylated rabbit anti mouse IgG (Amersham, U.K.) for a monoclonal antibody (NF) or with biotinylated sheep anti rabbit IgG (Amersham, U.K.) if a polyclonal antibody (S100, PGP-9.5, NPY, TH) was used. Both incubations lasted 45 minutes and were performed 
at room temperature. Sections stained with the antibody against neurofilaments (NF) and S100 were pretreated with pepsin $(1 \mathrm{mg} / \mathrm{ml})$ for 30 minutes at room temperature or with trypsin $(1 \mathrm{mg} / \mathrm{ml})$ for 15 minutes at $37^{\circ} \mathrm{C}$, respectively. Subsequently, the sections were labeled for 30 minutes at room temperature with an avidin/biotin-peroxidase complex (Vectastain-ABC kit, Vector Labs, Burlingame, CA, USA) and 3,3'diaminobenzidine was used as the chromogen. Omission of the primary antibody served as negative control. The sections were counterstained with haematoxylin, dehydrated through graded series of alcohols, cleared in xylene and mounted in entallan (Merck).

Table 6.1. Immunohistochemical innervation markers used.

\begin{tabular}{llll}
\hline ANTIBODY & MONO-/POLYCLONAL & LOCALIZATION & SOURCE \\
\hline $\begin{array}{l}\text { Neurofilament } \\
\begin{array}{l}\text { Protein gene } \\
\text { product } 9.5\end{array}\end{array}$ & $\begin{array}{l}\text { Monoclonal } \\
\begin{array}{l}\text { Tyrosine } \\
\text { hydroxylase }\end{array}\end{array}$ & $\begin{array}{l}\text { Neurofilament protein } \\
\text { Nerve endings }\end{array}$ & $\begin{array}{l}\text { Euro-Diagnostics } \\
\text { Ultraclone }\end{array}$ \\
$\begin{array}{l}\text { Polyclonal } \\
\text { Neuropeptide }\end{array}$ & Polyclonal & Nerve endings & Chemicon \\
\hline
\end{tabular}

Results

Control Vessels

Control, non-diseased human saphenous veins containing sympathetic nerves, were positive for S100, PGP-9.5, and TH. S100 and PGP-9.5 positive nerve bundles were present in the adventitia (figure 6.1a, b), but not in the media or intima. TH (figure 6.1c) stained nerve endings around small blood vessels in the adventitia. No S100, PGP-9.5 or TH positive fibers were found in the media and intima. NF or NPY positive nerve fibers could not be found, neither in the adventitia, nor in the media or intima.

\section{Peripheral Vein Grafts and AV-Shunts}

S100, PGP-9.5, and TH positive nerves were also found in peripheral bypass grafts, especially in the adventitia. S100 and PGP-9.5 positive nerve bundles were present in the adventitia (figure 6.1d, e), but not in the media or intima. TH (figure 6.1f) stained nerve endings around small blood vessels in the adventitia. No S100. PGP-9.5, or TH positive fibers were found in the media and intima. NF or NPY positive nerve fibers could not be found, neither in the adventitia, nor in the media or the intima. The innervation pattern of AV-shunts was identical to that observed in the peripheral vein grafts. Thus, sympathetic nerves were only found in the adventitia. Large bundles were $S 100$ and PGP-9.5 positive, while small fibers that were present around small blood vessels were positive for $\mathrm{TH}$ (data not shown). 

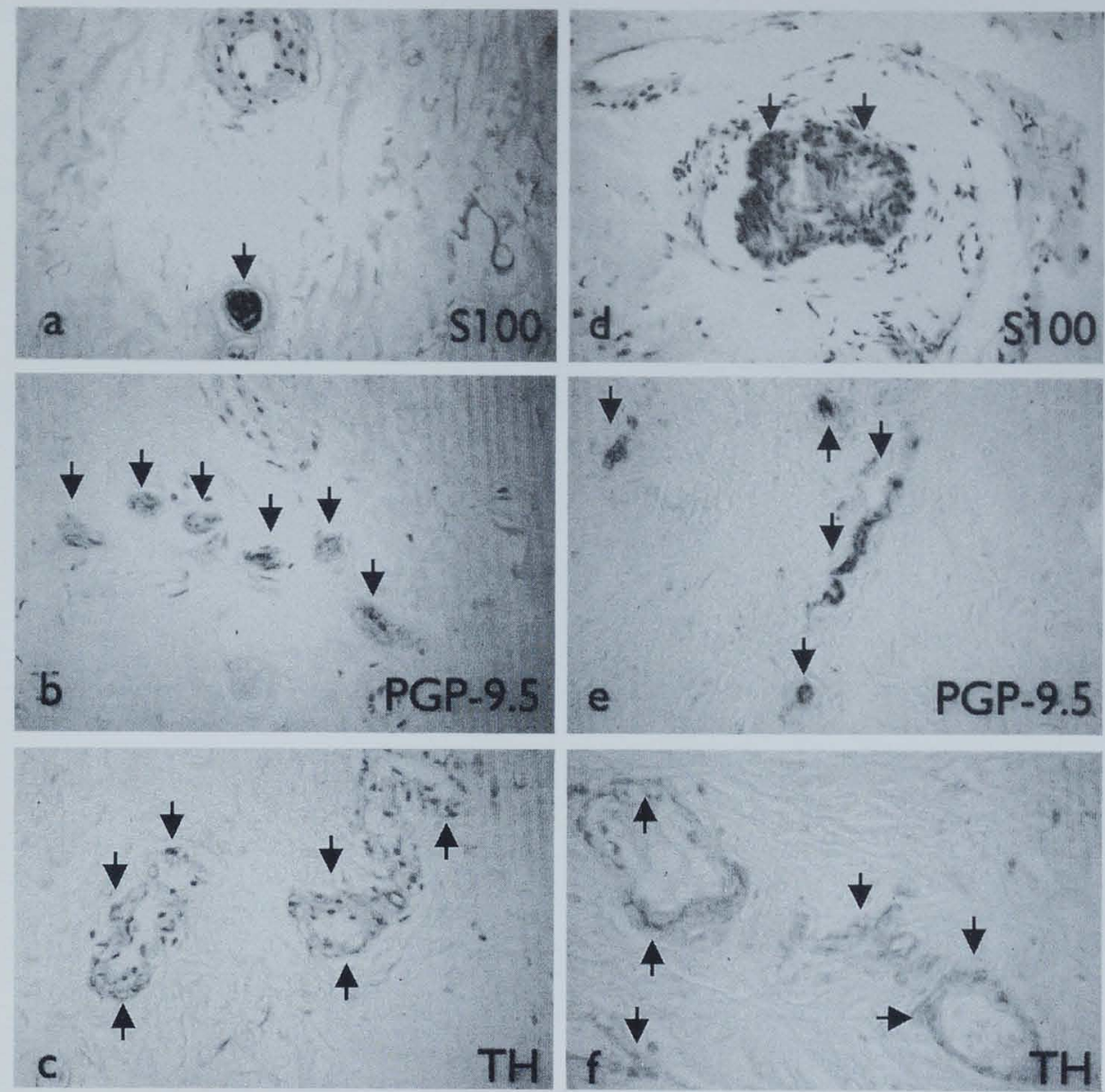

Figure 6.1 Photomicrographs of Non-Diseased Human Saphenous Veins (a-c) and Human Peripheral Bypass Grafts (d-f). Sections stained with antisera to $S 100(a, d)$, PGP-9.5 (b, e) or TH (c, f). Haematoxylin counterstain, magnification $\times 400$. Arrowheads indicate positivity

\section{Discussion}

In this study we have investigated whether the sympathetic nervous system may play a role in the control of intimal growth in human vascular stenotic tissues by staining human vascular stenotic tissue and control vessels with a panel of innervation markers. The data show that the innervation pattern of control human saphenous veins, peripheral bypass grafts and AV-fistula shows remarkable similarities. In the adventitia, relative large nerve fibers positive for $\mathrm{S} 100$ and PGP-9.5 are present as well as small TH positive nerve fibers around small vessels. Nerve fibers positive for NF or NPY were not found. Also, the media and intima was devoid of markers of sympathetic nerves, suggesting that sympathetic nerves do not play a major role in the regulation of intimal growth in vein grafts and $\mathrm{AV}$-shunts.

Amenta et al.(Amenta et al., 1983) were able to show, using glyoxylic acid histofluorescence and acetylcholinesterase histochemistry in specimens of the non- 
diseased human saphenous vein, a dual catecholamine and cholinergic innervation, that was organized in a plexus network at the adventitia-media border. Interestingly, no fibers were found in the media.(Amenta et al., 1983) In addition, peptidergic innervation of the human saphenous vein could be demonstrated by immunohistochemistry. Herbst et al.(Herbst et al., 1992) were able to show, in resected human saphenous vein, that the peptidergic fibers were organized along the vasa vasorum, whereas no immunoreactivity of neuronal fibers was found in the inner layers of the tunica media or in the intima.(Herbst et al., 1992) The present immunohistochemical study confirms the results obtained by Amenta and Herbst and shows that this pattern does not change in specimens of stenosed saphenous vein grafts and AV-shunts.

During the vein graft procedure sympathetic nerves in blood vessels are damaged by clamping or by removing of superficial connective tissue from the vessel wall.(Cowen et al., 1982) This renders the vessels denervated.(Holme et al., 1990) Studies, using the anterior chamber of the eye as an experimental model for studies on adrenergic nerve regeneration,(Todd, 1986) have shown that tissue transplants taken from organs normally without adrenergic innervation fail to become adrenergically innervated, whereas transplants taken from normally richly adrenergically innervated structures will become reinnervated. Hence, adrenergic nerves do possess the ability to regenerate.(Waris et al., 1984)

From animal studies it became clear that surgical denervation and 6-OHDA induced an increase in SMC size and ultrastructural changes compatible with increased synthetic activity.(Fronek et al., 1978; Branco et al., 1984; Bevan and Tsuru, 1981; Dimitriadou et al., 1988) Furthermore, a study in rabbits shows that intimal thickening in the carotid artery was associated with degeneration of the perivascular network, (Scott et al., 1992) whereas $\alpha_{1}$-adrenoceptors are present in the intima after balloon injury of the rat carotid artery (chapter 4). Thus, one may hypothesize that loss of sympathetic innervation may trigger intimal growth. This might also explain why patency rates of innervated internal mammary artery grafts(He et al., 1993) are better compared to denervated saphenous vein grafts.(Holme et al., 1990; Zeff et al., 1988; Pragliola et al., 1994; Gibson and Loop, 1986)

The data presented here, however, do not support a major role of sympathetic nerves in the regulation of intimal growth in human vein graft, since the intima and media lack sympathetic nerves, whereas the pattern of sympathetic innervation in the adventitia of stenosed grafts is identical to that found in control, undiseased saphenous veins. 



\section{CHAPTER 7}

General Discussion 


\section{1 introduction}

In this thesis we have further elucidated the role of Angll in neointima formation after balloon catheter induced injury of the rat carotid artery and the role of the sympathetic nervous system herein. By now it is quite evident that the Angll-induced responses in the media and the neointima after a balloon catheter induced injury of the rat carotid artery are differentially regulated (table 7.1). The findings that the Angll-induced increase in neointimal SMC DNA synthesis could not be blocked by $\alpha_{1}$-adrenoceptor antagonists and that direct stimulation of the $\alpha_{1}$-adrenoceptor with phenylephrine did not result in an increase in neointimal SMC DNA synthesis after injury are exactly opposite of the situation in the media. In the media the Angll-induced increase in SMC DNA synthesis can be blocked by an $\alpha_{1}$-adrenoceptor antagonist and phenylephrine increases medial SMC DNA synthesis (table 7.1). The studies described in this thesis were designed to further dissect the mechanisms of this differential responses of the media and neointima. We hypothesized that the differential responses of the media and the neointima to $\alpha_{1}$ adrenoceptor blockade/stimulation are due to differences in sympathetic innervation and/or differences in the presence of $\alpha_{1}$-adrenoceptor subtypes. Furthermore, we hypothesized that the neurogenic release of norepinephrine in the vasculature is under the control of Angll and the norepinephrine transporter and that Angll increases the systemic (humoral) release of (nor)epinephrine from the adrenal medulla and that this vascular NET is differentially upregulated in the media and neointima.

Table 7.1 Effect of Angli, AT,-R antagonist and $\alpha_{1}$-Adrenoceptor Agonist/Antagonist on SMC DNA synthesis

\begin{tabular}{lccl}
\hline Infusion & Injured neointima & Uninjured media & Reference \\
\hline Angll & $\uparrow \uparrow$ & $\uparrow$ & (Daemen et al., 1991) \\
Angll $+\mathrm{AT}_{1}$-receptor & $=$ & $=$ & (van Kleef et al., 1996b) \\
antagonist & $=$ & $\uparrow$ & (deBlois et al., 1996a) \\
$\alpha_{1}$-agonist & $\uparrow$ & $=$ & (van Kleef et al., 1996a) \\
Angll $+\alpha_{1}$-antagonist & & &
\end{tabular}

Table shows changes in SMC DNA synthesis in the injured neointima and uninjured media of the rat carotid artery. $\uparrow$ indicates increase; $=$ indicates no change compared to the correct control

\subsection{The Media}

\subsubsection{Role For $\alpha_{1}$-Adrenoceptors and Catecholamines}

The data in chapter 2 show that $\alpha_{1}$-adrenoceptor mRNAs of at least two subtypes are present in the media of uninjured rat carotid arteries which is supported by findings that the rat carotid media is sensitive to $\alpha_{1}$-adrenoceptor stimulation(deBlois et al., 1996a) and blockade.(van Kleef et al., 1996a) Furthermore, the data in chapter 3 show that the transcription of the NET gene is upregulated several hours after the start of Angll infusions which confirms our hypothesis that Angll regulates the NET in the vascular wall.

\subsubsection{Neurogenic or Systemic?}

The data in chapters 4 and 5 furthermore show that the Angll-induced medial SMC replication is sensitive to chemical sympathectomy by 6-OHDA and that the medial response to Angll is not influenced by removal of the adrenal medulla. This implies that the Angll-induced SMC replication is stimulated by norepinephrine released from the sympathetic nerve endings which are able to bind and stimulate the $\alpha_{1}$-adrenoceptors 
located on the SMC. Furthermore it implies that there is no important contribution of humoral derived catecholamines in this response (figure 7.1).

Peripheral Vein Grafts and AV-Shunts

S100, PGP-9.5, and TH positive nerves were also found in peripheral bypass grafts, especially in the adventitia. $\$ 100$ and PGP-9.5 positive nerve bundles were present in the adventitia (figure $6.1 \mathrm{~d}, \mathrm{e}$ ), but not in the media or intima. TH (figure 6.1f) stained nerve endings around small blood vessels in the adventitia. No S100, PGP-9.5, or TH positive fibers were found in the media and intima. NF or NPY positive nerve fibers could not be found, neither in the adventitia, nor in the media or the intima. The innervation pattern of AV-shunts was identical to that observed in the peripheral vein grafts. Thus, sympathetic nerves were only found in the adventitia. Large bundles were S100 and PGP-9.5 positive, while small fibers that were present around small blood vessels were positive for TH (data not shown).

\subsection{The Neointima}

\subsubsection{Role For $\alpha_{1}$-Adrenoceptors and Catecholamines}

The data presented in chapters 2 and 3 show that in the neointima formed after balloon catheter induced injury of the rat carotid artery i) the number of $\alpha_{1}$-adrenoceptors decreases, ii) there is no apparent shift in $\alpha_{1}$-adrenoceptor subtypes and iii) Angll increases the NET mRNA.

From that data it can be concluded that the relative insensitivity of the rat carotid artery neointima to $\alpha_{1}$-adrenoceptor stimulation(deBlois et al., 1996a) and blockade(van Kleef et al., 1996a) is not due to an absence of $\alpha_{1}$-adrenoceptors in the neointima, not due to a subtype switch, but may be due to a lack of a sufficient amount of $\alpha_{1}$-adrenoceptors in the neointima. Furthermore, the transcription of the NET gene, which is primarily responsible for the reuptake of released catecholamines into the synaptic nerve endings,(Axelrod, 1971 ) is increased in the injured rat carotid artery within hours after Angll infusion. This suggests that norepinephrine released from the sympathetic nerve endings upon Angll stimulation(Starke, 1977; Zimmerman, 1978) is rapidly removed to prevent further stimulation of $\alpha_{1}$-adrenoceptors in the neointimal SMCs.

\subsubsection{Neurogenic or Systemic?}

The data in chapters 4 and 5 furthermore show i) that the Angll-induced increase in neointimal SMC replication after balloon catheter induced injury of the rat carotid artery is insensitive to sympathetic denervation and ii) that the Angll-induced increase in neointimal growth response is insensitive to bilateral adrenal demedullectomy.

From these data it can be concluded that the release of adrenal medulla derived catecholamines, which is also stimulated by Angll(Feldberg and Lewis, 1964) and not affected by chemical sympathetic denervation,(Mueller et al., 1969) does not overrule the effect of sympathetic denervation on SMC replication (figure 7.1). 

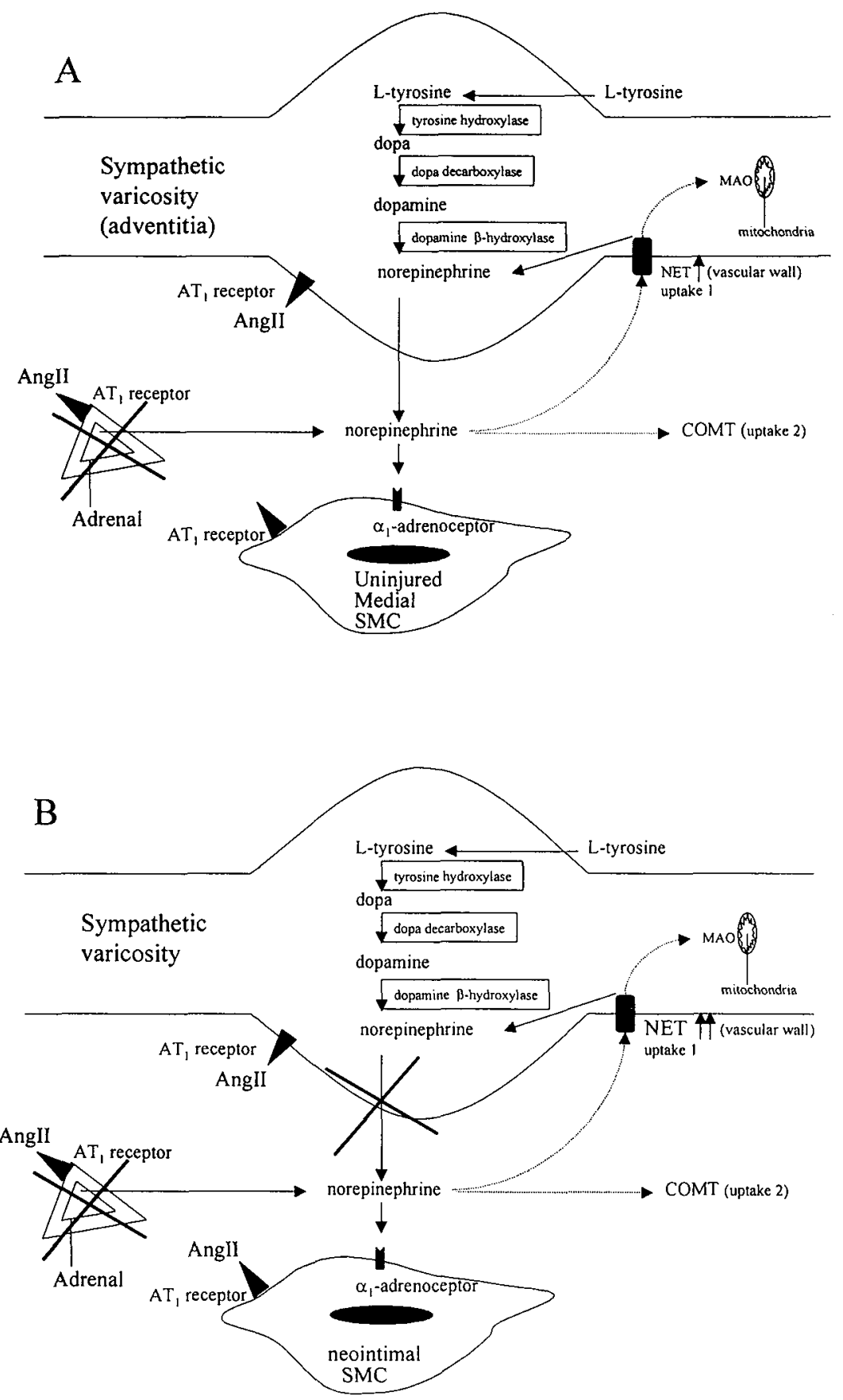

Figure 7.1 Proposed mechanisms of Angll-induced increase in SMC growth in the uninjured media (A) and the neointima $(B)$ after a balloon catheter induced injury of the rat carotid artery with regard to the SNS. $X$ indicates non-contributing pathway. 


\subsection{Presence of $\alpha_{1}$-Adrenoceptors}

Thus, the relative insensitivity of rat carotid artery growth responses to $\alpha_{1}$-adrenoceptor stimulation and blockade is not due to an absence of $\alpha_{1}$-adrenoceptors in the neointima, not due to a subtype switch, but may be due to a decrease in the total amount of $\alpha_{1}$ adrenoceptors present in the injured rat carotid artery as compared to the uninjured rat carotid artery. However, it is not clear why the density of $\alpha_{1}$-adrenoceptors is decreased after injury. One possible explanation may be the increased exposure of the vessel to neurogenic and circulating catecholamines after balloon injury that may downregulate $\alpha_{1}-$ adrenoceptors. Indirect evidence for this possibility is provided in the rabbit iliac artery injury model where the increase in local facilitation of adrenergic neurotransmission after injury resulted in decreased contractile responses to exogenous catecholamines.(Candipan et al., 1994) However, $\alpha_{1}$-adrenoceptors have been reported to be rather resistant to homologous downregulation,(Colucci et al., 1981) i.e. downregulation of $\alpha_{1}$-adrenoceptors to an increased catecholamine release by Angll. Other possibilities include heterologous downregulation of $\alpha_{1}$-adrenoceptors as a result of increased intra-arterial levels of Angll,(Clements and Faber, 1997) i.e. downregulation of $\alpha_{1}$-adrenoceptors by an upregulation of AT, receptors.

\subsection{Proposed Mechanisms of Angll-Induced Increase in SMC Growth of the Rat Carotid Artery}

Thus our working hypothesis is that in the uninjured media of the rat carotid artery, Angll stimulates the AT, receptors located on the sympathetic nerve endings and facilitates the release of norepinephrine (figure 7.1a). The released norepinephrine can either stimulate $\alpha_{1}$-adrenoceptors mediated processes in the SMC, be taken up in the sympathetic nerves via the NET (uptake 1) or taken up in extraneuronally organs and degraded by COMT and MAO (uptake 2). There is no involvement of the adrenal medulla in this response.

In the neointima of the injured rat carotid artery, however, neither norepinephrine released from the SNS, nor catecholamines released from the adrenal medulla are involved in the Angll-induced response (figure 7.1b). On the contrary, NET gene transcription is increased by Angll which indicates that even if norepinephrine is released into the synaptic cleft it will be rapidly removed by the NET. Direct activation of the AT, receptors by Angll is most likely the mechanism by which DNA synthesis is increased in the neointima of injured rat carotid artery (figure 7.1B),(van Kleef et al., 1996b) whereas indirect activation of the $\alpha_{1}$-adrenoceptors by Angll seems to be the mechanism via which DNA synthesis is increased in the media of uninjured rat carotid artery (chapter 4).

\subsection{Neointimal Innervation in Humans}

All the animal experiments discussed hitherto show that innervation does not seem to be important in the development of a neointima in the rat common carotid artery after injury. Alternatively, it might be that this lack of innervation contributes to the development of intimal hyperplasia. Prior to grafting human saphenous veins are cut and stripped of their adventitia which renders them denervated.(Waris et al., 1984; Meagher et al., 1984) Interestingly, replacement or bypass of sections of human diseased arteries with denervated autologous vein segments have low patency rates(Swedberg et al., 1989; Sottiurai, 1990) which may suggest that lack of innervation may contribute to intimal hyperplasia. However, immunohistochemical data presented in chapter 6 do not support this hypothesis since the pattern of sympathetic innervation in the adventitia of stenosed grafts is identical to that found in the control, undiseased autologous vein segments prior to grafting. No staining could be detected in the neointima of all vessels studied. These data leaves us to believe that innervation is not a necessity for neointima formation after 
injury. Alternatively one may conclude that the lack of sympathetic innervation may reduce neointima formation.

\subsection{Cross-talk Between Receptors}

As mentioned previously, direct activation of the AT, receptors by Angll is most likely the mechanism by which DNA synthesis is increased in the neointima of injured rat carotid artery (figure 7.1B), (van Kleef et al., 1996b) whereas indirect activation of the $\alpha_{1^{-}}$ adrenoceptors by Angll seems to be the mechanism via which DNA synthesis is increased in the media of the uninjured rat carotid artery (chapter 4). Remarkably, the signal transduction pathways of both receptors are very similar, which opens the possibility of cross-talk between the AT 1 - and the $\alpha_{1}$-adrenoceptor.

Both the $\alpha_{1}$-adrenoceptors and the $A T_{1}$ receptors are members of the 7transmembrane spanning domain group of receptors which produce intracellular changes through their coupling to guanine nucleotide-binding regulatory proteins. The $\mathrm{G}$ protein consists of 3 subunits, $\alpha, \beta$ and $\gamma$. Receptor activation causes replacement of the GDP bound to the $\alpha$-subunit with GTP and the dissociation of G $\alpha$ from G $\beta \gamma$ (figure 7.2). The potential complexity of the signaling mechanisms is increased by the finding of at least $16 \mathrm{G} \alpha$ subunits, $5 \mathrm{G} \beta$ subunits and $11 \mathrm{G} \gamma$ subunits. While many $\alpha_{1}$-adrenoceptors and $A T_{1}$ receptors have been reported to couple to phospholipase $C$, additional intracellular signaling effectors have been described including phospholipase $D$, and activation of $\mathrm{Ca}^{2+}$ and $\mathrm{K}^{+}$channels. In addition there are many different forms of DAG including the production of polyunsaturated 1,2-diacylglycerols by $\mathrm{PiP}_{2}$ specific phospholipase $\mathrm{C}$ and mono-unsaturated and saturated phosphatidates by the breakdown of phosphatidylcholine by phospholipase $\mathrm{D}$.

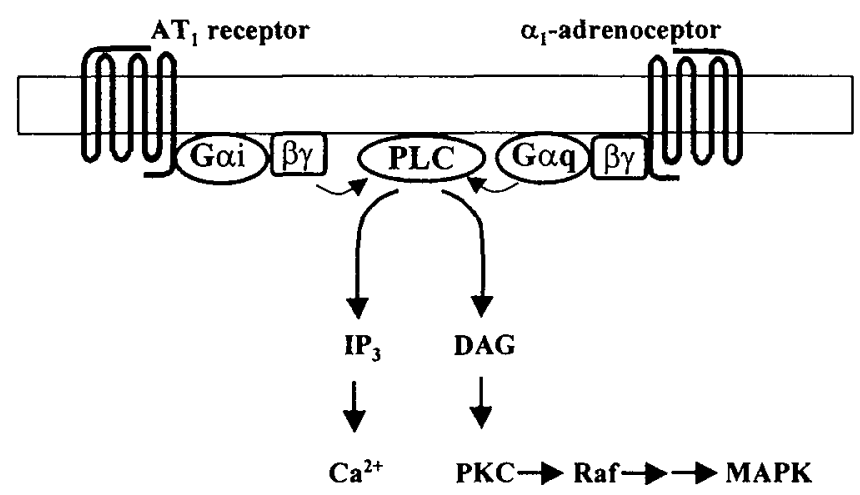

Figure 7.2 Activated $G_{i}$ and $G_{q}$ coupled receptors stimulate $P L C$ to release $\mathbb{P}_{3}$ and $D A G$, which cause the release of intracellular $\mathrm{Ca}^{2+}$ and activate $P K C$, respectively. Co-stimulation of $G_{i}-$ and $G_{q}$ coupled receptors could result in augmentation of PLC and PKC activity.(Selbie et al., 1995)

A model for cross-talk of two $\mathrm{G}$ protein coupled receptors requires in the simplest sense that the signal transduction of one receptor can be modified by that of the other receptor (figure 7.2). $\mathrm{G}_{\mathrm{i}^{-}}$(AT, receptor) and $\mathrm{G}_{\mathrm{q}^{-}}\left(\alpha_{1}\right.$-adrenoceptor) coupled receptors have been shown to stimulate MAPK activity, as well as other kinases, leading to changes in gene expression.(Vanbiesen et al., 1996; Okuda et al., 1996) In the case of $\mathrm{G}_{i}$ coupled effects on $\mathrm{G}_{\mathrm{q}}$ coupled receptor stimulated smooth muscle proliferation, receptor costimulation could result in augmentation of intracellular events that precede and/or modulate the final response. In studies using tissue preparations, stable cell lines and 
cells transfected with different $G$ protein coupled receptors, $G_{i}$ coupled receptor stimulation results in augmentation of $\mathrm{G}_{\mathrm{c}}$ coupled receptor mediated PLC activity and PKC activity.(Selbie et al., 1995) However, Angll induced medial SMC DNA synthesis could not only be inhibited by 6-OHDA (chapter 4) but also by the AT, receptor antagonist losartan.(van Kleef et al., 1996b) Both receptor ligands can stimulate growth in the uninjured rat carotid artery and therefore cross-talk is not a necessity, but cannot be ruled out. Not only cross-talk but also cooperatitivity, i.e. the same signal transcuuction pathway (e.g. $G_{q}$ coupled) can be activated by different receptors, between the $A T_{1}$ - and the $\alpha_{1}$ adrenoceptor is possible, since $A T_{1}$ receptors in uninjured medial SMCs are not only coupled to $\mathrm{G}_{\mathrm{i}}$ - but also to $\mathrm{G}_{\mathrm{q}}$ proteins.(Schmitz and Berk, 1997) However cooperatitivity seems unlikely, since the Angll-induced increase in the SMC DNA synthesis in the uninjured media is blocked both by an AT $T_{1}$ receptor antagonist and an $\alpha_{1}$-adrenoceptor antagonist (table 7.1). Furthermore, it seems that there is no need for cross-talk or cooperatitivity in the injured neointima since the Angll-induced effect on the neointima is insensitive for the blockade of $\alpha_{1}$-adrenoceptor mediated signal transduction pathway which seems to be lacking from the injured neointimal SMCs.

In conclusion, there are several different signal transduction pathways associated with $\alpha_{1}$-adrenoceptor subtypes in cells and tissues. One subtype does not couple uniquely to one transduction pathway and the determining factors are more likely to be tissue dependent in terms of the availability of particular $G$ proteins and effector enzymes. In some cells $\alpha_{1}$-adrenoceptors may couple to more than one pathway to produce a variety of responses. Measurement of a change in a second messenger does not necessarily imply that this is involved in mediating the observed response. Furthermore, there are different time scales of response following activation of $\alpha_{1}$-adrenoceptors; short term changes in e.g. vascular resistance and longer term increases in cell growth in the heart and vasculature. Cross-talk and cooperatitivity between receptors further complexes the signal transduction networks and renders the outcome of interventions in these signal transduction networks less certain.

\subsection{Limitations of the Study}

In this thesis we have used the balloon catheter induced injury model to study the differential effects of Angll on the media and neointima formation in the rat carotid artery. The rat carotid artery has provided perhaps the most widely used experimental preparation for the study of the response to acute injury.(Clowes et al., 1989) However, there were some unforeseen difficulties during the course of the studies and some insights which we had not anticipated.

\subsubsection{Proliferation and Apoptosis}

In all but one study, we have used male Wistar rats. With the Wistar rats we encountered rather tedious problems in trying to visualize the $\mathrm{BrdU}$. The $\mathrm{BrdU}$ concentration used was $30 \mathrm{mg} / \mathrm{ml}$ and was infused at a rate of $714 \mathrm{ng} / \mathrm{kg} / \mathrm{min}$. Although this concentration was sufficient to obtain labeling fractions in the male Wistar-Kyoto rats (chapter 4), no BrdU could be detected in the male Wistar rats (chapter 5). Whether this was due to strain differences or other factors involved is not known.

In recent years it became apparent that not only SMC proliferation but also SMC apoptosis is involved in the pathogenesis of vascular remodeling. Apoptosis is increased in the intima thickening at 15 days after a balloon catheter induced injury in the rat thoracic aorta.(Bochaton-Piallat et al., 1995) In cardiovascular disease, apoptosis of SMCs has been identified in atherosclerotic and restenotic lesions after PTCA.(Kearney et al., 1997; Malik et al., 1998) Many regulatory factors including humoral growth factors, cytokines and matrix components are well characterized in atherosclerotic and restenotic 
lesions.(Schwartz et al., 1995) Characterization of the role of e.g. anti-apoptotic genes in the pathogenesis of vascular diseases may provide a therapeutic opportunity. The induction of apoptosis by balloon injury of the rat carotid artery coincides with a marked downregulation of bcl-x expression.(Perlman et al., 1997) Recently, downregulation of intimal cell $b c /-x$ expression with the use of oligonucleotides induced apoptosis and acute regression of vascular lesions in cholesterol-fed rabbits.(Pollman et al., 1998) Angll antagonizes nitric oxide-induced apoptosis and inhibits apoptosis in vascular SMCs.(Pollman et al., 1996) However, the relative number of BrdU positive nuclei did not change throughout our experimental model (chapter 4), which may suggest that apoptosis does not play an important regulatory role in the Angll mediated neointima formation in the rat carotid artery after injury.

\subsubsection{Norepinephrine Content and Carotid Artery Innervation}

Data in this thesis shows that there seems to be a balance between norepinephrine release stimulated by Angll and reuptake by the NET in blood vessels (chapter 3 ). Plasma levels of norepinephrine do not reflect the amounts locally present in the vessels. Therefore, without knowledge of the exact amount of norepinephrine molecules which reside in the synaptic cleft during Angll infusion, it remains difficult to explain the differences in vascular growth between injured and uninjured vessels with regard to the SNS and the $\alpha_{1}$-adrenoceptors.

. One possible method to detect innervation of naive rat carotid arteries is with glyoxylic acid (data not shown).(Cowen and Burnstock, 1980) We did not evaluate the innervation of the rat carotid artery after balloon catheter induced injury. Furthermore, we were not able to stain the naive and balloon injured rat carotid arteries with the panel of antibodies used to evaluate the innervation of human AV-fistulas and peripheral bypass grafts (chapter 6) due to the lack of cross-reactivity between those human antibodies and the rat tissues. Recently, an antibody against the rat $\alpha_{18}$-adrenoceptor came available.(Piascik et al., 1997) It would be very interesting to see if the mRNA distribution and localization matches that of its protein.

\subsection{Future Outlook}

The findings in this thesis further dissect the role of Angll and the SNS in the regulation of neointimal growth after injury.

First, it has become apparent that neointimal SMCs and medial SMCs behave and react differently to Angll and catecholamine stimulation. It seems therefore imperative to study the effects of therapies in experimental models where a neointima is already formed, since this may alter the outcome.

Second, we expect that sympathetic innervation does not seem to be important in the Angll-induced increase in neointimal growth. Since data, presented in this thesis, also show that the neointima of human vessels is not innervated, we will not propose to use this sympathetic innervation as a potential target for the treatment of neointimal thickening in humans. 


\section{Reference List}

Abel, P.W., Zeng, W., Porter, J.E., Scofield, M.A., Liu, F., Gonzalez-Cabrera, I., Dowd, F.J., and Jeffries, W.B. (1995) The atypical $\alpha_{1}$-adrenoceptor. Pharmacology Communications 6, 2938.

Ahlquist, R.P. (1948) A study of the adrenotropic receptors. Am.J.Physiol. 153, 586-600.

Alexander, R.W., Brock, T.A., Gimbrone, M.A., and Rittenhouse, S.E. (1985) Angiotensin increases inositol triphosphate and calcium in vascular smooth muscle. Hypertension 7, 447-451.

Alonso-Llamazares, A., Zamanillo, D., Casanova, E., Ovalle, S., Calvo, P., and Chinchetru, M.A. (1995) Molecular cloning of $\alpha_{1 d}$-adrenergic receptor and tissue distribution of three $\alpha_{1}$ adrenergic receptor subtypes in mouse. J.Neurochem. 65, 2387-2392.

Amenta, F., Cavallotti, C., Dotta, F., Ferrante, F., Spinelli, F., and Vatrella, F. (1983) The autonomic innervation of the human saphenous vein. Acta. Histochem. 72, 111-116.

Andersen, H.R., Mæng, M.S., Thorwest, M., and Falk, E. (1996) Remodeling rather than neointimal formation explains luminal narrowing after deep vessel wall injury. Circulation 93, 17161724.

Aprigliano, O. and Hermsmeyer, K. (1976) In vitro denervation of the portal vein and caudal artery of the rat. J.Pharmacol.Exp.Ther. 198, 568-577.

Aprigliano, O. and Hermsmeyer, K. (1977) Trophic influence of the sympathetic nervous system on the rat portal vein. Circ. Res. 41, 198-206.

Axelrod, J. (1971) Noradrenaline: fate and control of its biosynthesis. Science 173, 598-606.

Bell, L. and Madri, J. (1990) Influence of the angiotensin system on endothelial and smooth muscle cell migration. Am.J.Pathol. 137, 7-12.

Benowitz, L.I. and Perrone-Bizzozero, N.I. (1991) The expression of GAP-43 in relation to neuronal growth and plasticity: when, where, how, and why? Prog.Brain Res. 89, 69-87.

Berk, B.C., Vekstein, V., Gordon, H.M., and Tsuda, T. (1989) Angiotensin Il-stimulated protein synthesis in cultured vascular smooth muscle cells. Hypertension 13, 305-314.

Berk, B.C. and Corson, M.A. (1997) Angiotensin II signal transduction in vascular smooth muscle. Role of tyrosine kinases. Circ. Res. 80, 607-616.

Berridge, M.J. (1993) Inositol trisphosphate and calcium signalling. Nature 361, 315-325.

Bevan, J.A. (1981) A comparison of the contractile responses of the rabbit basilar and pulmonary arteries to sympathomimetic agonists: further evidence for variation in vascular adrenoceptor characteristics. J.Pharmacol.Exp.Ther. 216, 83-89.

Bevan, R.D. (1975) Effect of sympathetic denervation on smooth muscle cell proliferation in the growing rabbit ear artery. Circ. Res. 37, 14-19.

Bevan, R.D. and Tsuru, H. (1981) Functional and structural changes in the rabbit ear artery after sympathetic denervation. Circ.Res. 49, 478-485.

Bevan, R.D. (1984) Trophic effects of peripheral adrenergic nerves on vascular structure. Hypertension 6, III19-III26

Biron, P., Koiw, E., and Nowaczynski, W. (1961) The effects of intravenous infusions of valine-5 angiotensin $I I$ and other pressor agents on urinary electrolytes and corticoids including aldosterone. J.Clin.Invest. 60, 338-347.

Blaes, N. and Boisell, J.P. (1983) Growth-stimulating effect of catecholamines on rat aortic smooth muscle cells in culture. J.Cell.Physiol. 116, 167-172.

Blank, J.L., Brattain, K.A., and Exton, J.H. (1992) Activation of cytosolic phosphoinositide phospholipase C by G-protein By subunits. J.Biol.Chem. 267, 23069-23075.

Bochaton-Piallat, M., Gabbiani, F., Redard, M., Desmoulière, A., and Gabbiani, G. (1995) Apoptosis participates in cellularity regulation during rat aortic intimal thickening. Am. J. Pathol. 146, 1059-1064.

Borkowski, K.R. and Quinn, P. (1983) The effect of bilateral adrenal demedullation on vascular reactivity and blood pressure in spontaneously hypertensive rats. Br.J.Pharmacol, 80, 429437.

Borowsky, B. and Hoffman, B.J. (1995) Neurotransmitter transporters: molecular biology, function, and regulation. Int.Rev. Neurobiol. 38, 139-199.

Bradford, M.M. (1976) A rapid and sensitive method for the quantitation of microgram quantities of protein utilizing the principle of protein-dye binding. Anal.Biochem. 72, 248-254. 
Branco, D., Teixeira, A.A., Azevedo, I., and Osswald, W. (1984) Structural and functional alterations caused at the extraneuronal level by sympathetic denervation of blood vessels. NaunynSchmiedeberg's Arch.Pharmacol. 326, 302-312.

Brock, T.A., Rittenhouse, S.E., Powers, C.W., Ekstein, L.S., Gimbrone, M.A., and Alexander, R.W. (1985) Phorbol ester and 1-oleoyl-2-acetylglycerol inhibit angiotensin activation of phospholipase $C$ in cultured vascular smooth muscle cells. J.Biol.Chem. 260, 14158-14162.

Brown, G.L. and Gillespie, J.S. (1957) The output of sympathetic transmitter from the spleen of the cat. J.Physiol. 138, 81-102.

Brown, N.J. and Vaughan, D.E. (1998) Angiotensin-converting enzyme inhibitors. Circulation 97 , 1411-1420.

Brüss, M., Kunz, J., Lingen, B., and Bönisch, H. (1993) Chromosomal mapping of the human gene for the tricyclic antidepressant- sensitive noradrenaline transporter. Hum.Genet. 91, 278280.

Brüss, M., Hammermann, R., Brimijoin, S., and Bönisch, H. (1995) Antipeptide antibodies confirm the topology of the human norepinephrine transporter. J.Biol.Chem. 270, 9197-9201.

Butcher, R.D., Schollmann, C., and Marme, D. (1993) Angiotensin II mediates intracellular signalling in vascular smooth muscle cells by activation of tyrosine-specific protein kinases and c-raf- 1 . Biochem.Biophys.Res. Commun. 196, 1280-1287.

Buth, J., Disselhof, B., Sommeling, C., and Stam, L. (1991) Color-flow duplex criteria for grading stenosis in infrainguinal vein grafts. J.Vasc. Surg. 14, 716-728.

Buxton, I.L. and Brunton, L.L. (1985) Action of the cardiac $\alpha_{1}$-adrenergic receptor: activation of cyclic AMP degradation. J.Biol.Chem. 260, 6733-6738.

Campbell, B.M. and Robertson, A.L.J. (1981) Effects of angiotensin II and vasopressin on human smooth muscle cells in vitro. Exp.Mol.Pathol. 35, 265-276.

Candipan, R.C., Hsiun, P.T., Pratt, R., and Cooke, J.P. (1994) Vascular injury augments adrenergic neurotransmission. Circulation 89, 777-784.

Carlos, T.M. and Harlan, J.M. (1990) Membrane proteins involved in phagocyte adherence to endothelium. Immunol Rev. 114, 5-28.

Castellot, J.J.J., Favreau, L.V., Karnovsky, M.J., and Rosenberg, R.D. (1982) Inhibition of vascular smooth muscle cell growth by endothelial cell- derived heparin. Possible role of a platelet endoglycosidase. J.Biol.Chem. 257, 11256-11260.

Chen, L.Q., Xin, X., Eckhart, A.D., Yang, N., and Faber, J.E. (1995) Regulation of vascular smooth muscle growth by $\alpha_{1}$-adrenoceptor subtypes in vitro and in situ. J.Biol.Chem. 270,3098030988.

Chidiac, P. (1998) Rethinking receptor-G protein-effector interactions. Biochem.Pharmacol. 55, 549556 .

Clements, M.L. and Faber, J.E. (1997) Mechanical load opposes angiotensin-mediated decrease in vascular $\alpha_{1}$-adrenoceptors. Hypertension 29, 1165-1172.

Clowes, A.W., Reidy, M.A., and Clowes, M.M. (1983a) Kinetics of cellular proliferation after arterial injury. I. Smooth muscle growth in the absence of endothelium. Lab.Invest. 49, 327-333.

Clowes, A.W., Reidy, M.A., and Clowes, M.M. (1983b) Mechanisms of stenosis after arterial injury. Lab.Invest. 49, 208-215.

Clowes, A.W. and Clowes, M.M. (1985) Kinetics of cellular proliferation after arterial injury. II. Inhibition of smooth muscle growth by heparin. Lab.Invest. 52, 611-616.

Clowes, A.W. and Schwartz, S.M. (1985) Significance of quiescent smooth muscle migration in the injured rat carotid artery. Circ.Res. 56, 139-145.

Clowes, A.W. Clowes, M.M., and Reidy, M.A. (1986) Kinetics of cellular proliferation after arterial injury. III. Endothelial and smooth muscle growth in chronically denuded vessels. Lab.Invest. 54, 295-303.

Clowes, A.W., Clowes, M.M., Fingerle, J., and Reidy, M.A. (1989) Regulation of smooth muscle cell growth in injured artery. J.Cardiovasc.Pharmacol. 14 (Suppl. 6), S12-S15

Colucci, W.S., Gimbrone, M.A., and Alexander, R.W. (1981) Regulation of the postsynaptic $\alpha-$ adrenergic receptor in rat mesenteric artery. Circ.Res. 48, 104-111.

Colucci, W.S., Brock, T.A., Grimbone, M.A., and Alexander, R.W. (1985) Non-linear relationship between $\alpha_{1}$-adrenergic receptor occupation and norepinephrine-stimulated calcium flux in cultured vascular smooth muscle cells. Mol.Pharmacol. 27, 517-524. 
Cotecchia, S., Schwinn, D.A., Randall, R.R., Lefkowitz, R.J., Caron, M.G., and Kobilka, B.K. (1988) Molecular cloning and expression of the cDNA for the hamster $\alpha_{1}$-adrenergic receptor. Proc.Natl.Acad.Sci.USA. 85, 7159-7163.

Cowen, T. and Burnstock, G. (1980) Quantitative analysis of the density and pattern of adrenergic innervation of blood vessels. Histochemistry 66, 19-34.

Cowen, T., MacCormick, D.E.M., Toff, W.D., Burnstock, G., and Lumley, J.S.P. (1982) The effect of surgical procedures on blood vessels innervation. A fluorescence histochemical study of degeneration and regrowth of perivascular adrenergic nerves. Blood Vessels 19, 65-78.

Cubells, J.F., Kim, K.S., Baker, H., Volpe, B.T., Chung, Y., Houpt, T.A., Wessel, T.C., and Joh, T.H. (1995a) Differential in vivo regulation of mRNA encoding the norepinephrine transporter and tyrosine hydroxylase in rat adrenal medulla and locus ceruleus. J.Neurochem. 65, 502-509.

Cubells, J.F., Baker, H., Volpe, B.T., Smith, G.P., Das, S.S., and Joh, T.H. (1995b) Innervationindependent changes in the mRNAs encoding tyrosine hydroxylase and the norepinephrine transporter in rat adrenal medulla after high-dose reserpine. Neurosci.Lett. 193, 189-192.

Daemen, M.J., Lombardi, D.M., Bosman, F.T., and Schwartz, S.M. (1991) Angiotensin II induces smooth muscle cell proliferation in the normal and injured rat arterial wall. Circ. Res. 68, 450456.

Daemen, M.J. and De Mey, J.G. (1995) Regional heterogeneity of arterial structural changes . Hypertension 25, 464-473.

de Champlain, J. and van Ameringen, M.R. (1975) Adrenergic mechanisms and the aetiology of hypertension. In: Central action of drugs in blood pressure regulation, 68-92. Edited by Davies, D.S., Pitman Medical, Kent.

de Gasparo, M., Husain, A., Alexander, W., Catt, K.J., Chiu, A.T., Drew, M., Goodfriend, T., Harding, J.W., Inagami, T., and Timmermans, P.B. (1995) Proposed update of angiotensin receptor nomenclature. Hypertension 25, 924-927.

De Meyer, G.R.Y., Van Put, D.J.M., Kockx, M.M., Van Schil, P., Bosmans, R., Bult, H., Buyssens, N., Vanmaele, R., and Herman, A.G. (1997) Possible mechanisms of collar-induced intimal thickening. Arterioscler. Thromb.Vasc.Biol. 17, 1924-1930.

deBlois, D., Schwartz, S.M., van Kleef, E.M., Su, J.E., Griffin, K.A., Bidani, A.K., Daemen, M.J.A.P., and Lombardi, D.M. (1996a) Chronic $\alpha_{1}$-adrenoreceptor stimulation increases DNA synthesis in rat arterial wall. Modulation of responsiveness after vascular injury. Arterioscler. Thromb. Vasc.Biol. 16, 1122-1129.

deBlois, D., Viswanathan, M., Su, J.E., Clowes, A.W., Saavedra, J.M., and Schwartz, S.M. (1996b) Smooth muscle DNA replication in response to angiotensin II is regulated differently in the neointima and media at different times after balloon injury in the rat carotid artery. Role of AT1 receptor expression. Arterioscler.Thromb.Vasc.Biol. 16, 1130-1137.

Delafontaine, P. and Lou, H. (1993) Angiotensin II regulates insulin-like growth factor I gene expression in vascular smooth muscle cells. J.Biol.Chem. 268, 16866-16870.

Dilley, R.J., McGeachie, J.K., and Prendergast, F.J. (1988) A review of the histologic changes in vein-to-artery grafts, with particular reference to intimal hyperplasia. Arch.Surg. 123, 691696.

Dimitriadou, V., Aubineau, P., Taxi, J., and Seylaz, J. (1988) Ultrastructural changes in the cerebral artery wall induced by long-term sympathetic denervation. Blood Vessels 25, 122-143.

Dostal, D.E., Booz, G.W., and Baker, K.M. (1996) Angiotensin II signalling pathways in cardiac fibroblasts: conventional versus novel mechanisms in mediating cardiac growth and function. Molecular and cellular biochemistry 157, 15-21.

Drew, G.M. and Whiting, S.B. (1979) Evidence for two distinct types of postsynaptic $\alpha$-adrenoceptors in vascular smooth muscle in vivo. Br.J.Pharmacol. 67, 207-215.

Dubey, R.K., Jackson, E.K., and Luscher, T.F. (1995) Nitric oxide inhibits angiotensin Il-induced migration of rat aortic smooth muscle cells: role of cyclic nucleotides and angiotensin-I receptors. J.Clin. Invest. 96, 141-149.

Dubocovich, M.L. and Langer, S.Z. (1974) Negative feed-back regulation of noradrenaline release by nerve stimulation in the perfused cat's spleen: differences in potency of phenoxybenzamine in blocking the pre- and post-synaptic adrenergic receptors. J.Physiol.Lond. 237, 505-519.

Dzau, V.J., Gibbons, G.H., and Pratt, R.E. (1991) Molecular mechanisms of vascular reninangiotensin system in myointimal hyperplasia. Hypertension 18, $11100-11105$

Elliott, D.F. and Peart, W.S. (1956) Amino acid sequence of a hypertensin. Nature 177, 527-528. 
Erdos, E.G. (1977) The angiotensin I converting enzyme. Federation Proc. 36, 1760-1765.

Erlinge, D., Yoo, H., Edvinsson, L., Reis, D.J., and Wahlestedt, C. (1993) Mitogenic effects of ATP on vascular smooth muscle cells vs. other growth and sympathetic cotransmitters. Am.J.Physiol. 265, H1089-H1097

Esbenshade, T.A., Han, C., Murphy, J., and Minneman, K.P. (1993) Comparison of $\alpha_{1}$-adrenergic receptor subtypes and signal transduction in SK-N-MC and NB41A3 neuronal cell lines. Mol.Pharmacol. 44, 76-86.

Faure, C., Pimoule, C., Vallancien, G., Langer, S.Z., and Graham, D. (1994) Identification of $\alpha_{1-}$ adrenoceptor subtypes present in the human prostate. Life.Sci. 54, 1595-1605.

Feldberg, W. and Lewis, G.P. (1964) The action of peptides on the adrenal medulla. Release of adrenaline by bradykinin and angiotensin. J.Physiol.Lond. 171, 98-108.

Figlewicz, D.P., Szot, P., Israel, P.A., Payne, C., and Dorsa, D.M. (1993) Insulin reduces norepinephrine transporter mRNA in vivo in rat locus coeruleus. Brain Res. 602, 161-164.

Fingerle, J., Sanders, K.H., and Fotev, Z. (1991) $\alpha_{1}$-Receptor antagonists urapidil and prazosin inhibit neointima formation in rat carotid artery induced by balloon catheter injury. Basic Res.Cardiol. 86 Suppl 1, 75-81.

Folkow, B., Johansson, B., and Mellander, S. (1961) The comparative effects of angiotensin and noradrenaline on consecutive vascular sections. Acta.Physiol.Scand. 53, 99-104.

Ford, A.P.D.W., Williams, T.J., Blue, D.R., and Clarke, D.E. (1994) $\alpha_{1}$-Adrenoceptor classification: sharpening occam's razor. Trends Pharmacol.Sci. 15, 167-170.

Ford, D.A. and Gross, R.W. (1989) Plasmenylethanolamine is the major storage depot for arachidonic acid in rabbit vascular smooth muscle and is rapidly hydrolyzed after Angll stimulation. Proc.Natl.Acad.Sci.USA. 86, 3479-3483.

Forray, C., Bard, J.A., Wetzel, J.M., Chiu, G., Shapiro, E., Tang, R., Lepor, H., Hartig, P.R., Weinshank, R.L., and Branchek, T.A. (1994) The $\alpha_{1}$-adrenergic receptor that mediates smooth muscle contraction in human prostate has the pharmacological properties of the cloned human $\alpha_{1 c}$ subtype. Mol.Pharmacol. 45, 703-708.

Fritze, L.M., Reilly, C.F., and Rosenberg, R.D. (1985) An antiproliferative heparan sulfate species produced by postconfluent smooth muscle cells. J.Cell.Biol. 100, 1041-1049.

Fronek, K., Bloor, C.M., Amiel, D., and Chvapil, M. (1978) Effect of long-term sympathectomy on the arterial wall in rabbits and rats. Exp.Mol.Pathol. 28, 279-289.

Fronek, K. (1983) Trophic effect of the sympathetic nervous system on vascular smooth muscle. Ann.Biomed.Eng. 11, 607-615.

Fuchs, J.C.A., Mitchener, J.S., and Hagen, P.O. (1978) Postoperative changes in autologous vein grafts. Ann.Surg. 188, 1-15

Gabbiani, G., Rungger-Brandle, E., deChastonay, C., and Franke, W.W. (1982) Vimentin-containing smooth muscle cells in aortic intimal thickening after endothelial injury. Lab. Invest. 47, 265269.

Gabbiani, G., Kocher, O., Bloom, W.S., VanDekerckhove, J., and Weber, K. (1984) Actin expression in smooth muscle cells of rat aortic intimal thickening, human atheromatous plaque, and cultured rat aortic media. J.Clin. Invest. 73, 148-152.

Gajdusek, C.M., Carbon, S., Ross, R., Nawroth, P., and Stern, D. (1986) Activation of coagulation releases endothelial cell mitogens. J.Cell.Biol. 103,419-428.

Gajdusek, C.M. and Carbon, S. (1989) Injury-induced release of basic fibroblast growth factor from bovine aortic endothelium. J.Cell.Physiol. 139, 570-579.

Gao, B. and Kunos, G. (1993) Isolation and characterization of the gene encoding the rat $\alpha_{18}$ adrenergic receptor. Gene 131, 243-247.

Gao, B. and Kunos, G. (1994) Transcription of the rat $\alpha_{(1 b)}$ adrenergic receptor gene in liver is controlled by three promoters. J.Biol.Chem. 269, 15762-15767.

Gao, B., Spector, M.S., and Kunos, G. (1995) The rat $\alpha_{18}$-adrenergic receptor gene middle promoter contains multiple binding sites for sequence-specific proteins including a novel ubiquitous transcription factor. J.Biol.Chem. 270, 5614-5619.

Gehlert, D.R., Gackenheimer, S.L., and Schober, D.A. (1991) Autoradiographic localization of subtypes of angiotensin II antagonist binding in the rat brain. Neuroscience 44, 501-514.

Geisterfer, A.A.T., Peach, M.J., and Owens, G.K. (1988) Angiotensin II induces hypertrophy, not hyperplasia, of cultured rat aortic smooth muscle cells. Circ. Res. 62, 749-756. 
Gibbons, G.H., Pratt, R.E., and Dzau, V.J. (1992) Vascular smooth muscle cell hypertrophy vs. hyperplasia. Autocrine transforming growth factor- $\beta_{1}$ expression determines growth response to angiotensin II. J.Clin.Invest. 90, 456-461.

Gibson, C.F. and Loop, F.D. (1986) Choice of internal mammary artery or saphenous vein graft for myocardial revascularization. Cardiology $73,235-241$.

Glagov, S., Weisenberg, E., Zarins, C.K., Stankunavicius, R., and Kolettis, G.J. (1987) Compensatory enlargement of human atherosclerotic coronary arteries. N.Engl.J.Med. 316, 1371-1375.

Glukhova, M.A., Kabakov, A.E., and Frid, M.G. (1988) Modulation of human aortic smooth muscle cell phenotype: A study of muscle-specific variants of vinculin, caldesmon, and actin expression. Proc.Natl.Acad.Sci.USA. 85, 9542-9546.

Glukhova, M.A., Frid, M.G., and Shekhonin, b. (1989) Expression of extra domain A fibronectin sequence in vascular smooth muscle cells is phenotype-dependent. J.Biol.Chem. 109, 357366.

Griendling, K.K., Rittenhouse, S.E., Brock, T.A., Ekstein, L.S., Gimbrone, M.A., and Alexander, R.W. (1986) Sustained diacylglycerol formation from inositol phospholipids in angiotensin Ifstimulated vascular smooth muscle cells. J.Biol.Chem. 261, 5901-5906.

Griendling, K.K., Ushiofukai, M., Lassegue, B., and Alexander, R.W. (1997) Angiotensin II signaling in vascular smooth muscle: new concepts. Hypertension 29, 366-373.

Griffin, S.A., Brown, W.C.B., MacPherson, F., McGrath, J.C., Wilson, V.G., Korsgaard, N., Mulvany, M.J., and Lever, A.F. (1991) Angiotensin II causes vascular hypertrophy in part by a nonpressor mechanism. Hypertension 17, 626-635.

Grotendorst, G.R., Seppa, H.E.J., Kleinman, H.K., and Martin, G.R. (1981) Attachment of smooth muscle cells to collagen and their migration toward platelet-derived growth factor. Proc.Nati.Acad.Sci.USA. 78, 3669-3672.

Grüntzig, A.R., Senning, A., and Siegenthaler, W.E. (1977) Nonoperative dilatation of coronary-artery stenosis: percutaneous transiuminal coronary angioplasty. N.Engl.J.Med. 301, 61-68.

Guarino, R.D., Perez, D.M., and Piascik, M.T. (1996) Recent advances in the molecular pharmacology of the $\alpha_{1}$-adrenergic receptors. Cell signal $8,323-333$.

Hamon, M., Vallet, B., Bauters, C., Wernert, N., McFadden, E.P., Lablanche, J.M., Dupuis, B., and Bertrand, M.E. (1994) Long-term oral administration of -arginine reduces intimal thickening and enhances neoendothelium-dependent acetylcholine-induced relaxation after arterial injury. Circulation 90, 1357-1362.

Hansson, G.K., Geng, Y.J., Holm, J., Hardhammar, P., Wennmalm, A., and Jennische, E. (1994) Arterial smooth muscle cells express nitric oxide synthase in response to endothelial injury. J.Exp.Med. 180, 733-738.

Harada, K., Komuro, I., Sugaya, T., Murakami, K., and Yazaki, Y. (1999) Vascular injury causes neointimal formation in angiotensin II type 1a receptor knockout mice. Circ.Res. 84, 179185.

Haudenschild, C.C. and Schwartz, S.M. (1979) Endothelial regeneration, II: restitution of endothelial continuity. Lab. Invest. 41, 407-418.

He, G.W., Shaw. J., Hughes, C.F., Yang, C.Q., Thomson, D.S., McCaughan, B., Hendle, P.N., and Baird, D.K. (1993) Predominant $\alpha_{1}$-adrenoceptor-mediated contraction in the human internal mammary artery. J.Cardiovasc. Pharmacol. 21, 256-263.

Heagerty, A.M., Aalkjaer, C., Bund, S.J., Korsgaard, N., and Mulvany. M.J. (1993) Small artery structure in hypertension. Dual processes of remodeling and growth. Hypertension 21, 391397.

Henegar, J.R., Brower, G.L., Kabour, A., and Janicki, J.S. (1995) Catecholamine response to chronic ANG II infusion and its role in myocyte and coronary vascular damage. Am.J.Physiol. 269, $\mathrm{H} 1564-\mathrm{H} 1569$

Henrion, D., Laher, I., Laporte, R., and Bevan, J.A. (1992a) Angiotensin II amplifies arterial contractile response to norepinephrine without increasing $\mathrm{Ca}++$ influx: role of protein kinase C. J.Pharmacol.Exp.Ther. 261, 835-840.

Henrion, D., Laher, I., Laporte, R., and Bevan, J.A. (1992b) Further evidence from an elastic artery that angiotensin II amplifies noradrenaline-induced contraction through activation of protein kinase C. Eur.J.Pharmacol. 224, 13-20.

Herbst, W.M., Eberle, K.P., Ozen, Y., and Hornstein, O.P. (1992) The innervation of the great saphenous vein: an immunohistochemical study with special regard to regulatory peptides. Vasa $21,253-257$. 
Hieble, J.P., Bylund, D.B., Clarke, D.E., Eikenburg, D.C., Langer, S.Z., Lefkowitz, R.J., Minneman, K.P., and Ruffolo, R.R. (1995) International union of pharmacology nomenclature of adrenoceptors. Recommendation for nomenclature of $\alpha_{1}$-adrenoceptors: consensus update. Pharmacol.Rev. 47, 267-270.

Hirasawa, A., Shibata, K., Horie, K., Takei, Y., Obika, K., Tanaka, T., Muramoto, N., Takagaki, K., Yano, J., and Tsujimoto, G. (1995) Cloning, functional expression and tissue distribution of human $\alpha_{1 c}$-adrenoceptor splice variants. FEBS.Lett. 363, 256-260.

Holme, J.B., Skajaa, K., and Holme, K. (1990) Incidence of lesions of the saphenous nerve after partial or complete stripping of the long saphenous vein. Acta.Chir.Scand. 156, 145-148.

Holycross, B.J., Peach, M.J., and Owens, G.K. (1993) Angiotensin II stimulates increased protein synthesis not increased DNA synthesis in intact rat aortic segments in vitro. J.Vasc.Res. 30 , 80-86.

Horowitz, A., Menice, C.B., Laporte, R., and Morgan, K.G. (1996) Mechanisms of smooth muscle contraction. Physiological Reviews 76, 967-1003.

Hu, Z.W. and Hoffman, B.B. (1993) Cycloheximide induces the $\alpha_{1}$-adrenergic receptor gene by activation of transcription in DDT1 MF-2 smooth muscle cells. Mol.Pharmacol. 44, 11051112.

Hu, Z.W., Shi, X.Y., Okazaki, M., and Hoffman, B.B. (1995) Angiotensin II induces transcription and expression of $\alpha_{1}$-adrenergic receptors in vascular smooth muscle cells. Am.J.Physiol. 268, $\mathrm{H} 1006-\mathrm{H} 1014$

Huang, X.C., Richards, E.M., and Sumners, C. (1996) Mitogen-activated protein kinases in rat brain neuronal cultures are activated by angiotensin II type 1 receptor and inhibited by angiotensin II type 2 receptors. J.Biol.Chem. 271, 15635-15641.

Huckle, W.R. and Earp, H.S. (1994) Regulation of cell proliferation and growth by angiotensin II. Prog.Growth Factor Res. 5, 177-194.

Ip, J.H., Fuster, V., Israel, D., Badimon, L., Badimon, J., and Chesebro, J.H. (1991) The role of platelets, thrombin, and hyperplasia in restenosis after coronary angioplasty. J.Am.Coll.Cardiol. 16, 77B-88B.

Itoh, H., Mukoyama, M., Pratt, R.E., Gibbons, G.H., and Dzau, V.J. (1993) Multiple autocrine growth factors modulate vascular smooth muscle cell growth response to angiotensin II. J.Clin.Invest. 91, 2268-2274.

Izzo, N.J., Jr., Tulenko, T.N., and Colucci, W.S. (1994) Phorbol esters and norepinephrine destabilize $\alpha_{18}$-adrenergic receptor mRNA in vascular smooth muscle cells. J.Biol.Chem. 269, 17051710 .

Jackson, C.L., Bush, R.C., and Bowyer, D.E. (1988) Inhibitory effect of calcium antagonists on balloon catheter-induced arterial smooth muscle cell proliferation and lesion size. Atherosclerosis 69, 115-122.

Jackson, C.L., Raines, E.W., Ross, R., and Reidy, M.A. (1993) Role of endogenous platelet-derived growth factor in arterial smooth muscle cell migration after balloon catheter injury. Arterioscler. Thromb. 13, 1218-1226.

Janiak, P., Pillon, A., Prost, J.F., and Vilaine, J.P. (1992) Role of angiotensin subtype 2 receptor in neointima formation after vascular injury. Hypertension 20, 737-745.

Johnson, R.D. and Minneman, K.P. (1987) Differentiation of $\alpha_{1}$-adrenergic receptors linked to phosphatidylinositol turnover and cyclic AMP accumulation in rat brain. Mol.Pharmacol. 31 , 239-246.

Johnston, C.I. (1990) Biochemistry and pharmacology of the renin-angiotensin system. Drugs 39 (Suppl. 1), 21-31.

Juhl, C.O., Jensen, L.S., and Mulvany, M.J. (1989) Time course of development of changes in the structure and reactivity of small veins from portal hypertensive rabbits. Clinical Science 77. 205-211.

Jursky, F., Tamura, S., Mandiyan, S., Nelson, H., and Nelson, N. (1994) Structure, function, and brain localization of neurotransmitter transporters. J.Exp.Biol. 196, 283-295.

Kanasaki, M., Matsubara, H., Murasawa, S., Masaki, H., Nio, Y., and Inada, M. (1994) cAMP responsive element-mediated regulation of the gene transcription of the $\alpha_{18}$ adrenergic receptor by thyrotropin. J.Clin. Invest. $94,2245-2254$.

Kato, H., Suzuki, H., Tajima, S., Ogata, Y., Tominaga, T., Sato, A., and Saruta, T. (1991) Angiotensin II stimulates collagen synthesis in cultured vascular smooth muscle cells. J.Hypertens. 9 , $17-22$. 
Kearney, M., Pieczek, A., Haley, L., Losordo, D.W., Andres, V., Schainfeld, R., Rosenfield, K., and Isner, J.M. (1997) Histopathology of in-stent restenosis in patients with peripheral artery disease. Circulation 95, 1998-2002.

Keeley, F.W., Elmoselhi, A., and Leenen, F.H. (1992) Enalapril suppresses normal accumulation of elastin and collagen in cardiovascular tissues of growing rats. Am.J.Physiol. 262, H1013H1021

Kenagy, R.D., Vergel, S., Mattsson, E., Bendeck, M., Reidy, M.A., and Clowes, A.W. (1996) The role of plasminogen, plasminogen activators, and matrix metalloproteinases in primate arterial smooth muscle cell migration. Arterioscler. Thromb. Vasc.Biol. 16, 1373-1382.

Kobayashi, S., Nishimura, J., and Kanaide, H. (1994) Cytosolic Ca++ transients are not required for platelet-derived growth factor to induced cell cycle progression of vascular smooth muscle cells in primary culture. J.Biol.Chem. 269, 9011-9018.

Kocher, O., Gabbiani, F., Gabbiani, G., Reidy, M.A., Cokay, M.S., Peters, H., and Huttner, I. (1991) Phenotypic features of smooth muscle cells during the evolution of experimental carotid artery intimal thickening. Biochemical and morphologic studies. Lab.Invest. 65, 459-470.

Kohno, Y., Saito, H., Takita, M., Kigoshi, S., and Muramatsu, I. (1994) Heterogeneity of $\alpha_{1^{-}}$ adrenoceptor subtypes involved in adrenergic contractions of dog blood vessels. Br.J.Pharmacol. 112, 1167-1173.

Korner, P., Bobik, A., Oddie, C., and Friberg, P. (1993) Sympathoadrenal system is critical for structural changes in genetic hypertension. Hypertension 22, 243-252.

Korsgaard, N. and Mulvany, M.J. (1988) Cellular hypertrophy in mesenteric resistance vessels from renal hypertensive rats. Hypertension 12, 162-167.

Kraiss, L.W. and Clowes, L.W. (1997) Response of the arterial wall to injury and intimal hyperplasia. In: The basic science of vascular disease, 289-313. Edited by Sidawy. A.N., Armonk, NY, Futura Publishing.

Kukreja, R.S., Datta, B.N., and Chakravarti, R.N. (1981) Catecholamine-induced aggravation of aortic and coronary atherosclerosis in monkeys. Atherosclerosis 40, 291-298.

Kureishi, Y., Kobayashi, S., Amano, M., Kimura, K., Kanaide, H., Nakano, T., Kaibuchi, K., and Ito, M. (1997) Rho-associated kinase directly induces smooth muscle contraction through myosin light chain phosphorylation. J.Biol.Chem. 272, 12257-12260.

Labarca, C. and Paigen, K. (1980) A simple, rapid, and sensitive DNA assay procedure. Anal.Biochem. 102, 344-352.

Langan, E.M., Youkey, J.R., Elmore, J.R., Franklin, D.P., and Singer, H.A. (1994) Regulation of MAP kinase activity by growth stimuli in vascular smooth muscle. J.Surg.Res. 57, 215-220.

Langer, S.Z. (1974) Presynaptic regulation of catecholamine release. Biochem.Pharmacol. 23, 1793-1800.

Lassegue, B., Alexander, R.W., Clark, M., Akers, M., and Griendling, K.K. (1993) Phosphatidy/choline is a major source of phosphatidic acid and diacylglycerol in angiotensin II-stimulated vascular smooth-muscle cells. Biochem.J. 292, 509-517.

Laz, T.M., Forray, C., Smith, K.E., Bard, J.A., Vaysse, P.J.J., Branchek, T.A., and Weinshank, R.L. (1994) The rat homologue of the bovine $\alpha_{(1 c)}$ adrenergic receptor shows the pharmacological properties of the classical $\alpha_{(1 a)}$ subtype. Mol. Pharmacol. 46, 414-422.

Leduc, I., Haddad, G., Giasson, E., and Meloche, S. (1995) Involvement of a tyrosine kinase pathway in the growth promoting effects of angiotensin $\|$ on aortic smooth muscle cells. J.Pharmacol.Exp.Ther. 48, 582-592.

Lee, R.M., Triggle, C.R., Cheung, D.W., and Coughlin, M.D. (1987) Structural and functional consequence of neonatal sympathectomy on the blood vessels of spontaneously hypertensive rats. Hypertension 10, 328-338.

Lee, R.M., Borkowski, K.R., Leenen, F.H., Tsoporis, J., and Coughlin, M. (1991) Combined effect of neonatal sympathectomy and adrenal demedullation on blood pressure and vascular changes in spontaneously hypertensive rats. Circ. Res. 69, 714-721.

Liao, D.F., Duff, J.L., Daum, G., Pelech, S.L., and Berk, B.C. (1996) Angiotensin II stimulates MAP kinase kinase kinase activity in vascular smooth muscle cells, role of raf. Circ. Res. 79, 10071014.

Liao, D.F., Monia, B., Dean, N., and Berk, B.C. (1997) Protein kinase c-zeta mediates angiotensin II activation of ERK $1 / 2$ in vascular smooth muscle cells. J.Biol.Chem. 272, 6146-6150. 
Lindner, V. and Reidy, M.A. (1991) Proliferation of smooth muscle cells after vascular injury is inhibited by an antibody against basic fibroblast growth factor. Proc.Natl.Acad.Sci.USA. 88, 3739-3743.

Lingen, B., Brüss, M., and Bönisch, H. (1994) Cloning and expression of the bovine sodium- and chloride-dependent noradrenaline transporter . FEBS.Lett, 342, 235-238.

Lomasney, J.W., Cotecchia, S., Lorenz, W., Leung, W.Y., Schwinn, D.A., Yang-Feng, T.L., Brownstein, M., Lefkowitz, R.J., and Caron, M.G. (1991a) Molecular cloning and expression of the cDNA for the $\alpha_{1 A}$-adrenergic receptor. The gene for which is located on human chromosome 5. J.Biol.Chem. 266, 6365-6369.

Lomasney, J.W., Cotecchia, S., Lefkowitz, R.J., and Caron, M.G. (1991b) Molecular biology of $\alpha-$ adrenergic receptors: implications for receptor classification and for structure-function relationships. Biochim. Biophys.Acta. 1095, 127-139.

Lorang, D., Amara, S.G., and Simerly, R.B. (1994) Cell-type-specific expression of catecholamine transporters in the rat brain. J.Neurosci. 14, 4903-4914.

Lu, D., Yu, K., Paddy, M.R., Rowland, N.E., and Raizada, M.K. (1996) Regulation of norepinephrine transport system by angiotensin II in neuronal cultures of normotensive and spontaneously hypertensive rat brains. Endocrinology 137, 763-772.

Majesky, M.W., Reidy, M.A., Benditt, E.P., and Juchau, M.R. (1985) Focal smooth muscle proliferation in the aortic intima produced by an initiation-promotion sequence. Proc.Natl.Acad.Sci.USA. 82, 3450-3454.

Majesky, M.W., Schwartz, S.M., Clowes, M.M., and Clowes, A.W. (1987) Heparin regulates smooth muscle $S$ phase entry in the injured rat carotid artery. Circ.Res. 61, 296-300.

Majesky, M.W., Daemen, M.J., and Schwartz, S.M. (1990) $\alpha_{1}$-Adrenergic stimulation of plateletderived growth factor A-chain gene expression in rat aorta. J.Biol.Chem. 265, 1082-1088.

Majesky, M.W., Giachelli, C.M., Reidy, M.A., and Schwartz, S.M. (1992) Rat carotid neointimal smooth muscle cells reexpress a developmentally regulated mRNA phenotype during repair of arterial injury. Circ.Res. 71, 759-768.

Malarkey, K., McLees, A., Paul, A., Gould, G.W., and Plevin, R. (1996) The role of protein kinase C in activation and termination of mitogen- activated protein kinase activity in angiotensin IIstimulated rat aortic smooth-muscle cells. Cell signal 8, 123-129.

Malik, N., Francis, S.E., Holt, C.M., Gunn, J., Thomas, G.L., Shepherd, L., Chamberlain. J., Newman, C.M., Cumberland, D.C., and Crossman, D.C. (1998) Apoptosis and cell proliferation after porcine coronary angioplasty. Circulation $98,1657-1665$.

Marrero, M.B., Schieffer, B., Paxton, W.G., Duff, J.L., Berk, B.C., and Bernstein, K.E. (1995a) The role of tyrosine phosphorylation in angiotensin II-mediated intracellular signalling. Cardiovasc. Res. 30, 530-536.

Marrero, M.B., Schieffer, B., Paxton, W.G., Heerdt, L., Berk, B.C., Delafontaine, P., and Bernstein, K.E. (1995b) Direct stimulation of Jak/STAT pathway by the angiotensin $\|$ AT1 receptor. Nature 375, 247-250.

McNamara, D.B., Bedi, B., Aurora, H., Tena, L., Ignarro, L.J., Kadowitz, P.J., and Akers, D.L. (1993) L-Arginine inhibits balloon catheter-induced intimal hyperplasia. Biochem.Biophys.Res.Commun. 193, 291-296.

Meagher, S., McGeachie, J., and Prendergast, F. (1984) Vein to artery grafts. An experimental study of reinnervation of the graft wall. Ann.Surg. 200, 153-158.

Melikian, H.E., McDonald, J.K., Gu, H., Rudnick, G., Moore, K.R., and Blakely, R.D. (1994) Human norepinephrine transporter. Biosynthetic studies using a site- directed polyclonal antibody. J.Biol.Chem. 269, 12290-12297.

Micalizzi, E.R. and Pals, D.T. (1979) Evaluation of plasma norepinephrine as an index of sympathetic neuron function in the conscious, unrestrained rat. Life.Sci. 24, 2071-2076.

Minneman, K.P. (1988) $\alpha_{1}$-Adrenergic receptor subtypes, inositol phosphates, and sources of cell Ca2t. Pharmacol.Rev. 40, 87-119.

Minneman, K.P., Han, C., and Abel, P.W. (1988) Comparison of $\alpha_{1}$-adrenergic receptor subtypes distinguished by chlorethylclonidine and WB4101. Mol.Pharmacol. 33, 509-514.

Minneman, K.P. and Esbenshade, T.A. (1994) $\alpha_{1}$-Adrenergic receptor subtypes. Annu.Rev.Pharmacol.Toxicol. 34, 117-133.

Morrow, A.L. and Creese, I. (1986) Characterization of $\alpha_{1}$-adrenergic receptor subtypes in rat brain: a reevaluation of $[3 \mathrm{H}] \mathrm{WB} 4104$ and $[3 \mathrm{H}]$ prazosin binding. Mol.Pharmacol. 29, 321-330. 
Motwani, J.G. and Topol, E.J. (1998) Aortocoronary saphenous vein graft disease. Pathogenesis, predisposition, and prevention. Circulation 97, 916-931.

Mueller, R.A., Thoenen, H., and Axelrod, J. (1969) Adrenal tyrosine hydroxylase: Compensatory increase in activity after chemical sympathectomy. Science 163, 468-469.

Mulvany, M.J., Baumbach, G.L., Aalkjaer, C., Heagerty, A.M., Korsgaard, N., Schiffrin, E.L., and Heistad, D.D. (1996) Vascular remodeling. Hypertension 28, 505-506.

Muramatsu, I., Ohmura, T., Kigoshi, S., Hashimoto, S., and Oshita, M. (1990) Pharmacological subclassification of $\alpha_{1}$-adrenoceptors in vascular smooth muscle. Br.J.Pharmacol. 99, 197201.

Muramałsu, I. (1991) Relation between adrenergic neurogenic contraction and $\alpha_{1}$-adrenoceptor suibtypes in dog mesenteric and carotid arteries and rabbit carotid arteries. Br.J.Pharmacol. 102, $210-214$

Nakajima, M., Uutchinson, H.G., Fuginaga, M., Hayashida, W., Zhang, L., Horiuchi, M., Pratt, R.E., and Dzati, V.J. (1995) The angiotensin II type 2 (AT2) antagonizes the growth effects of the AT1 recelstor: gain-of-function study using gene transfer. Proc.Natl.Acad.Sci.USA. 82. 10663-10667.

Nakaki, T., Nakayama, M., Yamamoto, S., and Kato, R. (1990) $\alpha_{1}$-Adrenergic stimulation and $\beta_{2}-$ adrenergic inhibition of DNA synthesis in vascular smooth muscle cells. Mol.Pharmacol. 37. 30-36.

Nakaoka, H., Perez, D.M., Baek, K.J., Das, T., Husain, A., Misono, K., Im, M.J., and Graham, R.J. (1994) Gh: a GTP-binding protein with transglutaminase activity and receptor signalling function. Science 264, 1593-1596.

Nebigil, C. and Malik, K.U. (1992) Comparison of signal transduction mechanisms of $\alpha_{2 C}$ and $\alpha_{1 A}$ adrenergic receptor-stimulated prostaglandin synthesis. J.Pharmacol.Exp.Ther. 263, 987996.

Neer, E.J. (1995) Heterotrimeric G proteins: organizers of transmembrane signals. Cell 80, 249-257.

O'Malley, M.K., McDermott, E.W., Mehigan, D., and O'Higgins, N.J. (1989) Role for prazosin in reducing the development of rabbit intimal hyperplasia after endothelial denudation. Br.J.Surg. 76, 936-938.

Okuda, M., Kawahara, Y., and Yokoyama, M! (1996) Angiotensin II type 1 receptor-mediated activation of Ras in cultured rat vascular smooth muscle cells. Am.J.Physiol. 271, H595$\mathrm{H} 601$

Orlandi, A., Ehrlich, H.P., Ropraz, P., Spagnoli, L.G., and Gabbiani, G. (1994) Rat aortic smooth muscle cells isolated from different layers and at different times after endothelial denudation show distinct biological features in vitro. Arterioscler. Thromb. 14, 982-989.

Osswald, W. (1991) Mediation by adenosine of the trophic effects exerted by the sympathetic innervation of blood vessels. J.Neural. Transm. 34 (suppl), 157-162.

Osswald, W. and Azevedo, I. (1991) Role of adenosine in the trophic effects of sympathetic innervation. TIPS 12, 442-443.

Pacholczyk, T., Blakely, R.D., and Amara, S.G. (1991) Expression cloning of a cocaine- and antidepressant-sensitive human noradrenaline transporter. Nature 350, 350-354.

Padfield, P.L. and Morton, J.J. (1977) Effects of angiotensin $\|$ on arginine-vasopressin in physiological and pathological situations in man. J.Clin.Endocrinol.Metab. 74, 251-259.

Passier, R.C., Smits, J.F., Verluyten, M.J., Studer, R., Drexler, H., and Daemen, M.J. (1995) Activation of angiotensin-converting enzyme expression in infarct zone following myocardial infarction. Am.J.Physiol. 269, H1268-H1276

Passier, R.C., Smits, J.F., Verluyten, M.J., and Daemen, M.J. (1996) Expression and localization of renin and angiotensinogen in rat heart after myocardial infarction. Am.J.Physiol. 271, H1040$\mathrm{H} 1048$

Pasterkamp, G., Schoneveld, A.H., van-der-Wal, A.C., Haudenschild, C.C., Clarijs, R.J., Becker, A.E., Hillen, B., and Borst, C. (1998) Relation of arterial geometry to luminal narrowing and histologic markers for plaque vulnerability: the remodeling paradox. J.Am.Coll.Cardiol. 32 , 655-662.

Pasterkamp, G., Schoneveld, A.H., van-der-Wal, A.C., Hijnen, D.J., van-Wolveren, W.J.A., Plomp, S. Teepen, H.L.J.M., and Borst, C. (1999) Inflammation of the atherosclerotic cap and shoulder of the plaque is a common and locally observed feature in unruptured plaques of femoral and coronary arteries. Arterioscler. Thromb.Vasc. Biol. 19, 54-58. 
Perez, D.M., Piascik, M.T., and Graham, R.M. (1991) Solution-phase library screening for the identification of rare clones: isolation of an $\alpha_{10}$-adrenergic receptor CDNA. Mol.Pharmacol. 40, 876-883.

Perez, D.M., DeYoung, M.B., and Graham, R.M. (1993) Coupling of expressed $\alpha_{18^{-}}$and $\alpha_{10^{-}}$ adrenergic receptors to multiple signalling pathways is both $\mathrm{G}$ protein and cell type specific Mol.Pharmacol. 44, 784-795.

Perez, D.M., Piascik, M.T., Malik, N., Gaivin, R., and Graham, R.M. (1994) Cloning, expression, and tissue distribution of the rat homolog of the bovine $\alpha_{10}$-adrenergic receptor provide evicience for its classification as the $\alpha_{1 \mathrm{~A}}$-subtype. Mol.Pharmacol. 46, 823-831.

Perlman, H., Maillard, L., Krasinski, K., and Walsh, K. (1997) Evidence for the rapid ónset of apoptosis in medial smooth muscle cells after balioon injury. Circulation 95, 981-987.

Piascik, M.T., Kusiak, J.W., Pitha, J., Butler, B.T., Le, H.T., and Babich, M. (1988) Alkylation of $\alpha_{1}$ receptors with a chemically reactive analog of prazosin reveals low affinity sites for norepinephrine in rabbit aorta. J.Pharmacol.Exp. Ther. 246, 1001-1011.

Piascik, M.T., Smith, M.S., Soltis, E.E., and Perez, D.M. (1994) Identification of the mRNA for the novel $\alpha_{(1 d)}$-adrenoceptor and two other $\alpha_{(1)}$-adrenoceptors in vascular smooth muscle. Mol.Pharmacol. 46, 30-40.

Piascik, M.T., Soltis, E.E., Piascik, M.M., and Macmillan, L.B. (1996) $\alpha$-Adrerioceptors and vascular regulation: molecular, pharmacologic and clinical correlates. Pharmacol.Ther. 72, 215-241.

Piascik, M.T., Hrometz, S.L., Edelmann, S.E., Guarino, R.D., Hadley, R.VV., and Brown, R.D. (1997) Immunocytochemical localization of the $\alpha_{1 \mathrm{~B}}$ adrenergic receptor and the contribution of this and the other subtypes to vascular smooth muscle contraction: Analysis with selective ligands and antisense oligonucleotides. J.Pharmacol.Exp.Ther. 283, 854-868.

P.ollman, M.J., Yamada, T., Horiuchi, M., and Gibbons, G.H. (1996) Vasoactive substances regulate vascular smooth muscle cell apoptosis. Circ.Res. 79, 748-756.

Pollman, M.J., Hall, J.L., Mann, M.J., Zhang, L., and Gibbons, G.H. (1998) Inhibition of neointimal cell bcl-x expression induces apoptosis and regression of vascular disease. Nature Medicine 4, 222-227.

Post, M.J., Borst, C., Pasterkamp, G., and Haude:ıschild, C.C. (1995) Arterial remodeling in atherosclerosis and restenosis: a vague concept of a distinct phenomenon. Atherosclerosis 188 (Suppl.), S115-S123

Pörzgen, P., Bönisch, H., and Brüss, M. (1995) Molecular cloning and organization of the coding region of the human norepinephrine transporter gene. Biochem.Biophys.Res.Commun. 215, $1145-1150$.

Pragliola, C., Kootstra, G.J., Lanzillo, G., Rose, P.A., Quafford, M., and Uitdenhaag, G. (1994) Current results of coronary bypass surgery after failed angioplasty. J.Cardiovasc.Surg. 35, 365-369.

Prescott, M.F., Webb, R.L., and Reidy, M.A. (1991) Angiotensin-converting enzyme inhibitor versus angiotensin 11, AT1 receptor antagonist. Effects on smooth muscle cell migration and proliferation after balloon catheter injury. Am.J.Pathol. 139, 1291-1296.

Price, D.T., Chari, R.S., Berkowitz, D.E., Meyers, W.C., and Schwinn, D.A. (1994) Expression of $\alpha_{(1)^{-}}$ adrenergic receptor subtype mRNA in rat tissues and human SK-n-MC neuronal cells: implications for $\alpha_{(1)}$-adrenergic receptor subtype classification. Mol.Pharmacol. 46, 221-226.

Ramamoorthy, S., Prasad, P.D., Kulanthaivel, P., Leibach, F.H., Blakely, R.D., and Ganapathy, V. (1993) Expression of a cocaine-sensitive norepinephrine transporter in the human placental syncytiotrophoblast. Biochemistry 32, 1346-1353.

Ramarao, C.S., Kincade, D., Perez, D.M., Gaivin, R.J., Riek, R.P., and Graham, R.M. (1992) Genomic organization and expression of the human $\alpha_{1 b}$-adrenergic receptor. J.Biol.Chem. 267, 21936-21945.

Rang, H.P., Dale, M.M., and Ritter, J.M. (1991) Pharmacology, 2nd Ed., 186-193, New York, Churchill Livingstone.

Rosenblum, W.I. and Chen, M. (1976) Density of perivascular nerves on some cerebral and extracerebral blood vessels. Blood Vessels 13, 374-378.

Ross, R. (1986) The pathogenesis of atherosclerosis--an update. N.Engl.J.Med. 314, 488-500.

Ross, R., Raines, E.W., and Bowen-Pope, D.F. (1986) The biology of platelet-derived growth factor. Cell 46, 155-169.

Ruffolo, R.R., Turowski, B.S., and Patil, P.N. (1977) Lack of cross desensitization between structurally dissimilar $\alpha$-adrenoceptor agonists. J.Pharmacol. 29, 378-380. 
Schelling, J.R., Nkemere, N., Konieczkowski, M., Martin, K.A., and Dubyak, G.R. (1997) Angiotensin Il activates the $\beta_{1}$ isoform of phospholipase $C$ in vascular smooth muscle cells. Am.J.Physiol. 272, C1558-C1566

Schelling, P., Fischer, H., and Ganten, D. (1991) Angiotensin and cell growth: a link to cardiovascular hypertrophy? J.Hypertens. 9, 3-15.

Schmitz, U. and Berk, B.C. (1997) Angiotensin II signal transduction. Stimulation of multiple mitogenactivated protein kinase pathways. Trends Endocrinol.Metab. 8, 261-266.

Schwartz, S.M., Stemerman, M.B., and Benditt, E.P. (1975) The aortic intima. II. Repair of the aortic lining after mechanical denudation. Am.J.Pathol. 81, 15-42.

Schwartz, S.M., Campbell, G.R., and Campbell, J.H. (1986) Replication of smooth muscle cells in vascular disease. Circ. Res. 58, 427-444.

Schwartz, S.M., deBlois, D., and O'Brien, E.R. (1995) The intima. Soil for atherosclerosis and restenosis. Circ. Res. 77, 445-465.

Schwinn, D.A., Lomasney, J.W., Lorenz, W., Szklut, P.J., Fremeau, R.T., Jr., Yang-Feng, T.L., Caron, M.G., Lefkowitz, R.J., and Cotecchia, S. (1990) Molecular cloning and expression of the cDNA for a novel $\alpha_{1}$-adrenergic receptor subtype. J.Biol.Chem. 265, 8183-8189.

Schwinn, D.A., Page, S.O., Middleton, J.P., Lorenz, W., Liggett, S.B., Yamamoto, K., Lapetina, E.G., Caron, M.G., Lefkowitz, R.J., and Cotecchia, S. (1991) The $\alpha_{1 c}$-adrenergic receptor: characterization of signal transduction pathways and mammalian tissue heterogeneity. Mol.Pharmacol. 40, 619-626.

Scofield, M.A., Liu, F., Abel, P.W., and Jeffries, W.B. (1995) Quantification of steady state expression of mRNA for $\alpha_{1}$ adrenergic receptor subtypes using reverse transcription and a competitive polymerase chain reaction. J.Pharmacol.Exp.Ther. 275, 1035-1042.

Scott, T.M., Honey, A.C., Martin, J.F., and Booth, R.F.G. (1992) Perivascular innervation is lost in experimental atherosclerosis. Cardioscience 3, 145-153.

Selbie, L.A., Darby, K., Schmitz, P.C., Browne, C.L., Herzog, H., Shine, J., and Biden, T.J. (1995) Synergistic interaction of $Y 1$-neuropeptide $Y$ and $\alpha_{1 b}$-adrenergic receptors in the regulation of phospholipase $C$, protein kinase $C$, and arachidonic acid production. J.Biol.Chem. 270, 11789-11796.

Shores, M.M., Szot, P., and Veith, R.C. (1994) Desipramine-induced increase in norepinephrine transporter mRNA is not mediated via $\alpha_{2}$ receptors. Mol.Brain Res. 27, 337-341.

Siwik, D. and Dale-Brown, R. (1996) Regulation of protein synthesis by $\alpha_{1}$-adrenergic receptor subtypes in cultured rabbit aortic vascular smooth muscle cells. J.Cardiovasc.Pharmacol. 27, 508-518.

Somlyo, A.P. and Somlyo, A.V. (1994) Signal transduction and regulation in smooth muscle. Nature $372,231-236$.

Sottiurai, V.S. (1990) Biogenesis and etiology of distal anastomotic intimal hyperplasia. Int.Angiol. 9, 59-69.

Starke, K., Werner, U., and Schumann, H.J. (1969) Wirkung von angiotensin auf funktion und noradrenalinabgabe isolierter kaninchenherzen im ruhe und bei sympathicusreizung. Schmiedebergs Archives of Pharmacology 265, 170-186.

Starke, K. (1977) Regulation of noradrenaline release by presynaptic receptor systems. Rev. Physiol.Biochem. Pharmacol. 77, 1-124.

Stassen, F.R.M., Willemsen, M.J.J.M., Janssen, G.M.J., and De Mey, J.G.R. (1997a) $\alpha_{1}$-Adrenoceptor subtypes in rat aorta and mesenteric small arteries are preserved during left ventricular dysfunction post-myocardial infarction. Cardiovasc.Res. 33, 706-713.

Stassen, F.R.M., Raat, N.J.H., Brouwers-Ceiler, D.L., Fazzi, G.E., Smits, J.F.M., and De Mey, J.G.R. (1997b) Angiotensin II induces media hypertrophy and hyperreactivity in mesenteric but not epigastric small arteries of the rat. J.Vasc.Res. 34, 289-297.

Stewart, A.F.R., Rokosh, D.G., Bailey, B.A., Karns, L.R., Chang, K.C., Long, C.S., Kariya, K.I., and Simpson, P.C. (1994) cloning of the rat $\alpha_{1 c}$-adrenergic receptor from cardiac myocytes. $\alpha_{1 c}$, $\alpha_{1 b}$, and $\alpha_{1 d}$ mRNAs are present in cardiac myocytes but not in cardiac fibroblasts. Circ. Res. 75, 796-802.

Stoll, M., Steckelings, U.M., Paul, M., Bottari, S.P., Metzger, R., and Unger, T. (1995) The angiotensin AT2-receptor mediates inhibition of cell proliferation in coronary endothelial cells. J.Clin. Invest. 95, 651-657.

Stull, J.T., Gallagher, P.J., Herring, B.P., and Kramm, K.E. (1991) Vascular smooth muscle contractile elements. Cellular regulation. Hypertension 17, 723-732. 
Suzuki, F., Miyamoto, S., Takita, M., Oshita, M., Watanabe, Y., Kakizuka, A., Narumiya, S., Taniguchi, T., and Muramatsu, I. (1997) Cloning, functional expression and tissue distribution of rabbit $\alpha_{(1 d)}$-adrenoceptor. Bba.Biomembranes. 1323, 6-11.

Swedberg, S.H., Brown, G., Sigley, R., Wight, T.N., Gordon, D., and Nicholls, S.C. (1989) Intimal fibromuscular hyperplasia at the venous anastomosis of PTFE grafts in hemodialysis patients. Clinical, immunocytochemical, light and electron microscopic assessment. Circulation 80, 1726-1736.

Tarry, W.C. and Makhoul, R.G. (1994) L-arginine improves endothelium-dependent vasorelaxation and reduces intimal hyperplasia after balloon angioplasty. Arterioscler. Thromb. 14, 938-943.

Theeuwes, F. and Yum, S.I. (1976) Principles of the design and operation of generic osmotic pumps for the delivery of semisolid or liquid drug formulations. Ann.Biomed.Eng. 4, 343-353.

Timmermans, P.B., Wong, P.C., Chiu, A.T., and Herblin, W.F. (1991) Nonpeptide angiotensin II receptor antagonists. Trends Pharmacol.Sci. 12, 55-62.

Todd, M.E. (1986) Trophic interactions between rat nerves and blood vessels in denervated peripheral arteries and in anterior eye chamber transplants. Circ. Res. 58, 641-652.

Tordoir, J.H.M., Herman, J.M.M.P., Kwan, T.S., and Diderich, P.M. (1987) Long-term follow-up of the polytetrafluoroethylene (PTFE) prosthesis as an arteriovenous fistula for haemodialysis. Eur.J.Vasc.Surg. 2, 3-7.

Tsuda, T., Kawahara, Y., Shii, K., Koide, M., Ishida, Y., and Yokoyama, M. (1991) Vasoconstrictorinduced protein-tyrosine phosphorylation in cultured vascular smooth muscle cells. FEBS.Lett. 285, 44-48.

van Bilsen, M. (1997) Signal transduction revisited: recent developments in angiotensin II signaling in the cardiovascular system. Cardiovasc. Res. 36, 310-322.

van der Hoorn, F.A.J., Boomsma, F., Man in 't Veld, A.J., and Schalekamp, M.A.D.H. (1989) Determination of catecholamines in human plasma by high-performance liquid chromatography: Comparison between a new method with fluorescence detection and an established method with electrochemical detection. J.Chromatogr. 487, 17-28.

van Kleef, E.M., Smits, J.F., De Mey, J.G., Cleutjens, J.P., Lombardi, D.M., Schwartz, S.M., and Daemen, M.J. (1992) $\alpha_{1}$-Adrenoreceptor blockade reduces the angiotensin Il-induced vascular smooth muscle cell DNA synthesis in the rat thoracic aorta and carotid artery. Circ.Res. 70, 1122-1127.

van Kleef, E.M., Smits, J.F.M., Schwartz, S.M., and Daemen, M.J.A.P. (1996a) Doxazosin blocks the angiotensin II-induced smooth muscle cell DNA synthesis in the media, but not in the neointima of the rat carotid artery after balloon injury. Cardiovasc. Res. 31, 324-330.

van Kleef, E.M., Fingerle, J., and Daemen, M.J.A.P. (1996b) Angiotensin II-induced progression of neointimal thickening in the balloon-injured rat carotid artery is AT1 receptor mediated. Arterioscler. Thromb.Vasc.Biol. 16, 857-863.

Vanbiesen, T., Luttrell, L.M., Hawes, B.E., and Lefkowitz, R.J. (1996) Mitogenic signaling via g protein-coupled receptors. Endocrine Rev. 17, 698-714.

Vanhoutte, P.M. (1989) Endothelium and control of vascular function: state of the art lecture. Hypertension 13, 658-667.

Vashisht, R., Sian, M., Franks, P.J., and O'Malley, M.K. (1992) Long-term reduction of intimal hyperplasia by the selective $\alpha_{1}$ adrenergic antagonist doxazosin. Br.J.Surg. 79, 1285-1288.

Voigt, M.M., Kispert, J., and Chin, H.M. (1990) Sequence of a rat brain CDNA encoding an $\alpha_{18}$ adrenergic receptor. Nucleic Acids Res. 18, 1053

Waris, T., Löfstedt, T., Partanen, S., and Smitten, K.V. (1984) Innervation of syngeneic vein grafts in the rat. The regeneration of adrenergic nerves. J.Surg.Res. 37, 472-478.

Weinberg, D.H., Trivedi, P., Tan, C.P., Mitra, S., Perkinsbarrow, A., Borkowski, D., Strader, C.D., and Bayne, M. (1994) Cloning, expression and characterization of human $\alpha$ adrenergic receptors $\alpha_{(1 \mathrm{a})}, \alpha_{(1 \mathrm{~b})}$ and $\alpha_{(1 \mathrm{c})}$. Biochem. Biophys. Res. Commun. 201, 1296-1304.

Whitebread, S., Mele, M., Kamber, B., and de Gasparo, M. (1989) Preliminary biochemical characterization of two angiotensin 11 receptor subtypes. Biochem.Biophys. Res.Commun. $163,284-291$.

Wolinsky, $H$. and Glagov, S. (1967) A lamellar unit of aortic medial structure and function in mammals. Circ. Res. 20,99-111.

Wong, P.C., Hart, S.D., Zaspel, A.M., Chiu, A.T., Ardecky, R.J., Smith, R.D., and Timmermans, P.B. (1990) Functional studies of nonpeptide angiotensin II receptor subtype-specific ligands: DuP 753 (All-1) and PD123177 (All-2). J.Pharmacol.Exp. Ther. 255, 584-592. 
Wu, D., Katz, A., Lee, C.H., and Simon, M.I. (1992) Activation of phospholipase C by $\alpha_{1}$-adrenergic receptors is mediated by the $\alpha$ subunits of Gq family. J.Biol.Chem. 267, 25798-25802.

Yamada, T., Horiuchi, M., and Dzau, V.J. (1996) Angiotensin II type 2 receptor mediates programmed cell death. Proc.Natl.Acad.Sci.USA. 93, 156-160.

Yamaguchi, T. and Nakada, T. (1992) Catecholamine metabolism in the vas deferens and the adrenal gland with special reference to the central catecholamine-depleted state. Experientia 48, 667-671.

Yamori, Y., Mano, M., Nara, Y., and Horie, R. (1987) Catecholamine-induced polyploidization in vascular smooth muscle cells. Circulation 75, 192-195

Yang, H., Lu, D., and Raizada, M.K. (1996) Lack of cross talk between $\alpha_{1}$-adrenergic and angiotensin type 1 receptors in neurons of spontaneously hypertensive rat brain. Hypertension 27, 1277-1283.

Yu, S.M., Tsai, S.Y., Guh, J.H., Ko, F.G., Teng, C.M., and Ou, J.T. (1996) Mechanism of catecholamine-induced proliferation of vascular smooth muscle cells. Circulation 94, 547554.

Zeff, R.H., Kongtahworn, C., lannone, L.A., Gordon, D.F., Brown, T.M., Phillips, S.J., Skinner, J.R., and Spector, M. (1988) Internal mammary artery versus saphenous vein graft to the left anterior descending coronary artery: Prospective randomized study with 10-year follow-up. Ann. Thorac.Surg. 45, 533-536.

Zhang, J. and Pratt, R.E. (1996) The AT2 receptor selectively associates with Gi $\square 2$ and Gi $\square 3$ in the rat fetus. J.Biol.Chem. 271, 15026-15033.

Zimmerman, B.G. and Whitmore, L. (1967) Effect of angiotensin and phenoxybenzamine in vessels during sympathetic nerve stimulation. International Journal of Neuropharmacology 6, 27-38.

Zimmerman, B.G. (1978) Actions of angiotensin on adrenergic nerve endings. Federation Proc. 37. 199-202.

Zimmerman, B.G., Sybertz, E.J., and Wong, P.C. (1984) Interaction between sympathetic and reninangiotensin system. J.Hypertens. 2, 581-587.

Zukowska-Grojec, Z., Pruszczyk, P. , Colton, C., Yao, J., Shen, G.H., Myers, A.K., and Wahlestedt, C. (1993) Mitogenic effect of neuropeptide $Y$ in rat vascular smooth muscle cells. Peptides 14, 263-268. 



\section{Samenvatting}

Het proces van vasculaire remodellering na vaatwandschade is zeer complex. In dit proefschrift is gekeken naar het effect van de groeifactor angiotensine II (Angll) op de neointimale groei na beschadiging van de arteria carotis van de rat. In het bijzonder is gekeken naar de rol van de $\alpha_{1}$-adrenoreceptoren en het sympathische zenuwstelsel (figuur 4.4).

Uit eerder onderzoek is gebleken dat de Angll respons na ballondenudatie van de arteria carotis van de rat verschilt tussen mediale en neointimale gladde spiercellen. De mediale gladde spiercellen zijn gevoelig voor $\alpha_{1}$-adrenoreceptoren blokkade en de neointimale gladde spiercellen niet. Dit proefschrift probeert een verklaring te vinden voor de relatieve ongevoeligheid van de neointima voor $\alpha_{1}$-adrenoreceptoren blokkade.

In het eerste experimentele hoofdstuk (hoofdstuk 2) is gekeken naar de hoeveelheid en locatie van de boodschapper RNA (mRNA) bij verschillende tijdstippen na ballondenudatie van de arteria carotis van de rat. Uit de resultaten blijkt dat er $\alpha_{1}{ }^{-}$ adrenoreceptoren aanwezig zijn in de gevormde neointima en dat de hoeveelheid, maar niet het subtype of de distributie van de $\alpha_{1}$-adrenoreceptoren verandert in de tijd. Dat de hoeveelheid receptoren veranderd is na ballondenudatie kan tevens worden aangetoond via een receptor bindingsstudie (hoofdstuk 4).

Een andere verklaring voor het gebrek aan gevoeligheid van de beschadigde neointima in de arteria carotis van de rat voor $\alpha_{1}$-adrenoreceptoren blokkade na infusie van Angll is de hoeveelheid catecholamine die vrij gemaakt wordt na stimulatie met Angll. Resultaten uit hoofdstuk 3 tonen aan dat de aanmaak van het mRNA voor het norepinephrine transporter (NET) gen opgereguleerd is en dat beschadigde vaten ontvankelijker zijn voor de door Angll geinduceerde toename in het NET mRNA. Aangezien het NET zorg draagt voor de opname van vrijgekomen catecholamines is het zeer goed mogelijk dat het NET belangrijk is voor de regulatie van de groeirespons van zowel beschadigde als intacte bloedvaten na stimulatie met Angll.

Om een onderscheid te kunnen maken tussen catecholamines vrijgemaakt uit de sympathische zenuwuiteinden (neuronaal), die de arteria carotis van de rat omgeven, en de catecholamines vrijgemaakt uit de bijnier, die via het bloed de arteria carotis bereiken (systemisch), is in hoofdstuk 4 enkel de neuronale catecholamines verwijderd met behulp van een chemische sympathectomie met 6-OHDA. Deze resultaten bevestigen eerdere studies dat de $\alpha_{1}$-adrenoreceptoren verantwoordelijk zijn voor de door Ang!l geinduceerde groeirespons in onbeschadigde bloedvaten. Nieuw in deze studie is de bevinding dat die respons neuronaal geregeld is en niet systemisch. Echter de neointima blijft ongevoelig voor sympathische denervatie. Wellicht wordt de neointimale groeirespons na Angll stimulatie systemisch gereguleerd, dit in tegenstelling tot de neuronale regulatie van de onbeschadigde media. Resultaten uit hoofdstuk 5 tonen echter aan dat noch de catecholamines afkomstig van de bijnier, noch de $\alpha_{1^{-}}$ adrenoreceptoren bijdragen aan de Angll geinduceerde neointimale groei.

In hoofdstuk 6 is gekeken of innervatie, of beter het gebrek aan innervatie, belangrijk is voor intimale groei in humane vaten. Er is gekeken naar de innervatie status van de anastomose regio van gestenoseerde getransplanteerde menselijke bloedvaten en naar dezelfde bloedvaten vóór transplantatie met een panel van antilichamen gericht tegen verschillende epitopen aanwezig in sympatische zenuwen. De resultaten tonen dat er geen bewijs is voor een bijdrage van de sympathische zenuwen in de intimale groei in getransplanteerde humane bloedvaten.

In conclusie kan gesteld worden dat de resultaten in dit proefschrift een verdere verklaring geven voor de rol van Angll en het sympathische zenuwstelsel in de neointimale groei van beschadigde bloedvaten. Vooraleer is het duidelijk geworden dat neointimale en mediale gladde spiercellen verschillend reageren op Angll en 
catecholamine stimulatie. Het is daarom zeer belangrijk om het effect van bepaalde therapieën ter voorkomen van restenose ook daadwerkelijk te onderzoeken in experimentele modellen waarbij al een intima aanwezig is. Voorts zijn wij van mening dat sympathische innervatie niet belangrijk is in de door Angll-geinduceerde toename in neointimale groei. Aangezien resultaten in dit proefschrift aantonen dat de neointima van humane vaten niet geïnnerveerd is lijkt het ons weinig zinvol om de sympathische innervatie als aangrijppunt voor een potentiële behandelingsmethode tegen restenose te gebruiken. 


\section{Curriculum Vitae}

Richard Bruijns

4 juni 1969 Geboren te Nijmegen

1981-1987 HAVO

Scholengemeenschap Nijmegen-West te Nijmegen

1987-1991 HLO

Hogeschool Gelderland Sektor Techniek te Nijmegen

afstudeerrichting klinische chemie

1991-1994

WO

Katholieke Universiteit Nijmegen

Biologie, HBO doorstroomprogramma

afstudeerrichting medische biologie

1994-1998

Assistent in opleiding

Cardiovascular Research Institute Maastricht

afdeling pathologie

1999

Post-doctoraal medewerker

Universiteit Antwerpen, België

afdeling farmacologie 

List of Publications

Bruijns $R$, van Kleef $E$, Smits J, Daemen $M$ : Heterogeneous effects of chemical sympathectomy on neointimal and medial growth after stimulation with angiotensin II. (abstract). J. Vasc. Res. 1996;33(suppl. 1):12.

Bruijns RHJ, van Kleef EM, Smits JFM, De Mey JGR, Daemen MJAP: Effects of chemical sympathectomy on angiotensin II-induced neointimal growth in the balloon injured rat carotid artery. (abstract). Hypertension. 1997;30:999.

Bruijns RHJ, van Kleef EM, Smits JFM, De Mey JGR, Daemen MJAP: Effects of chemical sympathectomy on angiotensin 11 -induced neointimal growth in the balloon injured rat carotid artery. J. Vasc. Res. 1998;35:124-133.

Bruijns RHJ, Van den Bossche RMA, Bult $H$ : Effect of cytochalasine D on contractile activity in the isolated rabbit carotid artery. (abstract). Fundam. Clin. Pharmacol. 1999:13:605-607.

Bruijns RHJ, Van den Bossche RMA, Bult $\mathrm{H}$ : Effect of cytochalasin $\mathrm{D}$ on vascular reactivity and cellular outgrowth in the rabbit carotid artery. (abstract). Br. J. Pharmacol. (suppl.). 2000:(in press). 



\section{Dankwoord}

Uit ervaring weet ik dat veel mensen dit gedeelte van een proefschrift (na de stellingen uiteraard) als eerste lezen. Vandaar dat ik dit dankwoord begin met een woord van welkom. Welkom in mijn proefschrift. I hoop dat jullie net zoveel plezier beleven aan het lezen van de experimenten als ik beleefd heb aan de uitvoering ervan.

$1 \mathrm{k}$ had jullie nooit welkom kunnen heten in mijn proefschrift als ik niet de mogelijkheid en de kans gekregen had van mijn promotor Mat Daemen om dit onderzoek uit te voeren en te documenteren. Bedankt en dank zij jou ken ik nu ook het genot van een 'Seattle taco shell'.

De commissie, Prof.dr. C.A. Bruggeman, Prof.dr. H. Bult, Prof.dr. J.M.A. van Engelshoven, Prof.dr. P.J.E.H.M. Kitslaar en Prof.dr. K.M.L. Leunissen, dank voor het beoordelen van het manuscript.

Ellen van Kleef dank ik voor het op de rails zetten van het onderzoek en Edwin Wijers voor de inleiding in de dierexperimentele operatietechnieken.

Wat is onderzoek zonder de juiste en kundige ondersteuning? Inderdaad, niets! Daarom dank ik Petra Aarts voor het uitvoeren van ontelbare BrdU- en andere immunohistochemische en histologische kleuringen en de fijne uren die we samen in de donkere kamer doorbrachten om in situ's te dippen (-). Monique Verluyten, jou wil ik bedanken voor hoofdstuk 2. De competitieve RT-PCRs gaven altijd 'strakke' banden. Loes van Eyck, de immunohistochemische kleuringen van hoofdstuk 6 zijn van jouw hand, dank. Anique Janssen, jij was altijd bereid om hand- en spandiensten te verrichten als de nood hoog was.

Ook de mensen aan de 'klinische kant' wil ik bedanken voor hun bereidwilligheid en geduld als ik weer eens kwam vragen naar de mogelijkheid om bij jullie een kleuring te doen of om één of ander exotisch monoklonaal kwam vragen.

Tevens wil ik iedereen bedanken met wie ik ooit een kamer heb gedeeld. Ik besef dat ik niet altijd de rustigste ben maar hé, je kan altijd nog thuis gaan werken, toch? *grin*

Natuurlijk zijn er enkele die ik bij naam moet noemen (ze zullen het me anders nooit vergeven). Dan bedoel ik de harde kern van de RPBS zijnde: Birgit 'the mother' Faber, E* 'de hippie' Creemers, Patrick 'foggy' Chames en Ivo 'le coq' Horn. Dank voor de gezellige uren in de vele kroegen van M'tricht en ik denk dat het werkwoord RPBSen binnenkort wordt opgenomen in de 'dikke van Dale'.

ledereen op farmacologie wil ik bedanken en in het bijzonder Caroline Eerdmans waarmee ik talloze denudaties heb uitgevoerd, what a team!

Debbie, merci beaucoup. Tu es une amie formidable. Ta porte etait toujours ouverte quand j'avais des soucis. Tes biscuits de Noël me manquent beaucoup. A bientôt á Paris.

I like to say thanks to $\mathrm{dr}$. Mohan Raizada and his co-workers at the department of Physiology at the University of Florida. The work I have performed at your lab has led to the results discussed in chapter 3 . Thanks again for having me over and 'go gators!'.

Paranimfen tijd...... Susan, ik weet nog goed de eerste keer dat ik je zag. Het was tijdens mijn eerste CARIM cursus en ik ben je nu nog dankbaar voor je duidelijke aantekeningen (-). I $\mathrm{k}$ heb zeer genoten van de onrust, roddel en achterklap die we gezaaid hebben in de kliniek.

Kim, jou frisse kijk op het leven verrast me telkens weer. Ik geniet van de spaarzame tijd die we samen doorbrengen en hoop die in de toekomst voort te zetten en liefst uit te breiden.

Lieve L, bedankt voor de gezellige avonden met heerlijk eten, verkwikkende discussies en vooral herkenning (mag ik de term 'soul mate' gebruiken? Vast wel!). Ik hoop dat je snel weer tijd vind om de draad van onze vriendschap op te pakken. Ja dat geldt ook voor jou Irma! Wanneer gaan we weer eens over het strand draven? 
Ook dank ik de oudstudiegenoten van de laboratoriumschool voor de nodige ontspanning na inspanning.

De nieuwe Belgische collega's wil ik bedanken voor de opname van 'die Ollander' in hun onderzoeksgroep. Amai, mijn vlaams wordt elke dag beter......

Voorts dank ik Dr. P. Van der Donckt, medical advisor van Solvay Pharma voor de stimulerende discussie en sponsering.

Als laatste wil ik mijn broers Ronnie en Wilco en mijn zus José bedanken want bloed is en blijft dikker dan water!

$\mathrm{Pa}$ en $\mathrm{Ma}$, bedankt voor het geloof dat jullie altijd in mij gehad hebben en de steun die jullie mij gegeven hebben bij de keuzes die ik in mijn leven genomen heb. Ik hoop me nog lang in jultie warmte te kunnen koesteren.

Aan allen die ik vergeten ben, uit het oog is niet uit het hart. Mijn dank is groot!

Allez, genoeg gezeverd. Het leven is een feest, laten we het gaan vieren.

Horeca est. 